Portland State University

PDXScholar

$1-1-1984$

\title{
The outcomes of a quality circle program in an electronics manufacturing firm
}

Martin L. Abbott

Portland State University

Follow this and additional works at: https://pdxscholar.library.pdx.edu/open_access_etds Let us know how access to this document benefits you.

\section{Recommended Citation}

Abbott, Martin L., "The outcomes of a quality circle program in an electronics manufacturing firm" (1984). Dissertations and Theses. Paper 724.

https://doi.org/10.15760/etd.724

This Dissertation is brought to you for free and open access. It has been accepted for inclusion in Dissertations and Theses by an authorized administrator of PDXScholar. Please contact us if we can make this document more accessible: pdxscholar@pdx.edu. 


\section{THE OUTCOMES OF A QUALITY CIRCLE \\ PROGRAM IN AN ELECTRONICS \\ MANUFACTURING FIRM}

by

MARTIN L. ABBOTT

A dissertation submitted in partial fulfillment of the requirements for the degree of

\section{DOCTOR OF PHILOSOPHY in \\ URBAN STUDIES}

Portland State University

(C) 1984 Martin L. Abbott 
TO THE OFFICE OF GRADUATE STUDIES AND RESEARCH:

The members of the Committee approve the dissertation of Martin L. Abbott presented April 18, 1984.
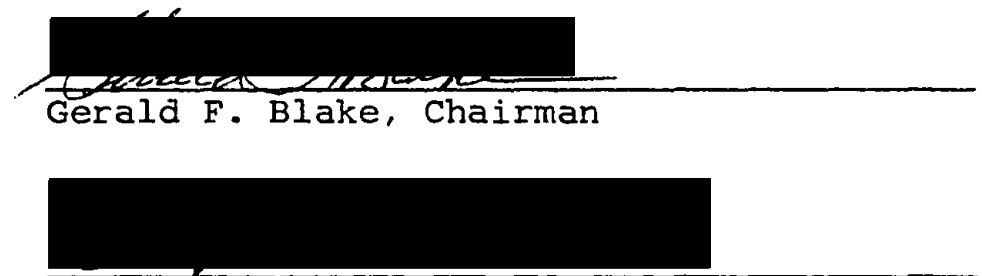

Seymoy Adler
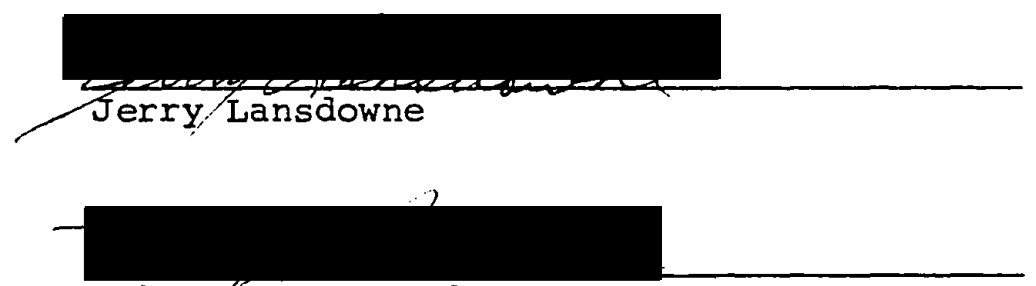

Robert $t \mathrm{~K}$. Hancock

APPROVED :

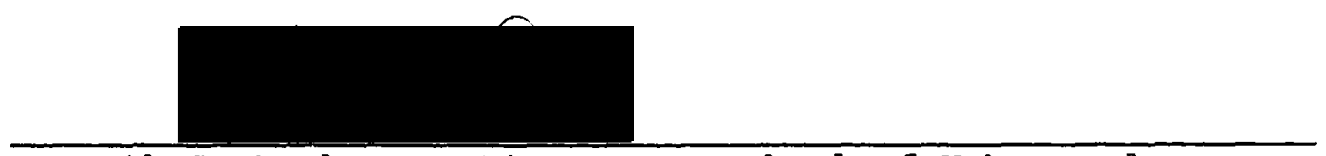

Kenneth J. Dueker, Acting Dean, School of Urban and Public Affairs

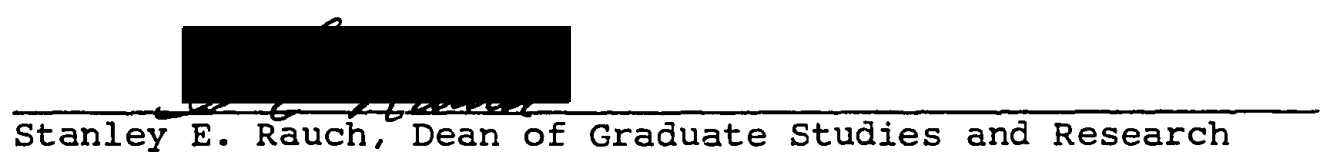




\section{ACKNOWLEDGEMENTS}

This dissertation is dedicated to my wife, Kathleen, and to my children, Kristin and Matthew. Their contribution is inestimable.

I would also like to thank Janice Johnson, Joe Parret, and all the workers who participated in this study.

A special thanks goes to my Committee for their encouragement and incisive comments. Dr. Blake deserves special mention for constant support and expert guidance.

I am also very grateful for the support of the entire Columbia Christian College community, especially the students.

In a much broader context, it is my hope that this project will contribute to an understanding and promotion of meaningful participation for workers everywhere. 
AN ABSTRACT OF THE DISSERTATION OF Martin L. Abbott for the Doctor of Philosophy in Urban Studies presented April 18, 1984 .

Title: The Outcomes of a Quality Circle Program in an Electronics Manufacturing Firm

APPROVED BY MEMBERS OF THE DISSERTATION COMMITTEE:

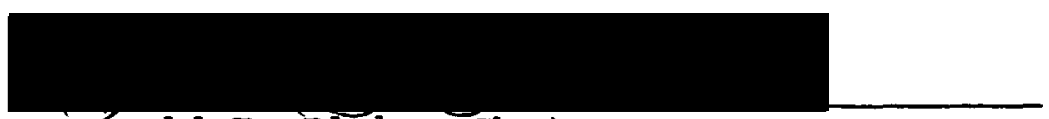
Gerald F. Blake, Chairman
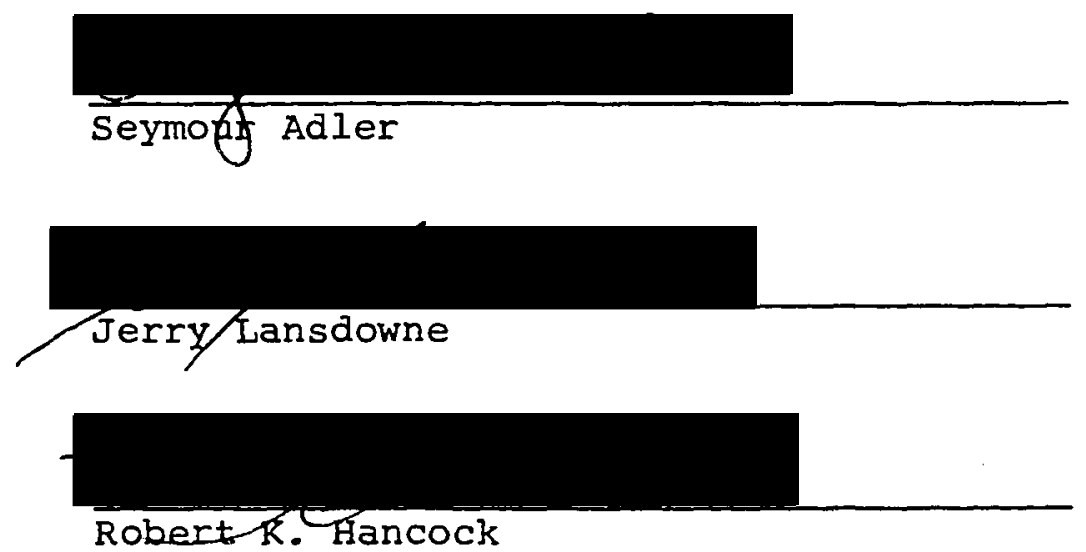

The literature on worker participation generally assumes that worker participation programs lead to positive work outcomes (e.g., job satisfaction) in more or less direct fashion. The current study chalienges this assumption and posits that "desire for participation," and 
"attitudes toward participation," may affect the participation-satisfaction relationship.

Data were gathered from a quality circle (QC) program at a large electronics manufacturing firm, using both quantitative (survey questionnaire), and qualitative (interviews, observation, meeting attendance) means. QC members and non members were compared on all attitude measures, and on general job satisfaction.

The results indicated the following: (a) the participation-satisfaction thesis was not supported, (b) desire for participation emerged as a salient variable in terms of its relationship to job satisfaction and selected attitudes toward participation, (c) QC membership did not sufficiently enlist workers with a strong desire for participation, (d) management was criticized for interfering with the QC process, and (e) QCs were categorized as "managerdominated," "stable," or "in crisis."

The overall conclusion was that the relationship between worker participation and job satisfaction is more complex than it is characterized in extant literature.

Recommendations for further research included: (a) the call for systematic exploration of desire for participation, and (b) annalyses of the performance outcomes (e.g., productivity) of QCs in terms of the model tested in this study. 
TABLE OF CONTENTS

PAGE

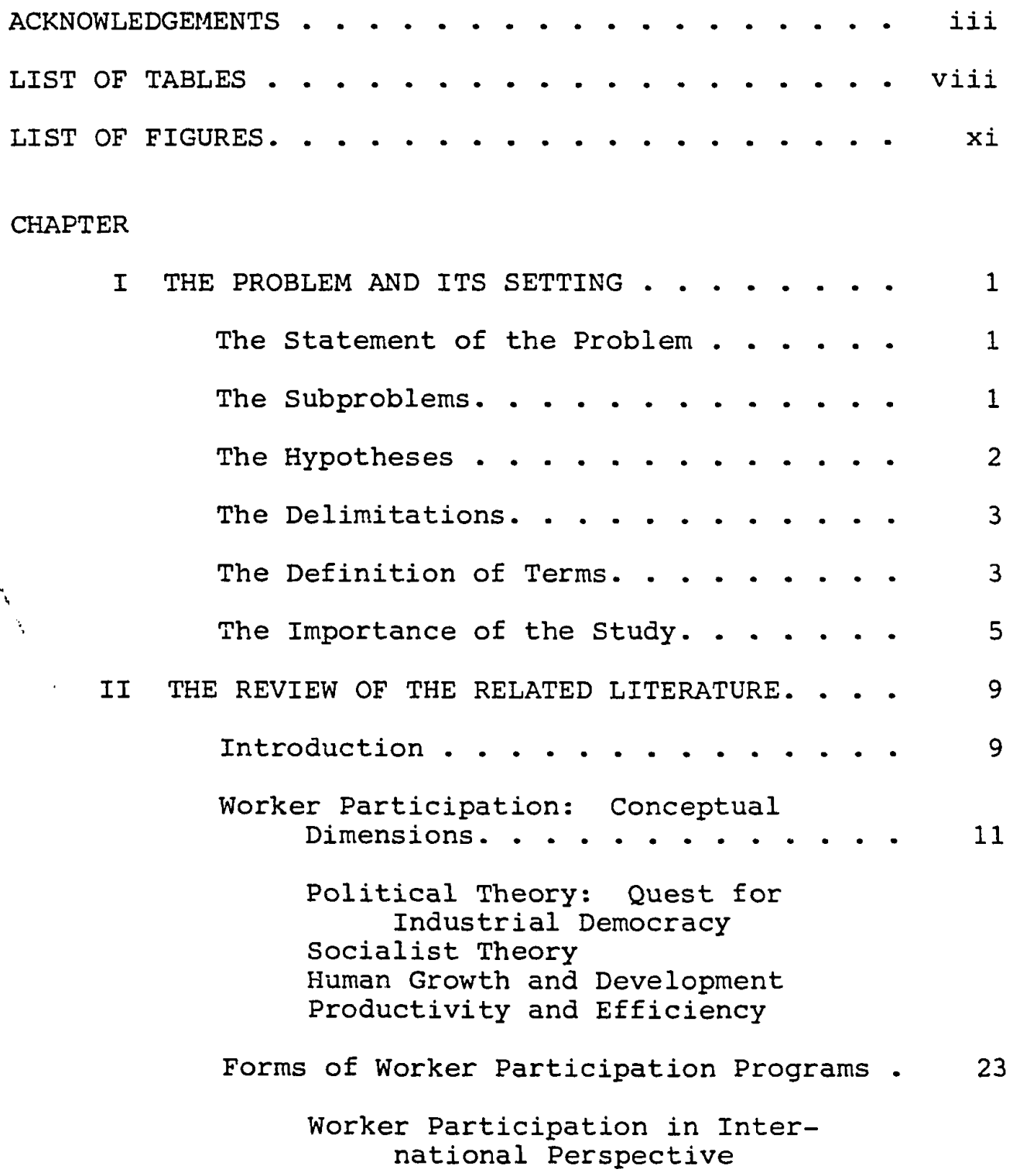


Hypothesis Three ................ 89 Discussion

Hypothesis Four. . . . . . . . . 96

Discussion

Hypotheses Five and Six. . . . . . 102

Hypothesis Five

Hypothesis Six

Discussion of Table XXIX

Discussion of Findings for

Hypotheses Two through Six. . . . 111

VI THE WORKER'S VIEW . . . . . . . . . . . 114

Introduction . . . . . . . . . . . 114

Desire for Participation: Why . . . . 116

Workers Perform the Work

Affects the Worker

Management Vehicle

Affects Quality

Desire for Participation: Why Not...

Management's Responsiblity

Lack of Worker Expertise

Affecting other Workers

No Area Prohibited

Discussion: Desire for Participation. .

QC: Membership. • . . . . . . . 126

QC Positive

QC Ambivalent

QC Negative

QC: Non Membership. . . . . . . . 131

Discussion: QC Participation. . . . - 132

Advantages

Disadvantages 
vii

CHAPTER

PAGE

Unsolicited Comments .... . . . . . 133

Poor Management

The Company Has Changed

Additional Categories

Discussion

Observations: QC Meetings . . . . . 139

Management Dominated Circles

Stable Circles

Circles in Crisis

VII CONCLUSIONS . . . . . . . . . . . 148

Introduction . . . . . . . . . 148

Summary of Conclusions . . . . . 149

The Practice of Quality Circles. . . . 150

QC Intervention. . . . . . . . 156

Areas for Future Study . . . . . . 158

REFERENCES CITED ................. 160

APPENDIX A . . . . . . . . . . . . . . 170

APPENDIX B.................... 182 


\section{LIST OF TABLES}

TABLE

PAGE

I Worker Sample By Sex . . . . . . . . . 60

II Age Distribution of Sample . . . . . . 61

III Educational Distribution of Sample . . . . 62

IV Job Title of Study Sample. . . . . . . . 62

$\mathrm{V}$ Characteristics of Interviewees. . . . . . 67

VI Participation in Quality Circles . . . . . 71

VII QC Participation By Sex. . . . . . . . 72

VIII QC Participation By Education. . . . . . . 73

IX QC Participation By Age. . . . . . . . . 73

X QC Groups By Postion . . . . . . . . . . 74

XI QC Participation By Job Satisfaction

Index . . . . . . . . . . . . 76

XII Normative Data on Job Satisfaction

for the current study and Related

Job Families. . . . . . . . . . . 79

X.II Desire for Participation Among

QC Workers. . . . . . . . . . . 82

XIV Desire for Participation Among QC

and Non QC Participants . . . . . . . 83 
XV Responses to selected Items of the

Desire to Participate Scale By QC

Participants and Non Participants. . . .

XVI Within Group Differences of Desire

for Participation. . . . . . . . . .

XVII Overall Attitudes Toward Participation

Among QC Participants and Non

Participants . . . . . . . . . . . .

XVIII QC Participation By Legitimacy

of Participation . . . . . . . . . .

XIX The Relationship of QC Participation to

Attitudes Regarding Participation. . . .

XX Within Group Differences of Attitude

Items. . . . . . . . . . . . . . . . .

XXI Relationship of Overall Desire for

Participation with Selected Attitude

Items Among All Workers. . . . . . .

XXII Relationship of Overall Desire to

Additional Attitude Items. . . . . . .

XXIII The Relationship Between Desire for

Participation and Specific Attitudes

Toward Participation Holding $Q C$

Participation Constant . . . . . . 101 
XXIV Independent Effects of Desire for

Participation on the Participation-

Satisfaction Relationsinip. . . . . . . 102

XXV The Relationship Between Desire

for Participation and Job

Satisfaction . . . . . . . . . . 103

XXVI The Effects of QC Participation Upon

the Desire-Job Satisfaction

Relationship . . . . . . . . . . . 104

XXVII Attitudes Toward Participation and

Job Satisfaction . . . . . . . . 106

XXVIII Independent Effects of an Overall

Attitude Index Upon the Participation-

Satisfaction Relationship. - . . . . . 106

XXIX The Desire-Satisfaction Relationship

Holding Attitude Items Constant

(in Percent). . . . . . . . . 108

XXX Workers' Rationale for Desire for

Participation. . . . . . . . . . 117

XXXI Workers' Rationale for Not

Desiring Participation . . . . . . . 122

XXXII Response Categories From Workers'

Unsolicited Comments . . . . . . . . 134 


\section{LIST OF FIGURES}

FIGURE

PAGE

1. Overall Model of the Participation-

Satisfaction Thesis Tested in the

Current study. . . . . . . . . . . 
CHAPTER I

THE PROBLEM AND ITS SETTING

THE STATEMENT OF THE PROBLEM

This research studies workers' desire for participation, and attitudes toward worker participation, and the effects of these variables upon the relationship between participation and job satisfaction in an electronics manufacturing plant which utilizes a Quality Circle (QC) participation program.

\section{THE SUBPROBLEMS}

The first subproblem is to determine the overall effect of the QC participation program upon job satisfaction.

The second subproblem is to examine the level of desire for participation among workers.

The third subproblem is to examine the attitudes of workers toward participation.

The fourth subproblem is to analyze the relationship between desire for participation and attitude toward participation.

The fifth subproblem is to determine the mediating effects of desire for participation upon the relationship 
between participation and job satisfaction.

The sixth subproblem is to determine the mediating effects of attitudes toward participation upon the relationship between participation and job satisfaction.

THE HYPOTHESES

All of the hypotheses are listed as null hypotheses. The first hypothesis is that there is no effect of participation upon job satisfaction.

The second hypothesis is that there are no differences among workers with respect to desire for participation.

The third hypothesis is that there are no differences among workers with respect to attitudes toward participation.

The fourth hypothesis is that there is no relationship between desire for participation and attitudes toward participation.

The fifth hypothesis is that there are no independent effects of desire for participation upon the relationship between participation and job satisfaction. The sixth hypothesis is that there are no independent effects of attitudes toward participation upon the relationship between participation and job satisfaction. 
THE DELIMITATIONS

The study is limited to the manufacturing and production areas of one plant within a large corporation. The study is focused upon a QC participation program, not worker participation programs generally. Data for the study are limited to American QC worker participation programs, although international programs are described in terms of the history and development of the QC movement.

The study does not attempt to include productivity indicators in the overall design, since the focus is primarily upon the mediating influence of specific variables upon an outcome (job satisfaction) which has a long history of study. To include additional productivity analyses would shift the main focus away from the proposed intervening variables. In addition, productivity indicators are problematic at the study site due to the accounting system, which mainly reports indirect labor figures. Also, using measures such as tardiness, absenteeism, and the like may not be valid indicators of productivity.

THE DEFINITION OF TERMS

\section{Participation}

The definition of participation used in this study 
comes from French, Israel and As' (1960) statement that

participation is:

A process in which two or more parties influence each other in making certain plans, policies, and decisions. It is restricted to decisions that have future effects on all those making the decisions and on those represented by them. (p. 3)

Throughout this study, emphasis is placed upon workers' attitudes and their perceptions of participation, as defined above.

Quality Circle

Quality circles are small groups of individuals who do similar work, choose their own projects, volunteer to meet on a regular basis in balanced and open participation, are trained to identify problems in their work areas, analyze causes, implement and track solutions, measure results and communicate recommendations and results to management (Gibson, 1983).

\section{Abbreviations}

QC is the abbreviation for Quality Circle.

DD is the abbreviation for Display Division. PP is the abbreviation for Peripheral Products. $\mathrm{SP}$ is the abbreviation for Systems Products. JDS is the abbreviation for Job Diagnostic Survey (Hackman and Oldham, 1980). 
THE IMPORTANCE OF THE STUDY

Recent years have witnessed a resurgence of interest in the concept of worker participation which, until recently, was largeiy unquestioned in its promise for industrial democracy (Pateman, 1970). Not only older classical studies (Mayo, 1933; Roethlisberger and Dickson, 1939) stemming from the famous Hawthorne experiments, but also more current studies such as the programs in the Volvo Corporation (Gyllenhammar, 1977), all attest to the beneficial consequences of worker participation. Blumberg (1968) summarized this assumption most succinctly in his statement that:

There is hardly a study in the entire literature which fails to demonstrate that satisfaction in work is enhanced or that other generally acknowledged beneficial consequences accrue from a genuine interest in workers' decision-making power. Such consistency of findings, I submit, is rare in social research. (p. 123)

These assumptions stand in marked contradistinction to several recent analyses which question the relationship between worker participation, job satisfaction, and productivity (Witte, 1980; Wall and Lischeron, 1977; Derber, 1970; Rus, 1970). John F. Witte (1980), for example, states boldly that the link between increased employee participation and increased productivity is not firmly established, citing the results of several studies, in addition to his own, as evidence for his conclusion. A 
number of studies, including witte, report that, for various reasons, workers do not desire participation and thus outcomes of worker participation programs (i.e., satisfaction and productivity) are vitally affected (Witte, 1980; Wall and Lischeron, 1977; Powell and Schlacter, 1971; French, et al., 1960; Leitko, et al., 1981; Leitko and Peterson, 1980).

While the efficacy of worker participation programs may seem self-evident, the growing body of antithetical literature suggests the need for a reexamination of the evidence and for analyses which seek to address the question directly. This study is an attempt to provide this analysis through a test of the "participation-satisfaction thesis" within the context of a large corporation which employs a Quality Circle (QC) worker participation program. In addition, this study examines "desire for participation" and workers' attitudes toward participation as potential mediating influences on the relationship between participation and job satisfaction. The mediating variables owe their derivation to a vast body of interdisciplinary studies on worker participation. In some studies the variables (i.e., "desire for participation") are explicit. However, in most studies the variables are more implicit, and emerge from widely varying disciplinary perspectives: sociology, political science, psychology and business administration. In this study, these 
important mediating influences are included in an overall design which empirically tests the participation-satisfaction thesis. Figure 1 iilustrates the conceptual model which is analyzed in this study.

\section{Independent Variables}

*Participation in $\mathrm{QC}$

Intervening Variables

*Desire for participation

*Attitudes toward participation

Dependent Variables

* Job satisfaction

Figure 1. Overall Model of the ParticipationSatisfaction Thesis Tested in the Current Study.

Beneficial outcones of such a study would be expected for business and industry through an examination of the practical effects of participation programs: the key elements of participation programs which insure their effectiveness or ineffectiveness; the most propitious conditions for beneficial programs; and a method for the development of a more comprehensive process of program evaluation.

The proposed study will benefit Quality Circle programs since they are relatively new and, according to Gibson (1981b), are at a pivotal point between "fundamentalism and fadism, between professionalism and 
amateurism." Extant research is scant and ongoing research is needed to refine the QC concept into a useful vehicle for worker participation. The same ongoing research is of significance to social science research literature, in terms of providing further critical insight into worker participation and the link between participation programs and worker attitudes. This is especially crucial since the popularity and growth of worker participation programs often exceeds the development of a sound theoretical and empirical foundation. Research will provide insight into the nature of worker participation programs in order to determine whether, as Greenburg (1975) states, "participation is a healthenhancing or passivity-inducing mechanism, or whether it is cooptive or revolutionary in character" (p. 209). 
CHAPTER II

THE REVIEW OF THE RELATED LITERATURE

INTRODUCTION

Worker participation and its effects upon the individual and industry is one of the most widely discussed and researched topics within the social science and business research literature. Worker participation is not only international in scope, but it is analytically multifaceted and interdisciplinary in nature. According to Dachler and wilpert (1978):

The questions that are asked about participation, and the answers which are sought, are shaped by various paradigms which come from the disciplines of psychology, sociology, economics, political science, and law. - . Since practice, policy-oriented discussion, and the scientific investigation of participation, transcend the purview of any given social science discipline, we find that the participation literature cuts across micro and macro issues. (p. 1)

While worker participation has a vast historical heritage, most would agree that the inception of contemporary thinking lies in the early studies of the Western Electric plant at Hawthorne, Illinois during the 1920's and 1930's. The early work by Mayo (1933) and the additional analysis by Roethlisberger and Dickson (1939) have provided an historical watershed for industrial sociology, 
and for industrial relations study generally.

One of the most compelling statements regarding research into industrial relations was made by $\mathrm{C}$. Wright Mills upon the occasion of the first meeting of the Industrial Relations Research Association (1948). In this analysis, Mills called for research that was intellectually honest and practical. After stressing the need for a synthesis between the grand theoretical analysis of the nineteenth century and the narrow empiricism of the twentieth century, Mills suggested a focus for study in industrial relations. The industrial context of the worker should not be studied in order to arm the managerial sector with tools of manipulation, but rather to examine the factors necessary for true participation, and the total impact of the work context upon the private spheres of life. To these, Mills added that research in industrial relations should examine the degree to which industrial experience yields a sense of political efficacy, a purpose which echoes a good deal of the writing of political theorists.

As noted in Chapter I, one of the most popular assumptions about worker participation is that it leads directly to outcomes such as job satisfaction, increased productivity, and political efficacy-the so-called participation-satisfaction thesis. An analysis of the literature related to worker participation and the 
specific forms of participation programs suggests a number of variables which may potentially affect the relationship between participation and job satisfaction as a chief outcome. In analyzing this problem, the current review examines the literature according to the conceptual model presented in figure 1: first, the theory and form of worker participation; next, potential intervening variables; last, job satisfaction as an outcome of worker participation.

WORKER PARTICIPATION: CONCEPTUAL DIMENSIONS

Due to the magnitude of the subject, attempts at providing a conceptual overview of worker participation have proliferated. Although these vary in length and analytical depth, there are several good reviews which are organized according to the values and assumptions of human nature which impel participation analysis. For the most part, these reviews agree on four primary assumptions which give rise to research and analysis within the total field: democratic theory, socialist theory, human growth and development, and productivity and efficiency. Dachler and Wilpert (1978), and Greenburg (1975) use these dimensions to highlight the different assumptions, and different expectations and values served by worker participation research. To these primary dimensions, strauss and Rosenstein (1970) add "collective bargaining," and union- 
management coalitions such as the scanlon Plan, which, having limited success, has left participation in the United states largely within the management reserve.

Political Theory: Quest For Industrial Democracy One of the most concise accounts that "brings forward" a host of historical analyses on the roots of political theory in industrial democracy is Pateman's Participation and Democratic Theory (1970). In this work, Pateman places two theories of democracy in contradistinction. The "contemporary theory of democracy, "founded on the works of Schumpeter, Berelson, Dahl, Sartori and Eckstein, is empirical or descriptive in nature, focusing upon the democratic political system as a whole, and grounded in current investigations of political attitudes and behavior. This theory of democracy, states Pateman, is ideological in nature, and serves only to justify the current democratic system. On the other hand, a reexamination of classical theorists gives rise to the theory of "participatory democracy." This theory emphasizes the fact that true democracy emanates from participatory structures throughout society rather than solely from representative institutions on a national level. Democracy results from the actual process of participation by individuals in many spheres in their daily lives. Participation has the primary function of education for the formation of psychological attitudes and general character 
of effectiveness and self-confidence.

For the purpose of this review, the crucial aspect is Pateman's insistence upon the importance of industry as the crucible within which this democratic character is formed. Individuals and their institutions must be viewed as interactive, rather than mutually exclusive. Thus, the political theory perspective views worker participation as a vehicle for the interplay of these forces in realizing a truly democratic ideal. Mansbridge (1980) provides an excellent contemporary study of the educative effects of political participation by contrasting two forms of democracy (unitary and adversary) that coexist in modern society. The author accomplishes the analysis through an examination of a town meeting and a crisis center. Both of these cases exemplify the extent to which participation is learned within small spheres connected to the working life.

Almond and Verba's (1965) classic cross-cultural study of political attitudes and behavior in five countries lends additional support to the educative function of participation. Crucial to the present review are the authors' conclusions that socialization within family and school is inadequate training for political participation. The most significant area for this development is the authority structure within the workplace. This suggests that participation in decision-making at the workplace is 
a vital factor in the generalizability of political efficacy from a non-political sphere to the polity.

It is this area, the decision-making dynamics within American industry, that witte (1980) uses in addressing the theoretical and empirical concerns of the political theory view regarding the ability of the workplace to engender widespread political efficacy. In contrast to the hope for work as a mediating device for political participation, Witte concludes, through an empirical study of an American corporation, that meritocracy is so entrenched ana pervasive in American culture that industrial democracy is unattainable. Most people, Witte argues, have no experience with direct democracy, nor can they conceive of it. Workplace institutions impose rigidly hierarchical norms upon workers, which precludes the development of training for social decision-making. Not only are management systems unwilling to accept democratic principles as a form of organization, but workers themselves have come to accept this hierarchical authority as an integral aspect of their jobs. Consequently, they are unwilling to seek participation in decisions other than those which affect their immediate jobs. Since authority is perceived as being legitimately owned by management, most workers do not aspire to decision-making since they perceive it as being within management's realm. Witte's argument thus suggests that workplace institutions create and reward 
worker attitudes which are inimical to industrial democracy. This assumes, however, that worker attitudes are stable and unaffected by the vagaries of the American workplace.

A similar theme is sounded by De Witte's (1980) cross-national study, which portrays worker participation programs as important for legitimating the political system and liberal democracy. According to the author, the guise of industrial democracy appeases the worker and propagates false consciousness.

Although witte and De Witte are not without their critics (Woodworth, 1982), the arguments presented are important to the overall issue of worker participation. Witte's empirical analysis is especially important in terms of its contribution to the notion of "desire for participation" in the current study.

\section{Socialist Theory}

According to writers in the socialist tradition the assumptions underlying worker participation are much different. Marx's concern for unalienated existence and the domination of capitalism over the individual worker has provided the primary impetus for this view. Whereas the political theory view emphasizes the goal of political efficacy through participatory spheres throughout society, socialist writers emphasize economic equality as the goal of worker participation. 
Although spanning both traditions, Vanek's (1970, 1971) work more properly belongs with the latter. Vanek does emphasize a participatory structure oriented to democratic majority rule and a decentralized, decision-making economy; however, his primary thrust is economic. In his "labor-managed market economy," Vanek stresses five basic characteristics: labor management of firms, income sharing, a decentralized market economy, "usufructus" (the right to control and manage the activities of the firm without ownership) and freedom of employment. These serve as the vehicle for the formation of a participative economy which is responsive to human personality, as well as economic development.

While the impulse of the political and socialist traditions is very different, they nevertheless point out the beneficial consequences that accrue to the individual. It is this potential that the human growth and development school (discussed below) points to as the ultimate meaning for worker participation. However, as Witte (1980) notes, the authority structure of American industry may well prevent this potential from developing.

The socialist tradition further views the management structure as being directly antithetical to the interests and benefits of worker participation. Ramsay's (1977) review of worker participation is a good example of this kind of thinking. He argues that since the experience 
and interests of management and workers are different, their interpretations of participation are different and contradictory. Management have their minds set on a unitary conception of "the company" and thus view all changes within the context of the goal of efficiency. Labor, on the other hand, has the primacy of democracy itself as the goal. Ramsay goes on to argue that worker participation must be viewed within an historical perspective. It did not evolve from the humanization of capitalism, but rather in cycles that correspond to times when management authority is challenged, thereby conforming to a Marxist conflict analysis.

Although Ramsay's analysis is set in Great Britain, the thrust of the argument is a valid representation of the socialist view, and germane to the current study. One of the tenets tested in this study relates to worker participation programs being perceived by workers as under the control of their superiors in order to ensure worker compliance, thus vitiating a total desire for involvement. Although the theoretical assumptions may differ from other views, the contributions of this perspective should not be overlooked.

Human Growth and Development

Perhaps the most expansive literature on worker participation during the 1960's and early 1970's comes from the human growth and development view. Writing primarily 
from a psychological perspective, this orientation focuses upon the development of human personality and mental health withir organizational life as the chief goal of worker participation. Although efficiency in work is recognized, the impact of programs upon individual functioning is paramount.

One of the most prominent writers located within this area is Chris Argyris. His writings span a quarter of a century and have served as a synthesis of theory and development, as well as a touchstone for writers in organizational and management areas. In a recent article, Argyris (1978) presented an alternative to socialist writers and others who would assert that attempts to improve the quality of life within organizations without changing the capitalist system are doomed to failure. Argyris recognized that forces within an authoritarian organizational hierarchy are antithetical to the quality of life. However, instead of attributing causes to political or economic forces, Argyris pointed to the nature of information systems as creating competing conceptions of responsibility, competence, causality, and requirements for effective order, between workers and management. His conclusion is that these problems are not limited to a particular political or economic system but should be viewed as an integral aspect of organizations per se. The prescription Argyris posits is to generate 
organizational problem-solving processes which can deal with the contrarictions and problems built into organizations.

Writing in this vein, it could be argued that Argyris should more properly be placed within the management tradition. However, the assumptions that Argyris makes are primarily psychological, in the sense that the focus is always upon the ultimate benefit of organizational change for the individual. This is made clear by examining Argyris' earlier works, which give coherence to the human growth and development field.

In Management and Organizational Development, Argyris (1971) develops a model for organizational development based upon earlier works of McGregor (1960). Likert (1961), and Maslow (1954), which reveals the extent of Argyris' linkage to the human development view. In this work, Argyris builds upon McGregor's analysis of Theories " $X$ " and " $Y$ " in such a way as to examine patterns ("A" and "B") of interpersonal behavior, group dynamics, and organizational norms that are associated with Theories $X$ and $Y$. Pattern $A$, for example, would include individuals in groups not expressing feelings, not being open to feelings and not helping others to express ideas and feelings. Pattern B would include more trust, concern for feelings, experimenting with new ideas and feelings "in such a way that others could do the same.. . if valid 
information was to be produced and internal commitment to decisions generated" (p. 18). The intent by Argyris in this and other works (e.g., 1970) is to move organizations from "XA" to "YB," thereby creating a better quality of life within them.

Writing squarely within the same tradition, Vroom.'s (1964) analysis of motivation and work is pivotal for understanding the human development perspective and as a document that summarizes almost all of the studies of this nature up to the publication date. Vroom argues that the key variable in understanding occupational choice, satisfaction with work roles and performance or effectiveness in work is the individual motivation of the worker.

The implication of these and other works within the human growth and development area, is that worker participation should be viewed as intrinsically worthwhile. Further, for worker participation programs to create desired organizational change, intrapsychological factors, which may affect the outcome of established programs, would need to be examined. While this study discusses the mediating influence of worker attitudes and desire, it does not make the same assumptions with respect to motivation, especially as Vroom has described. His view of motivation, including the concepts of "valence" and "expectancy" patterned after Lewin (1938), is mechanical, and downplays the impact of the situational forces posited 
by the political theory and socialist viewpoints. Although a comprehensive model of worker participation must include mediating influences, it would be problematic to do so by interpreting these influences as purely motivational in nature.

\section{Productivity And Efficiency}

While the human growth and development literature dominated the research of the 1960's and 1970's, much of the latter 1970's and early 1980's has witnessed the growth of literature oriented to the necessity for work and worker participation to conform to productivity and efficiency goals. One can almost say that management has returned to a "Theory X" mode (in McGregor's terms) which has been conditioned by "Theory Y." Although the management school is not a complete throwback to Taylor's (1916) "scientific management," business and industry are primarily interested in cost efficiency. Participation programs are perceived as partial solutions to these costs (e.g., declining productivity, absenteeism, inferior product quality) under the assumption that a satisfied workforce will lead to a productive and profitable workforce. Thus, production expediency appears to take precedence over the political, economic and humanitarian concerns of the views we have examined thus far.

Much of the immediate impetus for this orientation has come from declining American productivity and a 
concern expressed over the effectiveness of Japanese industry (e.g., see Cole, 1979). According to suda (1982):

Scientific interest in worker participation as a key variable determining work satisfaction has recently been stimulated because, somewhat unexpectedly, work satisfaction has become a priority with western industrial business managers. Their concern . . . has got particular (sic): many feel threatened by the competition from advanced nations outside the Atlantic alliance, especially Japan, and believe that the secret of Japanese business achievements lies in greater commitment to work on the part of the Japanese labor force. (p. 1)

William Ouchi's Theory $\underline{Z}$ How American Business can Meet the Japanese Challenge (1981) is one of the clearest accounts of this development for worker participation. In this work, Ouchi describes the benefits that can accrue to American corporations by borrowing from Japanese management style. By managing workers in a certain way, industry can be heir to lower turnover, increased job commitment, and higher productivity. This is basically achieved through the development of a strong sense of "company as community." That is, workers come to share a sense of collective responsibility, decision-making, and concern, through such mechanisms as lifetime employment, slow evaluation and promotion, and non-specialized career paths.

In some ways, the management view stands alone in contradistinction to the other views discussed. Since the ultimate goal is productivity, the case could be made in a 
Marxist analysis that business efforts to subjugate worker participation programs to efficiency is the ultimate manipulation, and antihumanitarian in tenor (Ellul, 1964).

The current study seeks to examine this situation by analyzing a worker participation program that is heir to the Japanese corporate philosophy. It is suggested that one of the sources of potential worker disinterest in participation may be a perception on the part of the worker that the program serves only management's interests (Gibson, 1981a).

FORMS OF WORKER PARTICIPATION PROGRAMS

Having examined the assumptions underlying worker participation, it is important to examine the various types and forms in which participation programs appear.

\section{Worker Participation in International Perspective}

Although this study is limited to an American corporation's worker participation program, it is necessary to first examine worker participation internationally for a complete picture of the variety of programs in operation. A more detailed analysis of these programs may be fruitful, however it is beyond the scope of this review to do more than simply indicate the diversity of participation attempts.

Probably the most heavily studied participation program on an international level is the Yugoslavian system 
(Vanek, 1971; Blumberg, 1968; Pateman, 1970)

utilizing a series of worker's councils. Also

important are analyses of joint consultation in

Britain (King and van de Vall, 1978; Clarke, et al.,

1972); co-determination in West Germany (King and van de

Vall, 1978); as well as aralyses of Israel's Histadrut

(Derber, 1970); and prograus in Peru (Berenbach, 1979);

Denmark (Westenholz, 1979); and Australia (Derber, 1970)

among a great many others. Several good reviews are

available which provide an overview of international pro-

grams and empirical studies (Strauss, 1982; Rowat, 1976;

Jacob and Ahn, 1978; Suda, 1982).

Worker Participation Programs: A Variety of Forms

The extent of international experimentation into

worker participation has manifested itself in the United

states in a wide variety of forms. Along with these forms has come a number of attempts to classify and identify key dimensions of participation programs. Among the popularly mentioned dimensions are formal vs. informal, direct vs. indirect, forced vs. voluntary (Locke and Schweiger, 1979; Dachler and wilpert, 1978), and immediate vs. distant participation (Wall and Lischeron, 1977).

In addition to these, Locke and Schweiger (1979)

note that participation programs can be classified according to the type of decisions in which workers are involved. The authors list routine personnel functions 
such as hiring, training, pay, discipline, and performance evaluation. Along with these are the features of work itself (job design, assignments, pace), working conditions (rest periods, hours, placement, lighting, etc.) and company policies (profit, layoffs, profit-sharing, wages, fringe benefits, executive hiring, capital investments, dividends and general policy-making.)

Pateman (1970) emphasizes two ways of conceptualizing the forms that participation programs can take. First, the author notes that three forms have emerged from an analysis of the effect of the relationship between the workers' desire for more control over work and job satisfaction: job enlargement (increasing the content of the job), collective contract (collective control by workers in matters such as hiring, pace, foreman choice, distribution of pay), and style of supervision. Second, Pateman makes a distinction between "pseudo participation" (where workers are given the perception, but not the reality of decision-making power by management), "partial participation" ( where workers are allowed to make decisions regarding largely shop floor issues), and "full participation" (where each individual member of a decision-making body has equal power to make decisions).

The analyses which include reference to decisionmaking ability are the chief concern of this study, since the treatment of participation emphasizes the perception 
which workers have about decision-making ability. As previously noted, for example, the workers' desire for participation may be affected by such things as their perceptions of managerial intent, which could then have an impact on job satisfaction.

In addition to the forms of worker participation listed above, it is necessary to examine other forms which are becoming increasingly prominent, especially those which have a more direct relationship to the program examined in the proposed study. Worker Ownership. One of the growing forms of worker participation is worker ownership. The popularity of this form may be loosely attributed to three causes. First, according to Long (1982) it has been advocated as a potential solution to a variety of problems facing industrial society, such as declining productivity and worker alienation. This cause is similar to older, more traditional forms in the emphasis upon the necessity for employee participation in decision-making. The author concludes, based upon a case study of one company employing ownership, that:

Increased employee participation at job and department levels, as well as at the organizational policy level, may be important in realizing the positive effects of employee ownership. (p. 211)

The second cause relates to the general economic climate and attempts by workers to rescue their jobs by 
purchase and operation of failing businesses. The option of "making a go" of ownership is much more appealing than public assistance to workers on the brink of unemployment (Zwerdling, 1980), especially if plant closure is likely to affect the economic health of the entire town or region (Lindenfeld, et al., 1982).

A third reason is couched in more positive terms. As Zwerdling (1980) states, attempts at worker ownership are efforts to realize the ideals of democracy by bringing democracy to the workplace.

Work As Community- Another form of participation that is becoming prominent, but which is very old in concept, is the view of work and workplace as a total community. Robert Blauner in his classic, Alienation and Freedom (1964) best expresses this idea in his development of the "industrial community." Blauner states that the industrial community is made up of a network of social relationships derived from a work organization and valued by the members of the community. In the author's words:

For many factory workers the plant as a whole is a community, a center of belongingness and identification, which mitigates feelings of isolation. It is quite common for workers to come to a factory thirty minutes early every day to relax in the company of their friends. (pp. 24-25)

Similar findings with respect to "occupational community" are reported by Durham, et al., (1981) and Lipset, et al. (1956) .

This type of participation is further explored in 
Turner's (1971) analysis of "industrial subcultures" in Britain and most recently in Ouchi's (1981) analysis of the Japanese corporation with the emphasis upon collective goals, responsibility and decision-making. The Japanese corporation is further viewed as a total community in the sense that it maintains individuals throughout their careers, and emphasizes mastery of a wide variety of functions. Further, Ouchi compares the "Z Company" philosophy to the traditional "Tanomoshi" (small revolving credit societies) in terms of its stable communal membership, and social/religious/economic network of ties. However, this community orientation is gained at the expense of type $z$ companies having "a tendency to be sexist and racist" (p. 91).

Work Redesign. One of the most influential works in this form of worker participation is Hackman and oldham's, Work Redesign (1980). The authors state that the problem facing workers and organizations is that workers are underchallenged and underutilized. They then review traditional answers from behavioral scientists regarding the question of how to match people to their work, and thus achieve higher productivity and improved quality of employee work experience: change the employee; change supervisors; change the physical context of the work; change the cost/benefit contingencies of work. Hackman and Oldham, however, state that a better solution is to 
redesign the actual structure of the jobs people perform. The assumption is that since work is done in organizations, it is necessary to organizationally structure jobs in such a way as to increase employee motivation and therefore job performance. The authors state that:

Key psychological states . . are by definition, internal to persons and therefore not directly manipulable in designing or managing work. What is needed are reasonably objective, measurable, changeable properties of the work itself that foster these psychological states, and through them enhance internal work motivation. (p. 77)

Technical engineering and psychological approaches to job design both err in their emphases, according to Hackman and Oldham. The former approach ignores the personal need of workers, whereas the latter approach underemphasizes the operation of the technical system and the importance of group relations and the organizational environment in affecting the workplace. Therefore, the authors posit that the best system of redesign combines behavioral and "sociotechnical" approaches, which involves

Simultaneous modification of technical and social systems to create designs for work that can lead both to greater task productivity and to increased fulfillment for organization members. (p. 63)

Quality Circles. According to authors such as Davis and Trist (1974), and Hackman and oldham (1980), sociotechnical changes focus upon multiple interventions into job change and the creation of small work groups which have decision-making power about how the group's work 
should be planned and executed. It is this theoretical emphasis, in conjunction with the practical necessity to achieve high quality, improve productivity and increase employee morale, at a low cost (Ouchi, 1981), which has spawned the quality circle "movement." According to ouchi, quality circles are extremely popular and are "in danger of becoming the management fad of the eighties" (p. 261) .

Quality circles, although relatively recent, expanded enormously during 1981 and 1982 (Gibson, 1982). Not only has the movement established a national newsletter ("Update"), but there are a number of published research studies which focus upon quality circles. Chief among these are projects undertaken by the General Electric Company (Keefe and Kraus, 1982), and a research report supported by the Office of Naval Research (Seelye, et al., 1982) which identifies over 1,500 worksites with functioning quality circles.

It is this proliferation which has caused quality circle practitioners to encourage research. According to one author (Thompson, 1982) quality circles are growing rapidly without the benefit of experience. However, Gibson (1981b) sees this development as "field testing" and stresses that research is needed in order to ensure that the quality circles movement will survive and succeed in the United States. 
Another motivation for research into quality circles is to identify successful and unsuccessful aspects of programs in an attempt to provide direction for successful implementation in the future. In a March, 1981 research report to the International Association of Quality Circles (IAQC), Price Gibson identifies among the successful aspects: open communications, heightened enthusiasm among workers, and improvement in morale. Among the problems identified by the report were: lack of middle management support, suspicion of management motives, negative attitudes toward change among the work force, problems chosen by management, and focusing on problems outside the circle's jurisdiction.

A third motivation for research into guality circles is intimated by Eugene Sprow in The Quality Commitment (1982a). In this study, sprow states that everyone is obliged to study circles, since if organizations are not committed to quality, and do not commit themselves immediately, the organizations will not survive. In another study, sprow (1982b) suggests that we need to adapt, not adopt Japanese management techniques. The suggestion here, and elsewhere (Ouchi, 1981), is that quality circles may be a vehicle for equalizing the Japanese advantage in industrial productivity, and therefore a convenient way to reestablish American corporate dominance. 
Implication of Quality Circles for the study The development of quality circles as a popular and prominent vehicle for worker participation, especially as it has been developed by Hackman and Oldham (1980), Ouchi (1981), and QC practitioners, leads to a number of issues which need to be addressed by empirical research. Foremost among these is that the model upon which QC is based is mechanical and automatic. Just as our earlier comments suggested that the human growth and development school did not take significant intervening variables into account, the same case could be made against the QC view. Hackman and Oldham's (1980) model, discussed earlier, posits that redesign of core job characteristics (including skill variety, task identity, task significance, autonomy, and feedback from the job) will lead to high internal work motivation outcomes by advancing critical psychological states (experienced meaningfulness of the work; experienced responsibility for outcomes of the work; and knowledge of the actual results of the work activities). In this respect, the model differs little from the model proposed by Blumberg (1968) and Verba (1961) which suggests an automatic linkage between participation, and outcomes such as job satisfaction and productivity. Although Hackman and Oldham do posit intervening variables, they are limited to conceptions of psychological states. While these may be crucial, other 
potential intervening variables, which have roots in other schools of thought previously discussed, are ignored. That is to say, there is no mention of the degree to which workers perceive, for example, that the worker participation program is manipulative, or that their decision-making power is circumscribed by limiting decisions to certain work assignments, or that the extra responsibility is simply unwanted. These perceptions and attitudes on the part of workers are, however, suggested by the political theory and socialist schools, and are strongly suggested in the quality circles literature previously cited (for example, Gibson's 1981a, analysis of the problems confronting QC programs). Hackman and Oldham (1980) do, however, state limitations to the sociotechnical approach in these respects, in their statement that the approach "does not adequately deal with differences among organization members in how they respond to work that is designed from the sociotechnical perspective" (p. 65).

The current study attempts to take the intervening variables "desire for participation" and "attitudes toward participation" into account and to examine how they affect outcomes such as job satisfaction. For if workers do not desire to participate, due to any number of reasons such as those suggested above, then QC groups will not achieve success in their stated goals. 


\section{INTERVENING VARIABLES}

As noted earlier, traditional views of worker participation programs posit a more or less direct relationship between participation and outcomes like job satisfaction and productivity. Which outcome to focus upon is related to the different assumptions upon which a philosophy of participation is based. For example, the human growth and development school points primarily to job satisfaction while the management school points to productivity as a major criterion of success. Many current schemes emphasize both. Hackman and oldham (1980) state that both job satisfaction and productivity are desirable goals, and in fact, cannot be achieved independently.

While there are suggestions in the literature regarding significant intervening variables which may affect this linear relationship, there are few explicit models which clearly define and explore these variables. One must closely examine Blumberg (1968), for example, to find an explanatory rationale for his roseate conclusion regarding the link between job satisfaction and decisionmaking power. Such a rationale is indicated by his statement that:

Even though there are strong alienation tendencies in much modern industrial work, these can be significantly offset by 'participation' which 
tends to transform the workers' definition of the work situation. (p. 69)

However, Blumberg's analysis of participation and its effects completely overshadows an examination of this redefinition process.

Dachler and Wilpert's (1978) review of participation in organizations is well developed, however there is little attention given to how the individual perceives and reacts to participatory opportunities. Other reviews include analyses of intervening variables, however these are often heavily psychological in nature (Hackman and Oldham, 1980; Locke and Schweiger, 1979; Sutermeister, 1969). While psychological variables cannot be ignored, it is also important to examine individual variables that may share different assumptions about the relationship between a participation program and the individual. Witte's (1980) analysis, reviewed earlier, is important in this respect since he examines the extent to which political attitudes and desires affect the participation-satisfaction relationship. Blumberg's (1968) notion of participation affecting satisfaction through changing the definition of the work situation is representative of a sociological view.

As noted earlier, this review follows the model upon which the study is based in an attempt to provide a thorough survey of the literature. Thus, since the importance of mediating variables is stressed, this review next 
explores "desire for participation" as an intervening

variable, and several potential reasons for discrepancies in worker desire. The review concludes with an examination of job satisfaction as a primary outcome of worker participation.

\section{Desire For Participation}

A careful examination of the literature on worker participation reveals that, while in many cases participation programs are warmly received by workers, there are other cases in which participation is not received so warmly (Durham, et al., 1981). In a report examining worker participation in a number of different countries, Derber (1970) reports that:

In none of the countries that I visited was there much evidence of widespread or intense worker interest in participation in management decision-making, even at the shop or departmental level. . . Clearly unless workers actively wish to participate, participation programs cannot work satisfactorily. (p. 133)

In a recent article by Halal and Brown (1981) regarding participative management, the authors noted that workers' desire for participation was one obstacle to adopting participative style management. In a study of three organizations focusing on sixteen different forms of participation (organized around work processes, communication, compensation, and personnel actions) Halal and Brown found that slightly over one half of the respondents demonstrated a preference for participation in the various 
programs. This led the authors to note that while about half of the respondents desired participation, a sizable portion did not. Using the analogy of a glass of water that is either half-full or half-empty, Halal and Brown state, "It may be true that slightly more than half of the persons surveyed favored participation, but it could also be said that almost half did not" (p. 29). This finding is very important, and often overlooked in studies of the effectiveness of participation. Wall and Lischeron (1977) regard this positive attribution of the effects of participation to distortions of the value orientation of researchers interpreting empirical evidence. While this may be somewhat harsh, it is nevertheless true that little is made of the often significant number of workers who choose not to participate.

There are several statements in the literature regarding the fact that employees do not desire participation to the extent popularly supposed. It is one of the main interests of this study to examine differences in desire among workers as a potential mediating factor between participation programs and job satisfaction. It is also a main interest of the study to investigate the determinants of differences in desire. Several key themes emerge from the literature as possible candidates: manipulation, the perceived legitimacy of participation, avoidance of responsiblility, the limitation of interest 
to shop floor issues, outside the purview of worker interests, as well as others. These are described separately below.

Manipulation. One common perception of worker participation schemes is that they are simply a means of engineering employee compliance, much as one would replace a worn gear in a car to achieve better performance. These criticisms are not limited to a single perspective. Thus far, the review has examined studies in both the political theory and socialist schools which have spoken to this point. What is lacking in the literature are studies which attempt to measure the extent to which individual workers perceive participation opportunities as compliance mechanisms. The socialist and political theory schools develop the concept broadly, but lack a closer examination of individual attitudes. The human growth and development school provides a close examination of individual variables, however most writers fail to squarely address the issue of perception of manipulation. one statement regarding the potential impact of workers' perceptions of participation programs as manipulative comes, surprisingly, from the managerial school. Halal and Brown (1981), in noting the shift from the authoritarian to human relations approaches to management, state:

The critical limitation of this prevailing form of leadership is that while managers may be more 
supportive and considerate now, this is largely a form of 'industrial courtesy' and does not comprise true participation in which subordinates actually share a significant degree of decisionmaking power. Just beneath the warm human relations exterior, both parties well understand that the superior retains almost sole control over their relationship. (p. 20)

Statements of this nature must be viewed against a larger historical backdrop in which early attempts to provide more meaningful work experiences to workers were challenged as being manipulative. Possibly the most scathing analysis was provided by C. Wright Mills (1948; 1959) in his discussion of the concept of "morale" and how managers can make use of "status formations" which occur within the "authoritative" structure of modern industry. Although this rebuke does not address worker participation specifically, it points out how management used the early evidence obtained from the human relations in industry school to secure the cooperation of workers. Mills states that the management ideal is to use these findings to create "cheerful and willing" workers out of workers who were formerly not participative in the objective power structure, and who were "uncheerful and unwilling."

More recently, but still in a classical vein, Ellul (1964) labels attempts at incorporating workers into decision-making as mere "technique," devoid of humanistic concern. Just as children are socially adapted by education, workers are "integrated" as a means of garnering 
greater compliance:

The worker is confronted by cut-and-dried procedures that must be carried out in unvarying sequence . . he is bored, slowed down, and psychologically constrained. It is necessary to arouse in him reflective thought and to make him participate in the life of the entire plant. He must be made to feel a community of interest; the idea that his labor has social meaning must be instilled in him. In short, he must be integrated into the enterprise in which he is working. (p. 351)

Thus, increasing the worker's decision-making power may be just one more tool in management's arsenal for promoting the goal of the organization.

These quotes serve to illustrate classical thinking about evidence gained from industrial relations regarding individual worker participation. Blumberg (1968) indicates that thinking such as this is directed toward attempts to give the worker the illusion of control without the reality of it, and therefore manipulation has become a replacement for more direct means of coercion. This reflects Pateman's (1970) discussion of pseudo participation, previously cited, in which the attempt is to increase efficiency by persuading employees to accept decisions which have already been made by management. Witte's (1980) analysis of several forms of "illusory democracy" mirror these comments in that workers are given the illusion of democratic equality via participation structures, however the reality of participation never materializes due to problems associated with 
management domination ("cooptation"), failure of the participation system leadership to work effectively ("misrepresentation"), and restrictions placed on the decisionmaking body ("structural impotence"). This last point is echoed by other authors (wall and Lischeron, 1977; Ouchi, 1981; and Gibson, 1981b), and relates to manipulation in the sense of expanding decision-making ability, but within restricted or non-essential areas, which essentially diffuses any real increase in decision-making power. Finally, Strauss and Rosenstein's (1970) crosscultural analysis of the nature of success with participation programs, concludes with several comments about the potential manipulative nature of participation. The authors first state that participation is designed for symbolic purposes to make workers feel that there is a difference, and that just the acceptance of the principle of participation is a victory, from the worker's view. Next, the authors conclude that participation has strengthened management through coopting union and workforce leadership, and through chanieling dissent. Last, participation has included top leadership more than rank and file. Thus it has not "unleashed workers' creativity or even actively involved the leadership in making production decisions. The division of labor between decisionmakers and those who carry out decisions has not been abolished" (pp. 212-213). 
Participation From The Top Down. A problem related to manipulation is the fact that, most of the time, it is management, not workers themselves, who decide the need to implement participation programs. Either for efficiency or quality of work-life goals, the primary decision usually comes from the top down. Consequently workers may identify the problem as being established by management, for management, and not for the workers, program mission statements to the contrary notwithstanding. Berenbach's (1979) analysis of Peru's Social Property Sector suggests that a potential factor in the problems plaguing the participation scheme may be the fact that it was introduced by the government in absence of "a widespread grassroots movement calling for such a reform" (p. 370). The author states flatly that "for real participation to occur, the workers must sense a concrete need to participate" (p. 372). Similar findings with respect to lack of popular, grassroots pressure or support are reported by Leitko, et al. (1980).

Wanous (1977) suggests that the problem with "job enrichment" programs (or any new technique that shows promise) is that it is often thrust onto the wrong people. Management is indiscriminate in implementing programs without inquiring into the desire of participants. A good deal is known about the characteristics of jobs which can successfully be enriched, according to the author, but 
little has been done regarding the characteristics of people who really want to participate. Wanous concludes that successful job enrichment in the past involved employees who had high desires for such jobs, and thus more attention should be pointed toward matching individual needs and job characteristics.

Although the assumptions are different, Cammann and Nadler (1977) also stress the importance of assessing individual desire to participate as a precursor to instituting the proper "control system." There is thus the recognition of the importance of desire for participation as a mediating variable, however, this recognition is couched paradoxicaliy in a discussion of how to choose an effective control system. As with other studies, programs are introduced, rather than discussed, by top-level management.

It is this recognition that leads Gibson (1981a) to identify several problems with implementation of $\mathrm{QC}$, associated with management-initiated programs. The author states that there may be employee suspicion of management's motives; the problems are chosen by management, and there may be resistance to change by employees. If participation programs are "handed down," they may cease to have credibility and legitimacy to employees.

Perceived Leqitimacy of Decision-making. Another potential determinant of desire for participation is the 
extent to which workers perceive that the decision-making in which they are involved is within the legitimate range of worker activity. Analyses of worker participation programs reviewed thus far would cast some doubt that workers desire a greater role in decision-making due to perceived discrepancies between themselves and management, and to management-worker dynamics. In a recent article, Leitko, et al. (1981) discuss the apathy of workers in the presence of opportunities to participate as a function of situationally-based attitudes. That is, in contrast to motivational theories which assume workers have autonomy and self-esteem needs that are thwarted by inflexible, bureaucratic work, workers may not desire participation due to a number of "lessons" learned in adjustment to the work environment. Primary among these lessons is that the worker has an "outside position" vis-a-vis management; that they are only paid for a day's work; that they are powerless, vulnerable and expendable; in short that they are second class citizens. Within this context, opportunities to participate may not change the reality of the perceived distinctions between themselves as workers, and management. Further, workers may gain the expectation of doing what they are paid to do, and letting management manage, which is seen as the proper state of affairs. Again, in this context, opportunities to participate may not be seized. Since workers are perceived, and perceive 
themselves, as appendages, opportunities to participate are viewed as extra work, or extracurricular, and actually within the jurisdiction of management.

Witte (1980) reflects this development in his analysis of workers' natural acceptance of the hierarchical structure of authority. Obedience to authority is an integral aspect of one's job, according to witte. Consequently, the accompanying attitude of "let managers manage" is also unquestioned. Witte further notes that workers perceive management's knowledge as superior to the workers', and thus managers should be allowed to "make the decisions." This assumed superiority of management's knowledge over worker's knowledge is prevalent in other studies as well. Halal and Brown (1981) note that employees prefer their superiors to make sensitive decisions rather than letting their peers do so. The authors note that this view is based upon workers' assumptions that these decisions require objective facts which superiors possess, and co-workers do not. Further, since workers are assumed not to have these facts, important decisions may be unduly affected by emotions which could cause disruptions. Durham et al. (1981) report from their research that desire for participation is minimized since workers feel that groups need leaders, and even in democratic decision-making contexts leaders would emerge to take supervisory roles. Suda (1982) notes in his 
cross-cultural analysis that workers simply do not wish to take over decision-making authority from managers.

In a very important study of participation in a Norwegian factory, French, Israel and As (1960) note that one critical intervening variable between participation and the dependent variables of production, management-worker relations and job satisfaction is the legitimacy of participation. By this the authors refer to the extent to which formal and informal organizational roles, which define the relations among members, prescribe the extent of individual participation in various areas of decisionmaking. Thus some workers may not consider it right and proper to engage in participation processes. The authors report moderate support for the conditioning effects of 'legitimacy of participation' upon participation and labor-management relations and attitudes.

Responsibility. It is not only the reticence to do management's job which may affect the outcomes of participation programs, but also perhaps an avoidance of the extra responsibility that participation includes. In a study examining the relatjonship between participation, productivity and worker morale, Powell and Schlacter (1971) report that, while there was some improvement in morale in their study of field crews, some workers may simply not be prepared to accept responsibility, especially in an atmosphere of authoritarian leadership. 
Halal and Brown (1981) suggest that some workers may avoid the responsibility associated with active management of their own affairs within the workplace. They state that job tasks are increasing in their complexity and problem-solving responsibilities due to corporate adjustments; adjustments which are caused by budget cutbacks, limited natural resources, governmental regulations, and the like. Thus, while organizations will be called upon to recruit the active participation of employees, many workers will have little desire to accept so demanding a role. Cammann and Nadler (1976) recognize the same problem in stating "some employees may respond well to the opportunity for participation, while others may not want to become involved or assume the responsibility that goes along with participation" (p. 222).

Limited participation. Another potential determinant of a lack of desire for participation among workers is a misperception on the part of management about what workers really want. A common assumption is that, given the opportunity to participate, almost all workers will grasp the chance to increase their decision-making power. In reality, this may be somewhat different. It has been suggested by a number of authors that, to the extent that workers desire increased participation, they will want it within arenas that pertain only to "job floor" issues or issues that have an immediate effect upon them. The 
following review discusses these findings briefly, and notes other studies which contradict the findings. Argyris (1970) reflects a common assumption in the statement that workers, "do not want to manage the entire plant. They wish greater influence, longer time perspective, and an opportunity for genuine participation at points, and during time spans, where it makes sense" (p. 106). Halal and Brown (1981) agree by stating that employees have sentiments against participation in decisions concerning wages, promotions, and particularly against the selection of supervisors. In order for participation to be meaningful in reducing worker alienation, the program must relate to the perceived control over the occupational task (Blauner, 1964; Suda, 1982).

Other studies posit that workers' reluctance to expand the scope of decision-making power beyond immediate concerns is related to a conflict with the workers' interests. Rus (1970) reports that some types of decisions are more central to workers' interests than others, for example "personnel decisions" (hiring, firing, earnings, work conditions). Thus a drop in worker desire for participation may be due to workers perceiving decisionmaking as being removed from the area of their true interests. A report by the Organization for Economic Cooperation and Development (1975) concurs with Rus, stating that "numerous participation schemes have failed 
in the past, precisely because the workers did not perceive any personal payoff resulting from them" (p. 44). Jain and Jain (1980) list similar conclusions, noting that the findings on workers' perceptions of interests as mediating influences are supported by studies and surveys on worker attitudes and motivation.

Witte (1980), however, lists an important qualification to these findings. He states that decision-making desire is not just a matter of immediate interests, but that workers only want to be involved in decisions which affect them personally (work rates, procedures, grievance, wages). Other decisions, although immediate in nature (hiring and firing, job assignments, promotions) may affect co-workers, and thus cause interpersonal conflict. In contrast to the findings presented above, other studies have come to conclusions that may conflict with findings which suggest a desire for immediate participation by workers. In a very influential critique of the literature on worker participation and workers' desire, wall and Lischeron (1977) report that:

On the basis of both the correlational and experimental evidence currently available we reach the conclusion that the importance of immediate participation as a determinant of satisfaction remains undetermined . . a number of suggestive investigations does not amount to proof, especially when considered in the context of studies which fail even to be suggestive. (p. 28)

The authors go on to state that evidence regarding the 
importance of "distant" participation to workers is also inconclusive.

Analyses such as this, which contain a detailed comparison of studies discussing desire for (immediate) participation, lend impetus to the current study in terms of providing an opportunity to test these assumptions and others relating to workers' desire for participation more directly. As mentioned earlier, studies often report positive results indicating greater worker desire for participation while ignoring other, potentially significant evidence to the contrary. This lack of attention may foster a "halo effect" towards participation and its outcomes. Holter's (1965) analysis of worker attitudes toward decision-making, for example, reports that a majority of blue collar (56\%) and white collar workers (63\%) desire participation at immediate levels. The study does not emphasize that over one-fifth of the sample report no interest in participation at either immediate or plant levels or the 11-16 percent that desire participation for the plant as a whole. The present study will examine the extent of desire for participation, and also the potential determinants of desire in an attempt to provide some evidence which can prove useful to this issue. Additional Determinants. Although the determinants discussed above are prevalent in the literature, there are other reasons for lack of desire in participation that 
should be noted. Wanous $(1974 ; 1977)$ attributes differences in the level of worker desire for participation to the basic work values of employees, noting that these differences moderate the relationship between desire and job outcome (satisfaction and behavior). Jacob and Ahn (1978) suggest that differences in desire for participation are a function of an "activism syndrome." Although an individual variable, this "syndrome" is a complex of attitudes which grows most Erequently:

Where societal conditions encourage a sense of political efficacy. When a worker feels that he counts.. . he will in turn put forth effort and concern to influence the direction of the productive process as well as the social development of the community. (p. 1)

Durham, et al. (1981) state that the determinants of workers' desire for increased worker control over the workplace are not well established or systematically explored.

Lastly, several important studies which have been reviewed (Witte, 1980; Wall and Lischeron, 1977; Holter, 1965; Halal and Brown, 1981; Clarke, et al., 1972) as well as others, note that certain demographic variables seem to be associated with different levels of desire: sex, age, race, education, skilled or unskilled occupation. Witte (1980), for example, concludes that "activists" (those with the greatest desire for participation) were more educated, younger, male, and white. To this list, Holter (1965) adds that skill is a distinguishing factor 
in all groups of people, although she found, in contrast to witte, that the age factor was less distinguishable. Skill is often cited in the literature (although without consensus), with employees of higher job classifications normally evincing more desire for participation. The current study will address the general impact of demographic variables upon the study variables. Wall and Lischeron's (1977) study is important in that the authors support older studies (e.g., Blauner, 1964) which demonstrate "type of occupation" as an important factor, noting that the desire for participation varied widely among nurses, factory workers, and local authority workers. Although all three groups show different relationships to desire for participation, workers in the last category show differences from other studies listed in terms of demographic variables. "Local authority workers" demonstrated some differences in terms of skill.

The current study does not specifically test this assertion. However, an analysis of occupations within high technology industry may prove to be useful for future comparative studies of participation and types of occupation.

OUTCOMES

What remains in this review is to briefly discuss 
the outcomes that are normally associated with worker participation programs. There are different levels of outcomes which could be explored, from societal and cultural to organizational to individual levels. While there have been analyses of each reported in the literature, the current study focuses upon job satisfaction as an individual level outcome. This is done for several reasons. First, few studies of participation and satisfaction take intervening variables into account. Second, while job satisfaction has been extensively explored, there are no analyses which specifically test the relationship between worker participation programs and job satisfaction, and also posit the mediating effects of desire for participation and the determinants which are suggested in this design. Third, it is beyond the scope of the project to account for more than one outcome.

\section{Job Satisfaction}

As discussed earlier, the primary impetus for studying job satisfaction arose from the Hawthorne studies and subsequent growth of analyses from the human relations in industry school. Another source of recent interest in job satisfaction came from studies of worker "alienation." Blauner's Alienation and Freedom (1964) is an attempt to describe the concept of alienation and its impact upon workers. Blauner posited that changes in social organization, as a result of the industrial revolution, have 
fragmented the individual worker's experience; this fragmentation of experience is responsible for feelings of powerlessness, meaninglessness, isolation and selfestrangement. The end result is that workers are increasingly used as means rather than ends, thus reducing them to "things." Blauner goes on to give a detailed analysis of four kinds of work and the degree to which alienation is present in each.

It is this alienation which Blumberg (1968) suggests can be alleviated by participation in work: "Even though there are strong alienating tendencies in much modern industrial work, these can be significantly offset by 'participation'" (p. 69). Blumberg then states what has become the touchstone for researchers examining the effects of participation upon job satisfaction in his assertion that virtually all studies agree upon the beneficial effects of increased decision-making power upon job satisfaction.

From the literature we have reviewed thus far, this assertion must be seriously questioned, especially within a contemporary context. Wall and Lischeron (1977) state that Blumberg's justification for the "participationsatisfaction" thesis is wrong. The authors comment, after an extensive review of the literature, that they are "impressed . . . by the lack of evidence in support of this thesis" (p. 14). 
In a recent article, Nord (1977) reported that by 1972, approximately 3,350 articles had been written on the subject of job satisfaction. Considering the current interest in quality of work life, this figure has surely mushroomed. Although the interest of this study is much more specific, there are nevertheless a great many studies which pertain to the participation-satisfaction thesis. Following Blumberg's (1968) optimistic assertion, it is not difficult to find studies, and reviews of studies which report the positive impact of participation upon satisfaction. In Work in America (1973), the U.S. DHEW reports on the nature of work in the United States and its impact upon problems of health, education, and welfare, noting several "case studies in the humanization of work" (p. 188). The suggestion is that work dissatisfaction can be alleviated through the redesign of work. The authors state, "if autonomy, participation . . are increased the satisfaction of workers with their job should increase" (p. 96). More recent studies such as the programs at Volvo (Gyllenhammar, 1977), work restructuring at Sherwin-Williams (Poza and Markus, 1980), General Foods, Procter and Gamble, General Electric and other major corporations (Pasmore, 1982), and the "Theory $\mathrm{Z}$ " programs at Hewlett-Packard, Dayton-Hudson, Rockwell International, Intel, and Eli Lilly Company (Ouchi, 1981) all attest to beneficial consequences received from worker 
participation. As noted earlier, studies cited by the QC movement also point to the success of participation programs to enhance job satisfaction attitudes, among other outcomes.

While they may not be visible, some attempts at worker participation fail to garner the outcomes envisioned by practitioners. Pasmore (1982) states that, "among the glowing reports of success, a few accounts of failures . . have found their way into the literature" (p. 55). The author mentions several studies which report either failures or serious problems with their programs. One of Pasmore's points is that, if worker participation programs are going to be implemented, practitioners must examine the failures as well as the successes in order to better understand how to structure and plan the programs. Pasmore also mentions that the failures need to be considered since, on the surface, they may appear to be successes. This was a point made earlier in this review concerning the negligence of researchers to consider data that do not fit into their interpretations. A good example of the problem Pasmore mentions is the study by Powell and schlacter (1971) reporting on a field experiment for the Ohio Department of Highways. Although this study reported negative results with respect to productivity, and, at best, weak results regarding morale in workers, it is often cited within the context of successful programs 
(U.S. DHEW, 1973). A more blatant example is the often cited program by General Foods, which, although heralded as very successful by General Foods, was reported by another source as an "experiment that turned sour" (Business Week, 1977).

A recent, comprehensive review of participation in decision-making (Locke and Schweiger, 1979) reports findings that are less than salutary for the participation-satisfaction thesis. Based upon analyses of over 40 studies in this area, the authors report, "With respect to satisfaction, the results generally favor participative over directive methods, although nearly 40 percent of the studies did not find (participation in decision-making) to be superior" (p. 316).

\section{CONCLUSIONS}

It is the mixed success of participation and job enrichment programs on improving job satisfaction among workers which has resulted in the call for a completely different way of conceptualizing the problem (Nord, 1977). This is especially true since a recent study reported declines in overall job satisfaction among U.S. Workers (Staines and Quinn, 1979).

The current study is an attempt to provide a partial answer to this conflicting evidence by providing an 
empirical test of the participation-satisfaction thesis, and by introducing a test of intervening variables which may impact upon this relationship. 


\section{CHAPTER III}

IMETHODOLOGY

\section{RESEARCH SETTING}

Data for this study were obtained from two production areas (PP and SP) within a major division (DD) of a large electronics manufacturing firm. These production units manufacture various electronic display systems (SP) and electronic peripheral processing equipment (PP). Although each area produces different instruments, the areas are linked to a common management structure, and job classifications are the same. Workers are occasionally reassigned or "loaned" between areas with minimal training for construction of the specific instrument being produced.

The study site has used the Quality Circle (QC) worker participation program since 1979. QC emerged largely from another worker participation program ("Improvement Through Involvement") which began in 1975. Since their inception, QCs grew steadily until workforce reductions and reorganizations occurred during the fall of 1981. From then until now, QCs have been reduced in number to about twenty. The current study is based upon ten circles which are involved in all phases of the 
production process (assembly, test and inspection) of various electronic instruments produced. Membership ranges between three and twelve with a mean size of about five. The groups differ in terms of how long they have functioned, with a mean length of about thirteen months .

\section{RESEARCH POPULATION}

All production workers within PP and SP were included in the study for a total study sample of $\mathrm{N}=98$. Although relatively small, the sample represents complete production areas. Table I describes the sample in terms of sex.

\section{TABLE I}

WORKER SAMPLE BY SEX

\begin{tabular}{lc}
\hline Worker & Percent \\
\hline Male & 47.0 \\
Female & 53.0 \\
Total & 100.0 \\
\hline
\end{tabular}

The age of the workers in the sample is described by Table II. The categories are those given by responses on the JDS and represent the only measure of age in the study • 
TABLE II

AGE DISTRIBUTION OF SAMPLE

\begin{tabular}{cc}
\hline Age Category & Percent \\
\hline $20-29$ & 40.0 \\
$30-39$ & 34.0 \\
$40-49$ & 19.0 \\
$50-59$ & 6.0 \\
$60-$ over & 1.0 \\
Total & 100.0 \\
\hline
\end{tabular}

It is difficult to report a mean educational level of workers due to the categories used in the JDS for reporting education. Table III describes the educational levels of respondents as listed in the JDS.

Within the areas of study there are essentially three occupational positions: assembler, technician, and inspector. Assemblers perform routine assembly operations for a variety of electronic equipment. Technicians inspect, repair, test, and calibrate assembled or partially assembled instruments. Inspectors review and inspect materials, components, subassemblies or finished instruments according to prescribed specifications. Table IV describes the study sample according to job title. The category of "other" in Table IV refers to jobs which are largely peripheral or supportive functions, such as "cabinetizer" (those who prepare cabinets to house 
instruments), "stockhandler" (those who prepare instruments for warehousing or shipping), or "utility person" (those who can be placed in a variety of jobs).

TABLE III

EDUCATIONAL DISTRIBUTION OF SAMPLE

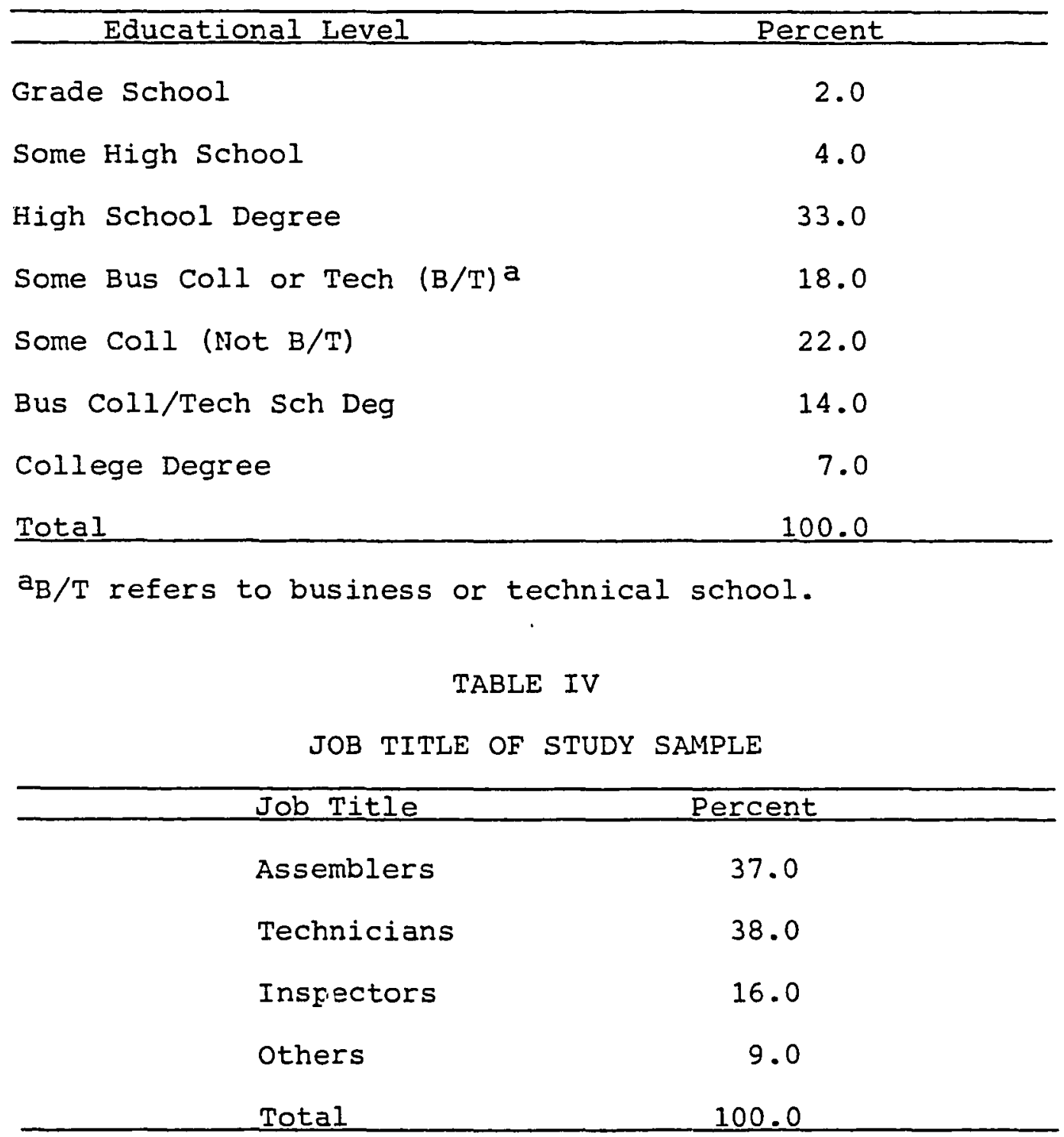




\section{Discussion}

It is important to note at this point that the study sample is fairly evenly distributed with respect to sex, age, education, and job title. There are slightly fewer males in the study, with the majority of individuals falling into the $20-49$ age range (93 percent) having at least a high school degree (94 percent). Workers in the sample more heavily represent assembler and technician occupations, however, this is a trend within the main division.

\section{RESEARCH PROCEDURES}

While the primary data gathering device is the Job Diagnostic Survey (JDS), this study also includes the more "qualitative" measures of interviews and observation.

\section{Job Diagnostic Survey}

The JDS is a well-established instrument for measuring job characteristics, having been used in numerous organizations and empirical tests. The authors of the JDS (Hackman and oldham, 1980) state that the major intended uses of the instrument are to diagnose the potential of jobs for work redesign, and to assess individual workers' attitudes as an evaluation for redesign. Normative data are available throughout the United states. One potential limitation of the JDS relates to the lack of discriminant 
validity between job design and job satisfaction when the JDS is coupled with other measures of job satisfaction (Ferratt, et al., 1981). In the current study, however, this limitation is precluded by using the JDS as the sole survey instrument for measuring job satisfaction. Other measures (such as the structured interview) are used to supplement the JDS, but without the confounding effects of a separate job satisfaction instrument. The primary reasons for using the JDS relate to standardization and continuity. As noted above, the JDS has been used extensively for research in organizations and, therefore, represents a standardized assessment procedure. Secondly, the JDS has been used within the organization under study (Shimada, 1983), which may provide additional normative data.

In addition to the JDS, the study included a set of questions designed to measure employee desire for participation and attitudes toward worker participation in the Quality Circle program. These additional items were generated in order to assess the potential explanatory power of attitudes toward worker participation in these programs. Of the seven additional attitude items, five were suggested or adapted from the literature and two were suggested by the manager of an area under study. The JDS and additional questions are located in Appendix $A$. The administration of the JDS rook place on 
consecutive days during the work week. For the most part, the survey was given to workers in their natural work groups at a neutral site in order to conform to the specific guidelines of the JDS. Prior permission for this activity was obtained from first and second-level managers, and workers returned to their work activity upon completion of the survey. On the average, workers took 30-45 minutes for completion of the survey.

\section{Interviews}

In addition to surveys, the study includes 39 personal interviews which were conducted largely as a followup to the JDS and to generate additional insight into the research questions. This method (discussed at length in Chapter Six) combines objective and more qualitative measures in an attempt to provide a more "holistic" portrayal of the focus of study, a method described by Jick (1979) as "triangulation."

Prior permission was also obtained from managers for this aspect of the study, and workers were scheduled for 10 to 15 minute appointments at a neutral site within the organization. Interviews were conducted on four separate days, within a two week time span in order to best accommodate workers' job demands.

Workers were selected for interviews through a quota sampling (Warwick and Lininger, 1975) technique in order to obtain a roughly representative approximation of the 
total population. Only in the number of $\mathrm{QC}$ members/non $\mathrm{QC}$ members chosen was there a deviation in this procedure. More QC members were chosen in order to lend an added degree of insight into the question of whether there had been a change in the workers' perception of QCs since joining. Table $\mathrm{V}$ notes that there is essential equivalence in the sample according to sex and job title, with a disproportionate number of QC members. According to the weakness of the quota sampling method, the researcher cannot insure the representativeness of people chosen within known categories. Although this was somewhat true in this study, the researcher did preclude gross unrepresentativeness through the selection of workers from naturally small work groups, enabling a more objective quota. Normally, each instrument is produced and checked by groups of assemblers, technicians, and inspectors, who comprise their own work units. Interviewees were chosen from within these groups according to QC membership, sex, and job title.

Since no tape recorders were allowed, responses were recorded by the researcher on interview sheets. Workers were assured of confidentiality and asked whether or not they preferred no notes of the comments being taken. The questions asked in the interviews were in three general areas. First, two questions were direct follow-up questions to the "desire to participate" items located with 
the JDS. Second, two questions were designed to assess attitudes toward QCs, for both members and non members. Third, one last question ("anything else?") was designed to allow workers to discuss any matter they felt to be important regarding the intent of the research or their jobs. The interview form is located in Appendix B.

TABLE V

CHARACTERISTICS OF INTERVIEWEES

\begin{tabular}{|c|c|}
\hline Group & Percent \\
\hline \multicolumn{2}{|c|}{ Sex } \\
\hline Men & 51.0 \\
\hline Women & 49.0 \\
\hline Total & 100.0 \\
\hline \multicolumn{2}{|c|}{ QC Participation } \\
\hline QC Members & 72.0 \\
\hline Non QC Members & 28.0 \\
\hline Total & 100.0 \\
\hline \multicolumn{2}{|c|}{ Job Title } \\
\hline As semblers & 28.0 \\
\hline Technicians & 46.0 \\
\hline Inspectors & 18.0 \\
\hline Others & 8.0 \\
\hline Total & 100.0 \\
\hline
\end{tabular}


Additional Methods

In conjunction with the survey and interviews, the study also includes observations made through attendance at $\mathrm{QC}$ meetings over a three month period, as well as observations of workers in their work context over a more extended time frame.

\section{RESEARCH METHODS}

Data from the JDS and additional survey questions were transfered to 80 column cards for computer processing. All statistical calculations were performed by the use of SPSS (Nie, et al., 1975; Hull and Nie, 1981). with the majority of calculations based upon crosstabulation.

Crosstabular analysis was chosen due to the nature of this research. As with most social science studies using survey data, crosstabulation is an appropriate method for establishing association based upor frequency. In addition to being used commonly, the advantages of crosstabulation include presentation of data in easily understood fashion. Most importantly, the nature of the data does not call for analyses which have greater complexity. Crosstabular analysis is especially suited for ordinal level data which are normally produced by survey questions assessing attitudes, even though social science 
researchers often assume ordinal data to be interval

level (Labovitz, 1970, 1972).

Interpretations of findings also include an

analysis of trends in percentages, as well as the use of

Kendall's "tau b" and "tau c," which provide excellent measures of correlation for ordinal level data (Siegel, 1956). These additional methods are used to assist in determining "when a difference is a difference." Especially since the study sample is relatively small, we expect that differences of perhaps 10-12 percentage points will be necessary for confidence in a certain finding. Although statistical significance is the crucial factor in these analyses, the practical differences are also important and are discussed in the tests to follow.

Interview and observational data were recorded and maintained on file. Analyses of these data sources were not subjected to quantitative measures, but are discussed in more qualitative fashion in Chapter Six. 


\section{CHAPTER IV \\ THE PARTICIPATION-SATISFACTION THESIS}

\section{INTRODUCTION}

The first hypothesis tested in this study is that there is no overall effect of participation upon job satisfaction. This hypothesis stems directly from an analysis of the literature on worker participation, which, until recently, was unquestioned in its beneficial effects upon worker satisfaction. The statement by Blumberg (1968), cited earlier, is one of the most succinct statements of this relationship. However, a number of studies which are cited in the literature review have challenged this assumption. Prominent among these is the extensive review by Locke and Schweiger (1979) which concludes that about 40 percent of laboratory, correlational and field studies either demonstrate no effect of worker participation on satisfaction, or deleterious effects. It is this disparity in the literature which provides the context for a test of the "participation-satisfaction" assumption. Further, this hypothesis is being tested in the electronics manufacturing industry, which has had little systematic research performed upon worker satisfaction, but 
which has widely adopted worker participation programs (Ouchi, 1981).

THE DATA UTILIZED

In order to test this hypothesis, it was first necessary to separate the study sample according to membership or non-membership in the worker participation program in operation (QC). Table VI describes the workers according to partisipation in QC. As the table illustrates, the total sample is very evenly distributed between workers who participated in QC and those who did not. The groups are separated by only a 6.2 percent difference.

TABLE VI

PARTICIPATION IN QUALITY CIRCLES

\begin{tabular}{lc}
\hline Group & Percent \\
\hline QC Participant & 46.9 \\
Non Participant & 53.1 \\
Total & 100.0 \\
\hline
\end{tabular}

It was next important to examine whether these groups varied according to the salient demographic variables of sex, age, education, and job position in order to establish comparability of groups. Table VII depicts the groups according to sex. Chi-square and tau b analyses determined that there were no significant differences 
between groups with respect to sex. In fact, the groups are remarkably similar, being separated by less than 2 percentage points.

TABLE VII

QC PARTICIPATION BY SEX

\begin{tabular}{lccc} 
& \multicolumn{2}{c}{ Sex (in percent) } & \\
\cline { 2 - 3 } Group & Male & Female & Total \\
QC Participant & 47.8 & 52.2 & 100.0 \\
Non Participant & 46.2 & 53.8 & 100.0 \\
\hline
\end{tabular}

Table VIII describes the groups by education. Chisquare and tau $c$ analyses determined that there were no significant differences between groups with respect to education. The chi-square did approach the .05 level of significance (actual chi-square $=.06$ ). This was potentially a function of the low cell frequency in several categories, however. In this instance, the tau $c$ is a better indicator of association, and the resultant figure was neither sufficient to reject the null hypothesis (.2231) nor to provide confidence that the two groups were significantly associated.

Table IX describes the groups by age. Chi-square and tau c analyses determined no significant differences between groups with respect to age. As the table illustrates, the age groups are quite similar in composition, with only the 40-49 group showing a small 16.4 
percent) disparity.

TABLE VIII

QC PARTICIPATION BY EDUCATION

\begin{tabular}{|c|c|c|c|c|c|c|c|c|}
\hline \multirow[b]{2}{*}{ Group } & \multicolumn{7}{|c|}{ Educational Level (in percent) } & \multirow[b]{2}{*}{ Total } \\
\hline & $\begin{array}{l}\mathrm{Gr} \\
\mathrm{Sch}\end{array}$ & $\begin{array}{c}\text { Some } \\
\text { HS }\end{array}$ & $\begin{array}{r}\text { HS } \\
\text { Deg }\end{array}$ & $\begin{array}{l}\text { Some } \\
\mathrm{B} / \mathrm{T}^{\mathrm{a}}\end{array}$ & $\begin{array}{l}\text { Some } \\
\text { Coll }\end{array}$ & $\begin{array}{l}\mathrm{B} / \mathrm{T} \\
\mathrm{Deg}\end{array}$ & $\begin{array}{l}\text { Col } \\
\text { Deg }\end{array}$ & \\
\hline QC Part. & 4.3 & 0 & 26.1 & 26.1 & 23.9 & 10.9 & 8.7 & 100.0 \\
\hline Non Part. & 0 & 7.8 & 39.2 & 9.8 & 19.6 & 17.6 & 5.9 & 100. \\
\hline
\end{tabular}

$a_{B} / T$ refers to business or technical school.

TABLE IX

QC PARTICIPATION BY AGE

\begin{tabular}{lcccccc}
\hline & \multicolumn{5}{c}{ Age Categories (in percent) } \\
\cline { 2 - 6 } Group & $20-29$ & $30-39$ & $40-49$ & $50-59$ & 60 -over & Total \\
\hline QC Part. & 41.3 & 34.8 & 15.2 & 8.7 & 0 & 100.0 \\
Non Part. & 39.2 & 33.3 & 21.6 & 3.9 & 2.0 & 100.0 \\
\hline
\end{tabular}

Table $x$ describes the groups by position in the organization. A chi-square analysis revealed no significant differences between the groups with respect to position. A tau c analysis did reveal a significant association between the groups (actual tau c significant at the .04 level). This may be a function of the $\mathrm{QC}$ participant group showing a smaller percentage of assemblers and slightly more inspectors. However, due to the chi-square results (which determine whether there is 
a systematic relationship between the variables) and the size of the actual significance level of the tau c, a decision to reject the null hypothesis would be seriously suspect. It is also important to note that the differences in the number of cases with respect to assemblers is only 10. Thus, rejecting the null hypothesis may be inappropriate on practical grounds as well. A more crucial test would be to hold this variable constant on key statistical tests to observe its effects. For example, this was done for a test of hypothesis one (discussed below) with the result of no independent effects of position upon the job satisfaction and QC participation relationship.

\section{TABLE X}

QC GROUPS BY POSITION

\begin{tabular}{lcccrr}
\hline & \multicolumn{3}{c}{ Job Title (in percent) } & \\
\cline { 2 - 5 } Group & Assemblers & Technicians & Inspectors & Others & Total \\
\hline QC Part. & 28.3 & 39.1 & 21.7 & 10.9 & 100.0 \\
Non Part. & 44.2 & 36.5 & 11.5 & 7.7 & 100.0 \\
\hline
\end{tabular}

Thus, from Tables VII through $x$, it is accurate to conclude that there are no clear significant differences among the demographic variables with QC membership. This is important to note at this juncture since the comparability of groups is needed to prevent confounding effects witin key statistical analyses of the hypotheses. At 
each point where there were potential confounding effects, these were taken into account by independent tests (as noted above for position).

With these analyses completed, hypothesis one was analyzed, which provided an overall test of the participation-satisfaction assumption with this study sample.

MEASURES OF JOB SATISFACTION-JSAT

In order to perform a test of hypothesis one, it was first necessary to generate a measure of job satisfaction. This was accomplished by constructing a job satisfaction index (JSAT), using three items of the JDS: "Generally speaking, I am very satisfied with this job (JDS303)," "I frequently think of quitting this job (JDS309 reversed scoring)," and "I am generally satisfied with the kind of work I do in this job (JDS313)." The same response scale was used for these items: Disagree Strongly, Disagree, Disagree Slightly, Neutral, Agree Slightly, Agree, Agree Strongly. This procedure is suggested by the authors of the JDS (Hackman and Oldham, 1980) as a measure of general satisfaction. As noted previously, this measure of job satisfaction and the JDS have been used widely in the literature. Normative data for a variety of studies using the JDS in the United States is available.

The JSAT index was constructed by recoding item JDS309, and computing a mean for the three items. 
Categories were then tabulated across cases with responses from 1 to 2.5 labelled low satisfaction; responses from 2.5 through 5.5 labelled medium satisfaction; and responses from 5.5 to 7 labelled high satisfaction. Since SPSS recodes values into the first of overlapping categories, this resulted in the JSAT "low" being composed of "Disagree" and "Strongly Disagree"; JSAT "medium" being composed of "Disagree Slightly," "Neutral," "Agree Slightly"; and JSAT "high" being composed of "Agree" and "Agree Strongly".

\section{HYPOTHESIS ONE}

A Crosstabs analysis of hypothesis one yielded the following results:

TABLE XI

QC PARTICIPATION BY JOB SATISFACTION INDEX

\begin{tabular}{lcccc}
\hline \multicolumn{4}{c}{ Job Satisfaction (in percent) } \\
Group & Low & Medium & High & Total \\
\hline \multirow{2}{*}{ QC participant } & 13.0 & 60.9 & 26.1 & 100.0 \\
Non participant & 15.4 & 61.5 & 23.1 & 100.0 \\
\hline
\end{tabular}

A chi-square analysis yielded a significance level of 0.9113 which is insufficient to reject the null hypothesis. Particularly salient is the similarity of responses across categories. In no case were the groups separated by more than 3 percentage points, which 
essentially precluded an analysis of trends in percent. The findings based upon chi-square were supported by an actual tau $c$ significance of .34 , which is not sufficient to indicate a significant relationship between the groups.

These findings do not support the participationsatisfaction thesis, since from the survey data, the conclusion is that no systematic relationship exists between QC participation and job satisfaction. While the retention of the null hypothesis in this analysis is not conclusive, it does present evidence challenging the participation-satisfaction linkage. That is, the assumption of a simple, automatic relationship between worker participation and job satisfaction is not supported by these data. This finding suggests that researchers should reexamine the participation-satisfaction relationship for plausible reasons why it is unsupported by a sizable number of studies in the literature. Locke and Schweiger (1979) and others note that almost 40 percent of the studies of programs involving participation in decisionmaking and job satisfaction show either no effects or deleterious effects. An examination of the evidence presented for tests of subsequent hypotheses and analyses of qualitative data in the current study may shed light on possible reasons for the lack of statistical significance between the QC program and job satisfaction. 
It should be noted at this point that independent chi-square tests were performed for hypothesis one, holding each of the aforementioned demographic variables (sex, age, education, job position) constant. In each of these tests, the level of significance was insufficient to reject the null hypothesis.

Although there were no statistically significant differences in this study between QC participants and non participants in terms of job satisfaction, the overall level of job satisfaction is generally lower when compared to other jobs. Table XII presents the mean and standard deviation of this sample along with several job "families" derived from the normative data presented by Hackman and Oldham (1980).

Subsequent analyses address the extent to which "desire for participation" and "attitudes toward participation" differ among workers, and how these variables may potentially affect the participation-satisfaction thesis. 


\section{TABLE XII}

NORMATIVE DATA ON JOB SATISFACTION

FOR THE CURRENT STUDY AND

RELATED JOB FAMILIES

\begin{tabular}{llr}
\hline & \multicolumn{2}{l}{ Job Satisfaction } \\
\cline { 2 - 3 } Group & Mean & S.D. \\
\hline Current Study & 4.23 & 1.54 \\
Prof/Tech & 4.9 & .97 \\
Managerial & 4.9 & 1.00 \\
Service & 4.6 & 1.20 \\
Processing & 4.6 & 1.20 \\
Machine Trades & 4.9 & 1.10 \\
Bench Work & 4.7 & 1.10 \\
\hline
\end{tabular}




\section{CHAPTER V \\ DESIRE FOR PARTICIPATION AND ATTITUDES \\ TOWARD PARTICIPATION}

\section{INTRODUCTION}

Following from the overall test of hypothesis one, hypotheses two through six address variables which emerge from the literature which may potentially affect the participation-satisfaction thesis. Hypotheses two and three examine whether or not differences exist among workers with respect to their desire for participation in decisionmaking, and in their attitudes toward worker participation. Hypothesis four tests the extent of the relationship between "desire" and "attitudes." Hypotheses five and six examine whether or not there are independent effects of "desire" and "attitudes" upon the participationsatisfaction relationship.

As with hypothesis two, tests for hypotheses three through six utilize the survey data from the JDS as well as the additional items assessing "desire" and "attitudes." A complete survey is located in Appendix A.

$$
\text { HYPOTHESIS TWO }
$$

Hypothesis two addresses the question of whether or 
not there are differences among workers with respect to desire for participation in decision-making using an index composed of a question ("To what extent do you desire participation in these areas?") followed by sixteen decisionmaking areas. Respondents chose among "none," "a little," "some," and "a lot" for each of the decisions.

Table XIII describes the scale items and the data for all QC workers in the study. As noted earlier, the response items were adapted from Witte (1980). The questions in the current study addressed desire for participation, rather than workers' assessments of how much participation they should have as in Witte's study.

For the overall test of hypothesis two, a chi-square analysis was performed on membership in $Q C$ by mean responses of desire for participation. Table XIV shows the results of this analysis.

The chi-square results reveal a significant relationship between the variables (.045 level) with QC participants showing more desire for participation than non participants. This finding is given support by a tau b with a .0229 level of significance.

Since the overall results for hypothesis two indicate that $Q C$ participants and non participants differ with respect to desire for participation (therefore rejecting the null hypothesis), it is important to examine where the differences are found within the items composing the 
TABLE XIII

DESIRE FOR PARTICIPATION AMONG QC WORKERSa

\begin{tabular}{|c|c|c|c|c|c|c|}
\hline \multirow[b]{2}{*}{ Response Items } & \multicolumn{4}{|c|}{ Response Category } & \multirow[b]{2}{*}{ Mean } & \multirow[b]{2}{*}{$r^{b}$} \\
\hline & None & A Little & Some & A Lot & & \\
\hline $\begin{array}{l}\text { The way the work is done- } \\
\text { methods and procedures }\end{array}$ & 0 & 7 & 28 & 61 & 3.57 & .23 \\
\hline The level or quality of work & 0 & 4 & 35 & 54 & 3.54 & .57 \\
\hline $\begin{array}{l}\text { How fast the work should be } \\
\text { done-the work rate }\end{array}$ & 2 & 13 & 37 & 44 & 3.27 & .23 \\
\hline $\begin{array}{l}\text { When the work day begins and } \\
\text { ends }\end{array}$ & 11 & 11 & 37 & 39 & 3.07 & .24 \\
\hline $\begin{array}{l}\text { The way the company spends its } \\
\text { money-how it invests its } \\
\text { profits }\end{array}$ & 21 & 15 & 33 & 37 & 3.00 & .43 \\
\hline $\begin{array}{l}\text { Who should do what job in your } \\
\text { group or section }\end{array}$ & 7 & 24 & 41 & 24 & 2.86 & .51 \\
\hline Pay scales or wages & 13 & 17 & 37 & 28 & 2.84 & .44 \\
\hline Selection of Leads & 7 & 28 & 39 & 24 & 2.82 & .39 \\
\hline $\begin{array}{l}\text { How much work people should } \\
\text { do in a day }\end{array}$ & 15 & 26 & 33 & 22 & 2.64 & .48 \\
\hline $\begin{array}{l}\text { Handling complaints or } \\
\text { grievances }\end{array}$ & 22 & 24 & 26 & 24 & 2.55 & .67 \\
\hline Management salaries & 37 & 13 & 22 & 22 & 2.30 & .54 \\
\hline Who gets promoted & 37 & 13 & 26 & 17 & 2.26 & .61 \\
\hline $\begin{array}{l}\text { Which workers join your } \\
\text { group (section) }\end{array}$ & 24 & 37 & 30 & 7 & 2.20 & .41 \\
\hline Helping to plan new plants & 41 & 17 & 28 & 9 & 2.05 & .57 \\
\hline $\begin{array}{l}\text { Hiring or promotions to } \\
\text { upper level management } \\
\text { positions like plant } \\
\text { manager or department heads }\end{array}$ & 41 & 20 & 28 & 7 & 2.00 & .69 \\
\hline $\begin{array}{l}\text { Who should be fired if they } \\
\text { do a bad job or don't } \\
\text { come to work }\end{array}$ & 41 & 26 & 20 & 9 & 1.96 & .60 \\
\hline
\end{tabular}

Note. The item responses are in percentage.

$a_{\underline{n}}=46$

$b_{r}=$ Spearman correlation of the 1 ten with scale minus the item 
desire for participation index. This lends a greater sense of understanding to the overail research question. The data from interviews and observational sources (explored in Chapter VI) are also germane to the findings for the test of this hypothesis.

TABLE XIV

DESIRE FOR PARTICIPATION AMONG

QC AND NON QC PARTICIPANTS

\begin{tabular}{llll}
\hline & \multicolumn{2}{c}{ Overall Desire for Participation (in percent) } \\
\cline { 2 - 4 } Group & Low & High & Total \\
\hline QC Participants & 15.2 & 84.8 & 100.0 \\
Non Participants & 32.7 & 67.3 & 100.0 \\
\hline
\end{tabular}

Table XV lists the items on the "desire" question in which there were significant differences between QC participants and non participants. Although the chi-square analyses for the three items are significant beyond the .05 level, the tau $c$ for Item 7 does not indicate significance (actual significance level $=.3317$ ). It would thus be problematic to reject the null hypothesis for this item since, although the variables appear to be related on the basis of chi-square, the relationship measured from tau $c$ is not considered to be significant. The discrepancy appears to be caused by the disparity in the "A Little" category, with QC participants showing 27 percent vis-a-vis 6 percent for non participants. 
Although the data do not clearly establish a significant association between variables, the percentages suggest an important trend. In general, non participants desire to participate more in terms of how much work people should do in a day. On the other hand, QC participants desire to participate more in matters which clearly exceed decision-making on specific work tasks. This latter view stands in contradistinction to the majority of stlidies cited earlier (i.e., Argyris, 1970; Halal and Brown, 1981; Blauner, 1964; Suda, 1982; Rus, 1970; Witte, 1980) which support the view that workers want more control over tasks directly related to their work. Wall and Lischeron's (1977) discussion of "distant" participation fits the results of the test for hypothesis two more closely. At least in this study sample, QC participants appeared to desire participation more than non participants, and on non-shop-floor issues.

Additional analyses of hypothesis two were performed by examining differences, within QC participants and non participants, of desire for participation. Within group analyses were important for the purpose of gaining insight into the overall hypothesis. Table XVI shows the results of non-parametric chi-square tests for within group analyses of QC participants and non participants with respect to desire for participation. The results show which items reveal significant (at or beyond $p=.05$ ) 
TABLE XV

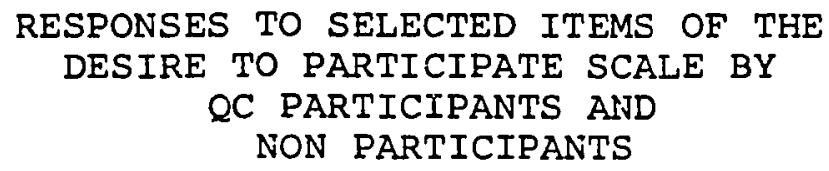

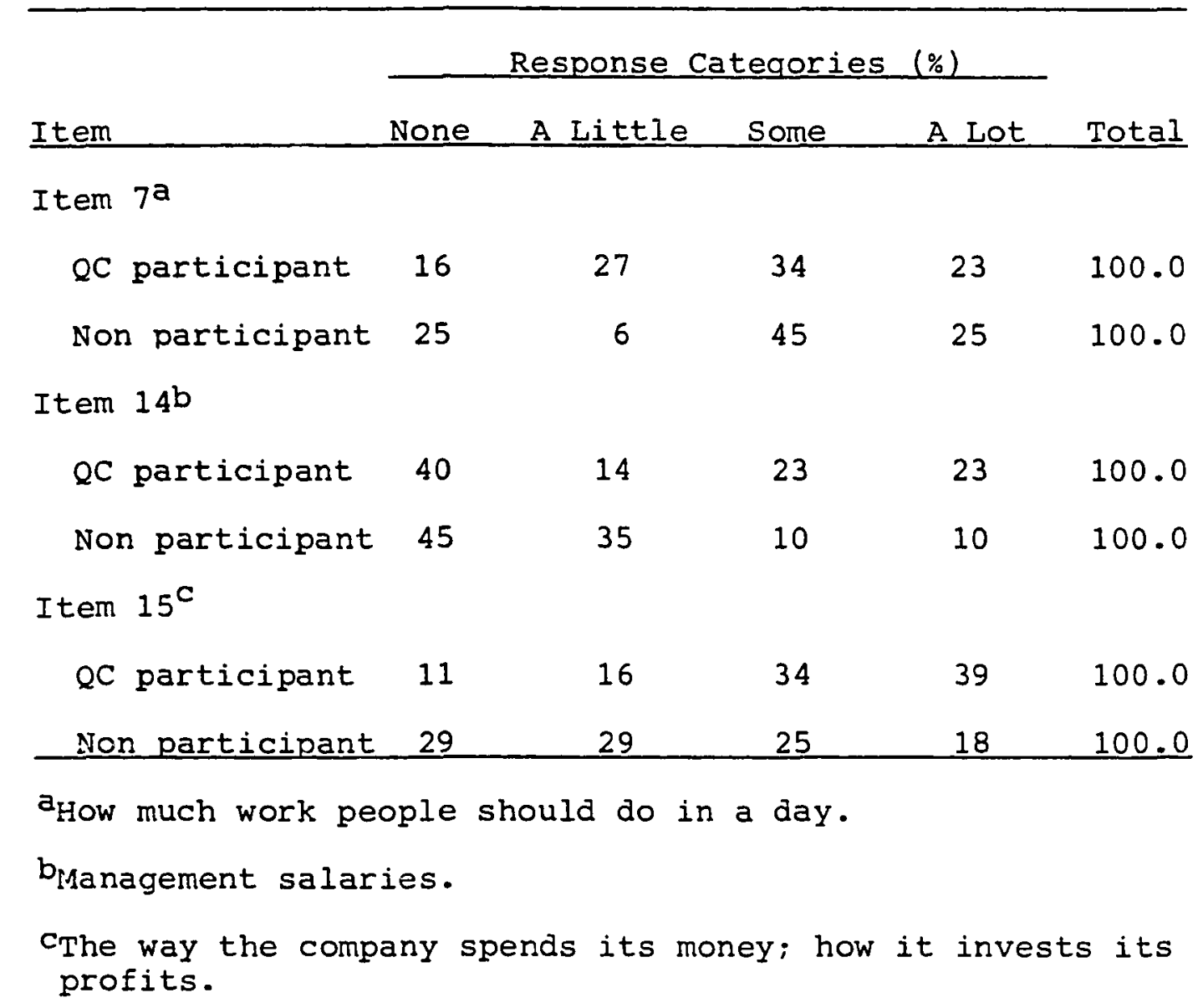


differences within groups. As shown below, workers in both groups differ significantly upon a majority of items.

\section{Discussion}

Based upon the analyses of QC participants and non participants, and desire for participation, hypothesis two was rejected which indicated that there were differences among workers with regard to desire for participation. Subsequent analyses revealed that QC participants differed significantly on two items in the desire index, and the percentage trend suggested differences on a third. Further analyses established differences within the groups with respect to desire for participation. Analyses of hypotheses three through six examine the impact of this finding on other variables. However, it remained for the interviews and other qualitative data (Chapter VI) to further explore the dynamics of differences in desire among workers. It is this variable which has received so little systematic attention in the literature (as discussed in Chapter II) and which is hypothesized in the current study as a potential confounding factor upon the overall relationship between participation and job satisfaction.

DESIRE FOR PARTICIPATION AND QC PARTICIPATION

As noted earlier, the data reveal a significant association between desire for participation and QC 
participation. Both chi-square and tau b analyses are sufficient to reject the null hypothesis at the .0447 and .0229 levels respectively (Table XIV).

TABLE XVI

WITHIN GROUP DIFFERENCES OF DESIRE FOR PARTICIPATION

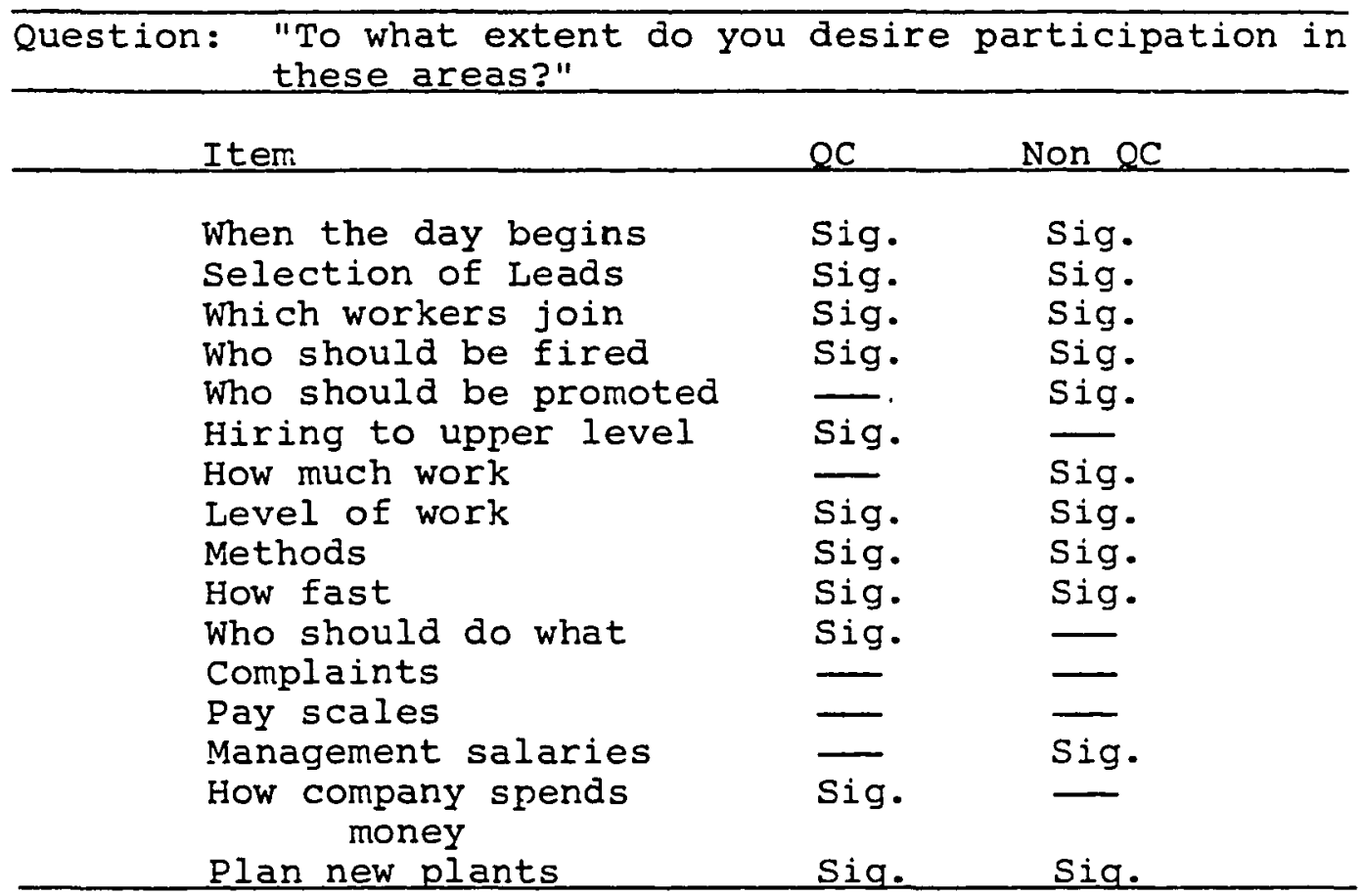

What is noteworthy in these data, in addition to the overall conclusion of a significant association, are two important trends. First, clearly two thirds of the non participants have a desire for more participation in decision-making. This dispels the assumption that all workers with strong desire for participation will automatically be represented in programs which will increase their decision-making ability; and in addition, that 
participation programs will sufficiently enlist a majority of workers with a high desire for participation. Although the QC participation program in this sample is composed of a majority (but not all) of workers with a high desire for participation, the program has only garnered half of the workers (52 percent) who desire more participation. Thus, membership in a participation program is not simply a matter of desire for participation. Although these two variables are significantly associated, there may be many other motivations for joining and for non participation. It is fair to say at this point that workers differ in their desize for participation and that this is especially evident in the three areas mentioned, but that the QC program does not sufficiently represent desire for participation. Some analyses to follow suggest that desire for participation may be a more appropriate variable for the overall research question than QC participation. Among the questions which arise concerning the QC program are (1) What characteristics of the QC participation programs fail to enlist workers with a desire for more participation? (2) Have QC participants' attitudes about the QC program changed since joining? (3) Which features of the QC program are perceived by workers as beneficial. and which features are perceived as non beneficial? In the interview data to be addressed in Chapter VI, these issues and others will be explored further. 


\section{HYPOTHESIS THREE}

Hypothesis three addresses the question of whether there are differences among workers witr: respect to their attitudes toward participation in decision-making. As noted earlier, these items were derived through an examination of the literature on participation in decisionmaking, and follow the analysis of potential determinants of desire for participation in Chapter Two. In two cases, questions were included in the survey from the suggestion of the production manager in charge of one section (PP) of the research population ("Management can be trusted to support the worker participation program which gives the worker increased decision-making ability" and "worker participation programs are just more work for the worker").

While there was no attempt to construct a scale, the analysis did include generating an overall mean response across cases for the seven "attitude toward participation" items. An analysis of the average responses across cases was a bit more difficult for this aspect of the study since the scoring for some items was reversed due to the wording of the questions. Table XVII gives the results of a test for QC participants and non participants in terms of overall responses to the attitude toward participation items recoded into "Negative" ("Strongly Agree" 
through "Agree Slightly") and "Positive" ("Disagree Slightly" through "Stongly Disagree") categories.

TABLE XVII

OVERALL ATTITUDES TOWARD PARTICIPATION AMONG QC PARTICIPANTS AND NON PARTICIPANTS

\begin{tabular}{lccc}
\hline & \multicolumn{2}{c}{ Attitudes (in percent) } & \\
\cline { 2 - 3 } Group & Neqative & Positive & Total \\
\hline \multirow{2}{*}{ QC Participants } & 52.2 & 47.8 & 100.0 \\
Non Participants & 44.2 & 55.8 & 100.0 \\
\hline
\end{tabular}

A chi-square analysis revealed results (chi-square $=$ $.617,1 \mathrm{df})$ which were insufficient to reject the null hypothesis at the .05 level of significance (Sig. $=.43$ ). Results from the tau c confirm this finding with a significance level of .22. The percentages do show a trend, however, in that $Q C$ participants demonstrate more negative attitudes toward participation than non participants. Although this is not statistically significant, it does indicate a direction in the data which is important in later analyses. The interviews discussed in Chapter VI will especially address this trend.

What makes the findings in Table XVII problematic to interpret is the nature of the items composing the overall attitude index. Since the items seek to measure a number of different attitudes, it is more accurate to examine each of the specific attitude items in the overall list. 
Table XVIII describes the result of a test between QC membership and Item 1, which is a measure of the extent to which decisions are perceived as legitimately falling within management's domain.

TABLE XVIII

QC PARTICIPATION BY LEGITIMACY OF PARTICIFATION

\begin{tabular}{|c|c|c|c|c|}
\hline \multirow[b]{2}{*}{ Item } & \multicolumn{4}{|c|}{ Response Categories (in percent) } \\
\hline & $\begin{array}{l}\text { Str. Agree Agree } \\
\text { Agree } \\
\text { Al }\end{array}$ & $\begin{array}{l}\text { Disagree Disagree } \\
\text { Slightly }\end{array}$ & $\begin{array}{l}\text { Strongly } \\
\text { Disagree }\end{array}$ & Total \\
\hline
\end{tabular}

Item 1 a

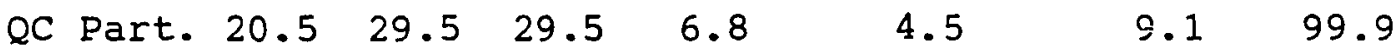

Non Part. $15.7 \quad 41.2 \quad 13.7 \quad 19.6 \quad 9 \quad 9.8 \quad-\quad 100.0$

aIt is management's job to make decisions concerning job activity.

The chi-square analysis was sufficient to reject the null hypothesis at the .05 level of significance (actual significance $=.03$ ). The tau c results are less conclusive, showing a .4969 significance level, which is not sufficient to indicate a significant association. The disparity in findings may be a function of small cell size for computing statistics. The percentages show a trend, however, in that QC participants generally agree more than non participants with the item. This would indicate that QC participants appeared to be justifying the right of management to control decisions. The interview data discussed in Chapter VI will address this issue more 
specifically in an attempt to identify worker attitudes toward management and decision-making.

Table XIX illustrates the data for the remaining attitude items when tested with QC participation. In no case were the chi-square or tau c findings significant at, or exceeding the .05 level. A perusal of the percentages does indicate some important trends on selected items, however. The data for item two suggest that a large majority of both $Q C$ participants and non participants indicate a marked positive attitude toward the responsibility associated with increased decision-making ability. This is confirmed by non parametric within group analyses of QC participants and non participants (see Table XX). Similar disparities are observed for items four and five. A clear majority of both QC participants and non participants indicate agreement with the items suggesting that they believe management to be in control of decisionmaking (item four) and that added decision-making ability could create conflict with co-workers (item five). The percentages on item seven indicate that QC participants are more likely than non participants to agree that worker participation programs are a way of controlling workers. Non parametric chi-square tests were performed for each item in order to assess the potential differences within the QC participation and non participation groups. 
TABLE XIX

THE RELATIONSHIP OF QC PARTICIPATION TO

ATTITUDES REGARDING PARTICIPATION

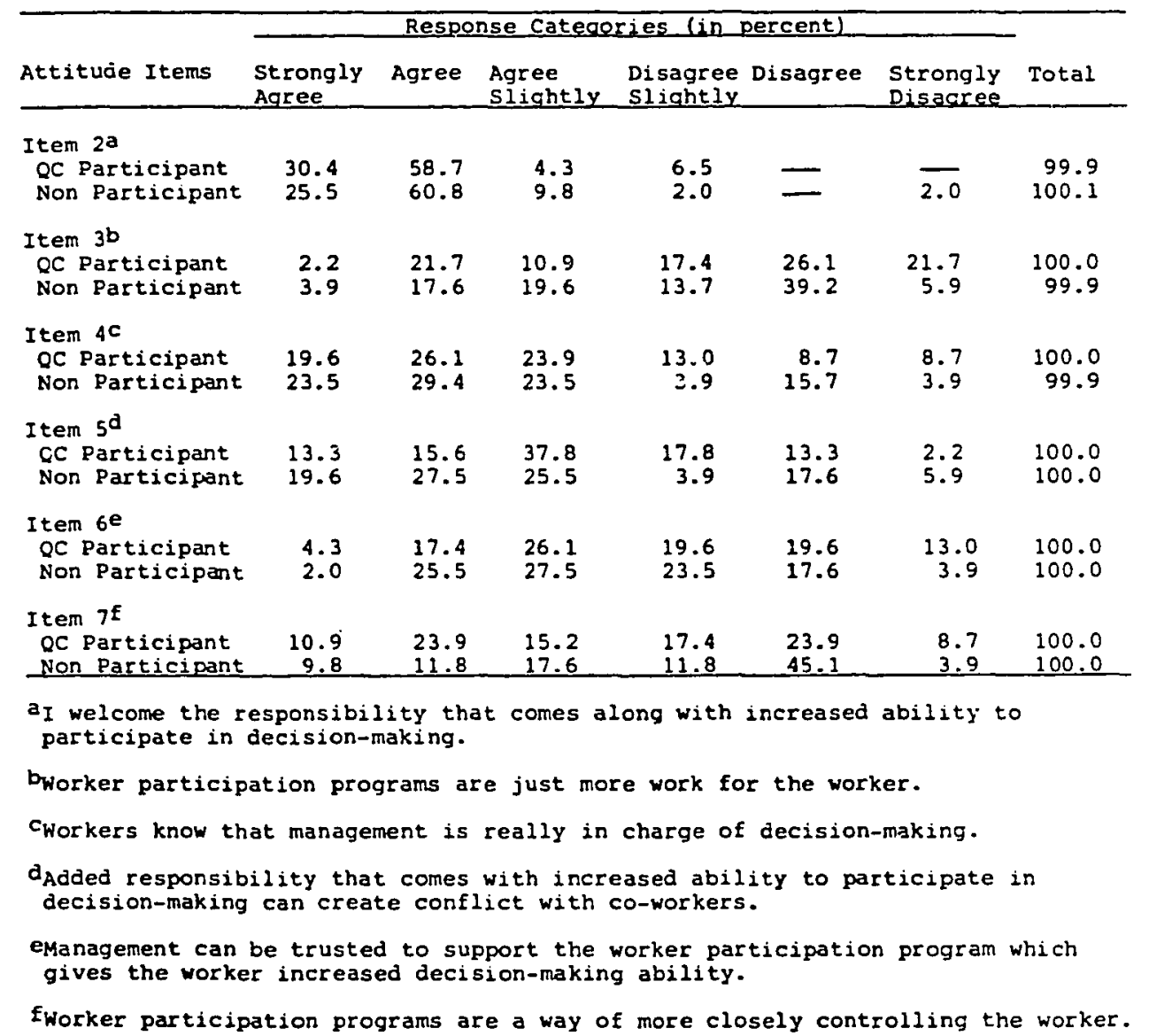


Table XX describes the results of these tests for both groups by indicating which items exceeded the .05 level of significance.

TABLE $X X$

WITHIN GROUP DIFFERENCES OF ATTITUDE ITEMS

\begin{tabular}{|c|c|c|c|}
\hline & Attitude Items & $\mathrm{QC}$ & Non $\mathrm{QC}$ \\
\hline 1. & $\begin{array}{l}\text { It is management's job to make } \\
\text { decisions concerning job activity. }\end{array}$ & sig. & sig. \\
\hline 2. & $\begin{array}{l}\text { I welcome the responsibility that } \\
\text { comes along with increased ability } \\
\text { to participate in decision-making. }\end{array}$ & Sig. & Sig. \\
\hline 3. & $\begin{array}{l}\text { Worker participation programs are } \\
\text { just more work for the worker. }\end{array}$ & $\longrightarrow$ & Sig. \\
\hline 4. & $\begin{array}{l}\text { Workers know that management is } \\
\text { really in charge of decision-making. }\end{array}$ & - & Sig. \\
\hline 5. & $\begin{array}{l}\text { Added responsibility that comes } \\
\text { with increased ability to parti- } \\
\text { cipate in decision-making can } \\
\text { create conflict with co-workers. }\end{array}$ & Sig. & Sig. \\
\hline 6. & $\begin{array}{l}\text { Management can be trusted to sup- } \\
\text { port the worker participation } \\
\text { program which gives the worker } \\
\text { increased decision-making ability. }\end{array}$ & $\longrightarrow$ & Sig. \\
\hline 7. & $\begin{array}{l}\text { Worker participation programs are } \\
\text { a way of more closeiy controlling } \\
\text { the worker. }\end{array}$ & - & Sig. \\
\hline
\end{tabular}

Discussion

From the analyses described in Tables XVII to XIX, it appears that the evidence is insufficient to reject the null hypothesis in terms of an overall attitude difference between $\mathrm{QC}$ and non $\mathrm{QC}$ participants. When the items were taken individually, however, at least one item 
(number 1) resulted in a significant difference between the groups based upon a chi-square test. Further, analyses of the percentages on additional attitude items revealed trends which are helpful in clarifying the relationship between QC participation and attitudes toward participation.

Subsequent non parametric analyses of within group differences among QC participants and non participants revealed that, while the QC participant group evinced mixed results, the non participant group revealed significant differences on all attitude items. While this may provide sufficient evidence to reject the null hypothesis, the trends decribed above from between group analyses are more helpful for understanding the overall research question.

These comments must be viewed against a backdrop of the findings (in hypothesis two) that there is a relationship between QC participation and desire for participation. Thus, an analysis of the relationship between desire for participation and attitudes toward participation will provide two things. First, it will reveal which variable (desire for participation or QC participation) is more salient for understanding the overall research hypothesis. Second, it will provide further insight into workers' attitudes toward participation and the success or 
failure of the worker participation program. These issues are addressed in the analysis of hypothesis four.

HYPOTHESIS FOUR

The fourth hypothesis examines the relationship between desire for participation and workers' attitudes toward participation, using the desire and attitude items included on the worker survey. Although the analysis does not permit causal statements, it nevertheless describes whether or not a significant relationship exists between the variables. In the following analyses, the overall desire measure is correlated first with the overall attitude measure, and then with each item independently, for the entire worker sample.

A Spearman Rank correlation between overall desire and overall attitudes toward participation among all workers was insufficient to reject the null hypothesis $(r=.244)$. However, due to the nature of the overall attitude measure, separate tests were performed between attitude items and overall desire for participation.

A chi-square analysis of overall desire with each attitude item (for all workers) revealed that items two and three were significant beyond the .05 level. The tau c results for these items revealed figures significant at the .002 and .0008 levels respectively. Table XXI describes the data for these items. 
The findings for item two may be problematic due to small cell size. However, a significant relationship is indicated such that workers who more strongly desire participation also welcome the responsibility which accompanies decision-making. The percentages indicate that this relationship is mainly observed within the categories indicating overall agreement ("Strongly Agree" through "Agree Slightly"), however. Although the relationship may be sound statistically, it is nevertheless important to note the trend of general agreement within low desire workers as being slightly less than that of high desire workers.

TABLE XXI

RELATIONSHIP OF OVERALL DESIRE FOR PARTICIPATION WITH SELECTED ATTITUDE ITEMS AMONG ALL WORKERS

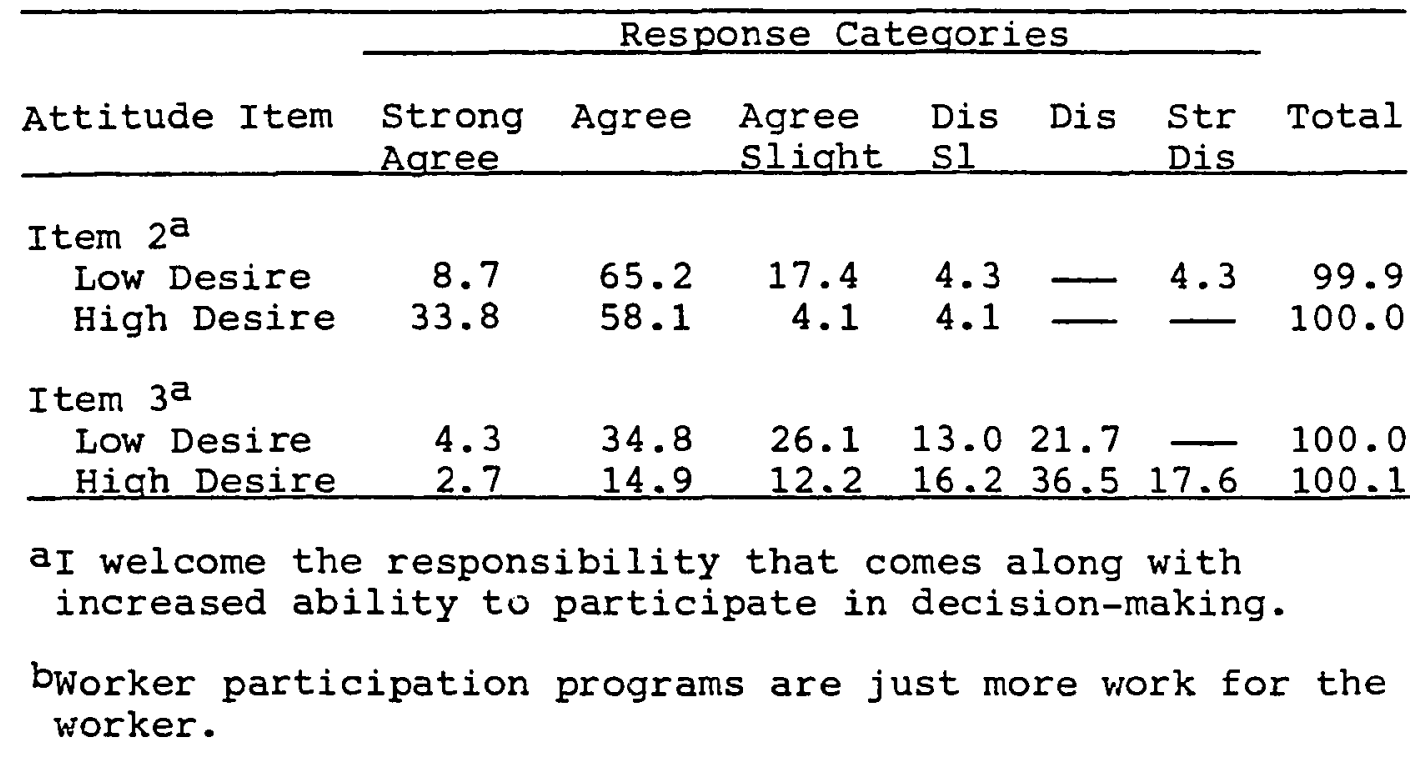


The data for analysis of item three may be likewise problematic due to small cell size, especially among the low desire group. The association and trends among percentages are fairly clear, however, in establishing that "high desirers" tend more often than "low desirers" to disagree with this item. This suggests two things. First, those who strongly desire to participate do not perceive participation programs as extra work. Secona, low desirers do perceive these programs as burdensome, and this may partially suggest why they do not opt to join. Subsequent analyses of additional data in Chapter VI will shed light on this particular issue.

In addition to these attitude items for which there were statistically significant findings, two other items indicated mixed findings, but served as important indications of overall attitude trends. Table XXII gives the results of crosstabular analyses on items six and seven. The chi-square results were non significant for each item (.1355 and .3509 levels of significance respectively), however, the tau c results indicate significant relationships. For item six, the tau c was significant at the .0397 level of significance, at least partially suggesting that low desirers tended to trust management more to support participation programs which give workers increased decision-making ability. High desirers, 
however, tend to evince more distrust of management in

this respect.

TABLE XXII

RELATIONSHIP OF OVERAIL DESIRE TO ADDITIONAL ATTITUDE ITEMS

\begin{tabular}{|c|c|c|c|c|c|c|c|}
\hline \multirow[b]{2}{*}{ Attitude Item } & \multicolumn{6}{|c|}{ Response Categories } & \multirow[b]{2}{*}{ Total } \\
\hline & $\begin{array}{l}\text { Strong } \\
\text { Agree }\end{array}$ & Agree & $\begin{array}{l}\text { Agree } \\
\text { Slight }\end{array}$ & $\begin{array}{l}\text { Dis } \\
\text { Sl }\end{array}$ & Dis & $\begin{array}{l}\text { Str } \\
\text { Dis }\end{array}$ & \\
\hline \multicolumn{8}{|l|}{ Item $6^{\mathrm{a}}$} \\
\hline $\begin{array}{l}\text { Low Desire } \\
\text { High Desire }\end{array}$ & $\overline{4.1}$ & $\begin{array}{l}26.1 \\
20.3\end{array}$ & $\begin{array}{l}43.5 \\
21.6\end{array}$ & $\begin{array}{l}21.7 \\
21.6\end{array}$ & $\begin{array}{r}8.7 \\
21.6\end{array}$ & $\overline{10.8}$ & $\begin{array}{l}100.0 \\
100.0\end{array}$ \\
\hline \multicolumn{8}{|l|}{ Item $7^{b}$} \\
\hline $\begin{array}{l}\text { Low Desire } \\
\text { High Desire }\end{array}$ & $\begin{array}{c}0 \\
13.5 \\
\end{array}$ & $\begin{array}{l}13.0 \\
18.9 \\
\end{array}$ & $\begin{array}{l}21.7 \\
14.9 \\
\end{array}$ & $\begin{array}{l}13.0 \\
14.9 \\
\end{array}$ & $\begin{array}{r}47.8 \\
31.1 \\
\end{array}$ & $\begin{array}{l}4.3 \\
6.8 \\
\end{array}$ & $\begin{array}{l}100.0 \\
100.1 \\
\end{array}$ \\
\hline
\end{tabular}

a Management can be trusted to support the worker participation program which gives the worker increased decisionmaking ability.

bworker participation programs are a way of more closely controlling the worker.

Although the tau c results for item seven only approach an acceptable level of significance (actual tau c $=.0654)$, the percentages indicate a slight trend toward greater agreement on this item among high desirers. The suggestion at this point is that those more strongly desiring participation may view participation programs as a vehicle for control over workers.

\section{Discussion}

While tests of overall measures were not sufficient to reject hypothesis four, individual item analyses 
revealed significant relationships between overall desire for participation and workers' attitudes toward participation. Specifically, it was noted that workers who indicated a desire for more participation also tended (a) to welcome the responsibility associated with increased ability for decision-making, (b) not to view participation programs as extra work, (c) to trust management less as being supportive of those programs, and, (d) to possibly view participation programs as being a venicle of control over workers. Conclusions based upon these findings are discussed below (see "Discussion of Findings for Hypotheses Two Through Six").

When the findings discussed from Tables XXI and XXII were examined in light of the "desire-QC participation" relationship it was found that QC participation did not exert a significant effect when held constant. Table XXIII illustrates this relationship.

A comparison of these results with Tables XXI and XXII reveals that the tau c significance levels for attitude items two and three correspond directly. Those for items six and seven show a bit of deviation, however, this may be a function of low cell size. The chi-square results are less clear in their correspondence, however, this statistical measure is suspect in a three dimensional analysis due to the sensitivity to cell size. In most cases, 58 to 75 percent of the cells had less than 5 cases. 
Another method for assessing the effect of QC participation upon the desire-attitudes relationship was the partial correlation procedure. In this analysis attitude items two and three resulted in significant relationships with desire for particpation (.002 and .001 respectively) when controlling for QC participation. Items six and seven were less significant (.065 and .115 respectively), however, they approached the levels obtained by chi-square and tau $c$ analyses in Table XXIII.

\section{TABLE XXIII}

THE RELATIONSHIP BETWEEN DESIRE FOR PARTICIPATION AND SPECIFIC ATTITUDES TOWARD PARTICIPATION HOLDING QC PARTICIPATION CONSTANT

\begin{tabular}{ccccc}
\hline & \multicolumn{2}{c}{ Chi-Square } & \multicolumn{2}{c}{ Tau C } \\
\cline { 2 - 5 } (Significance Level) & (Sianficance Level) \\
\cline { 2 - 5 } Attitude Item & OC Part. & Non Part. & OC Part. & Non Part. \\
\hline Two & .11 & .09 & .05 & .009 \\
Three & .44 & .16 & .03 & .006 \\
Six & .08 & .47 & .27 & .05 \\
Seven & .61 & .56 & .31 & .08 \\
\hline
\end{tabular}

These analyses indicate a much clearer set of relationships between "desire" and "attitudes" than between "QC participation" and "attitudes" especially in light of the findings based upon the three dimensional analysis. In addition, since the QC program does not accurately represent workers in terms of their desire for participation, the latter variable may be very important in describing 
worker attitudes generally, as well as to provide insight into the functioning of the QC program itself. In the hypothesis tests to follow, both "desire" and "QC participation" are taken into account for a more comprehensive analysis of the research problem.

HYPOTHESES FIVE AND SIX

Hypotheses five and six test the independent effects of desire for participation and attitudes toward participation upon the relationship between QC participation and job satisfaction. These tests used the desire and attitude items along with the JDS survey items composing the job satisfaction index.

Hypothesis Five

In this analysis, QC participation and job satisfaction were tested, holding desire for participation constant. Table XXIV shows the results for this test.

\section{TABLE XXIV}

INDEPENDENT EFFECTS OF DESIRE FOR PARTICIPATION ON THE PARTICIPATION-SATISFACTION RELATIONSHIP

\begin{tabular}{llllllllll}
\hline & \multicolumn{3}{c}{ Low Desire } & & \multicolumn{3}{c}{ High Desire } \\
\hline & Job Satisfaction $(\%)$ & & Job Satisfaction $(\%)$ \\
Group & Low & Med. High & Total & Low & Med. High Total \\
QC Part. & - & 71.4 & 28.6 & 100.0 & 15.4 & 59.0 & 25.6 & 100.0 \\
Non Part. & 5.9 & 58.8 & 35.3 & 100.0 & 20.0 & 62.9 & 17.1 & 100.0 \\
\hline
\end{tabular}


Neither the chi-square nor tau c results demonstrated a significant difference. Thus, it appears that there are no significant independent effects of desire for participation upon the participation-satisfaction relationship.

When the association between overall desire for participation and QC participation is taken into account, however (as discussed under hypothesis two), the relationship with job satisfaction revealed significant findings. That is, since QC participation is not adequate to represent desire for participation, job satisfaction was tested with desire for participation alone, with the results shown in Table XXV.

TABLE XXV

THE RELATIONSHIP BETWEEN DESIRE FOR PARTICIPATION AND JOB

SATISFACTION

\section{Job Satisfaction $(\%)$}

\begin{tabular}{lrrrr} 
Desire & Low & Medium & High & Total \\
\hline Low & 4.2 & 62.5 & 33.3 & 100.0 \\
High & 17.6 & 60.8 & 21.6 & 100.0 \\
\hline
\end{tabular}

Although the chi-square results were not significant, the tau $c$ was significant at the .0442 level. This indicated a relationship between the variables such that, in general, the higher the desire for participation, the lower the job satisfaction. This would appear to 
contradict general expectation, unless there were factors present which prevented those with high desire from realizing the increased decision-making ability. Including QC participation into the design (Table XXVI) provided an added degree of insight.

In this analysis, the relationship between desire and job satisfaction was significant among non- $Q C$ participants, while it was not significant among QC participants. Neither the chi-square nor tau $c$ were significant among QC participants, however, the direction among the percentage suggests that the higher the desire, the lower the job satisfaction. This direction is significant among non participants. Although the chi-square test is not significant, the tau $c$ is significant at the .0396 level. Thus, the result is that, the higher the desire for participation, the lower the job satisfaction.

TABLE XXVI

THE EFFECTSS OF QC PARTICIPATION UPON THE DESIRE-JOB SATISFACTION RELATIONSHIP

\begin{tabular}{llllllllll}
\hline & \multicolumn{3}{c}{ QC Participation } & & \multicolumn{3}{c}{ Non Participation } \\
\hline & Job Satisfaction $(\%)$ & & \multicolumn{3}{c}{ Job Satisfaction $(\%)$} \\
\cline { 2 - 6 } Desire Low & Med. High & Total & Low & Med. High Total \\
Low & & 71.4 & 28.6 & 100.0 & & 5.9 & 58.8 & 35.3 & 100.0 \\
High & 15.4 & 59.0 & 25.6 & 100.0 & 20.0 & 62.9 & 17.1 & 100.0 \\
\hline
\end{tabular}

The conclusion from these data is that desire for participation demonstrates a clearer association with job 
satisfaction than does QC participation. Thus, although hypothesis five cannot be rejected, the analyses lend considerable insight into the relationship among the variables. In addition, the data strongly suggest that, since there is no significant relationship between QC participation and job satisfaction (hypothesis one), that the QC program is ineffective on two counts, (1) failing to enlist workers with a high desire for participation; (2) failing to deliver the conditions necessary for workers with a desire for participation to perceive greater satisfaction in their jobs. The anlayses of hypothesis three and four suggested potential reasons for these failures in an examination of worker attitudes toward participation. Hypothesis six is an extention of those analyses.

Hypothesis Six

In an overall sense, hypothesis six tests for the effects of attitudes upon the QC participation-job satisfaction relationship. Table XXVII describes the findings for the test of overall attitudes toward participation with job satisfaction, the zero order analysis. Neither the chi-square nor the tau c results were significant for this test.

Next, an analysis was performed on the relationship between QC participation and job satisfaction holding the overall attitude measure constant. Table XXVIII lists the results of this test. No significant effects of attitudes 
TABLE XXVII

ATTITUDES TOWARD PARTICIPATION AND JOB SATISFACTION

\begin{tabular}{lcccc}
\hline & \multicolumn{3}{c}{ Job Satisfaction $(\%)$} & \\
\cline { 2 - 4 } Attitude & Low & Medium & High & Total \\
\hline Negative & 8.5 & 68.1 & 23.4 & 100.0 \\
Positive & 19.6 & 54.9 & 25.5 & 100.0 \\
\hline
\end{tabular}

were found upon the relationship between $Q C$ participation and job satisfaction, thus resulting in the retention of the null hypothesis. Due to the nature of the overall attitude measure, however, the same analysis was performed holding each attitude item (items one through seven) constant. In none of these tests were there significant findings among either chi-square or tau c figures.

TABLE XXVIII

INDEPENDENT EFFECTS OF AN OVERALI ATTITUDE INDEX UPON THE PARTICIPATIONSATISFACTION RELATIONSHIP

\begin{tabular}{|c|c|c|c|c|c|c|c|}
\hline \multirow[b]{3}{*}{ Group } & \multicolumn{4}{|c|}{ Neqative Attitudes } & \multicolumn{3}{|c|}{ Positive Attitudes } \\
\hline & \multicolumn{4}{|c|}{ Job Satisfaction $(\%)$} & \multicolumn{3}{|c|}{ Job Satisfaction $(\%)$} \\
\hline & Low & Med. & High & Total & Low & Med. & Hiah Total \\
\hline QC & 4.2 & 66.7 & 29.2 & 100.1 & 22.7 & 54.5 & 22.7 \\
\hline Non $\mathrm{Pa}$ & 13.0 & 69.6 & 17.4 & 100.0 & 17.2 & 55.2 & $27.6 \quad 100$. \\
\hline
\end{tabular}

Given the nature of the relationship between desire and attitudes (hypothesis four), and given the discussion of hypothesis five, attitudes were tested with desire and 
job satisfaction in an attempt to gain insight into the effects of worker attitudes toward participation. Specifically, desire for participation was tested with job satisfaction, holding attitudes toward participation constant. The intent was to ascertain which attitude items affected the desire-job satisfaction relationship and thus perhaps to suggest explanations for the apparent shortcomings of the QC program.

The test holding attitudes constant revealed significant effects upon the desire-satisfaction relationship upon all but item six. Some of the effects, although significant, are not strong effects; however, some are very important to the overall analysis. Table XXIX lists the items in which there were statistically significant differences.

\section{Discussion of Table XXIX}

Attitude Item one. Both the chi-square (Sig. = $.0035)$ and tau c (Sig. $=.0076)$ results demonstrated significant differences among workers with "positive" attitudes. That is, among workers who generally disagree with item one ("It is management's job to make decisions concerning job activity"), those with greater desire for participation are less satisfied with their jobs. This suggests that workers who desire participation may be frustrated in their actual decision-making ability, leading to job dissatisfaction. This finding must be 
TABLE XXJX

THE DESIRE-SATISFACTION RELATIONSHIP HOLDING ATTITUDE ITEMS CONSTANT (IN PERCENT)

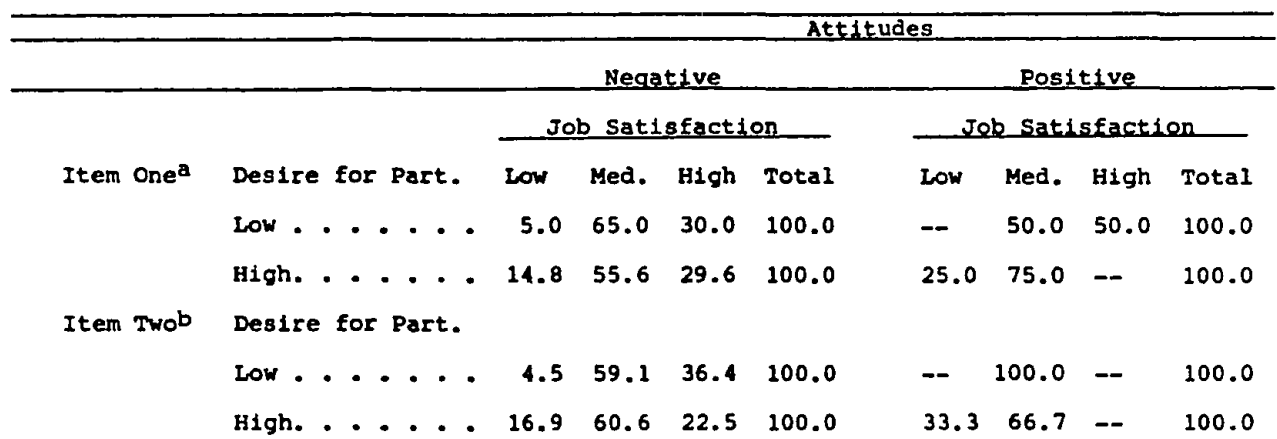

Item Threec Desire for Part.

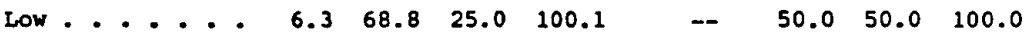

High. . . . $\begin{array}{llllllll}13.6 & 63.6 & 22.7 & 99.9 & 19.2 & 59.6 & 21.2 & 100.0\end{array}$

Item Fourd Desire for Part.

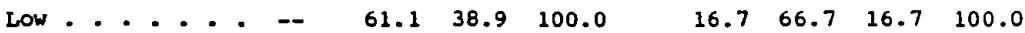

High. . . . $\begin{array}{llllllllll}13.0 & 64.8 & 22.2 & 200.0 & 30.0 & 50.0 & 20.0 & 100.0\end{array}$

Item Five ${ }^{e}$ Desire for Part.

Low . . . . $5.6 \quad 66.7 \quad 27.8 \quad 100.1 \quad 3 \quad 5 \quad 50.0 \quad 50.0 \quad 100.0$

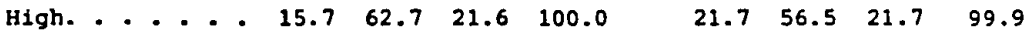

Item Sevenf Desire for Part.

\begin{tabular}{lllllllll} 
Low . . . . & 11.1 & 77.8 & 11.1 & 100.0 & - & 53.3 & 46.7 & 100.0 \\
High._...... & 14.3 & 62.9 & 22.9 & 100.1 & 20.5 & 59.0 & 20.5 & 100.0 \\
\hline
\end{tabular}

at is management's job to make decisions concerning job activity.

$b_{I}$ welcome the responsibility that comes along with increased ablitty to participate in decision-making.

Worker participation programs are just inore work for the worker.

dworkers know that management is really in charge of decision-making.

eAdded responsibility that comes with increased ability to participate in decisionmaking can create conflict with co-workers.

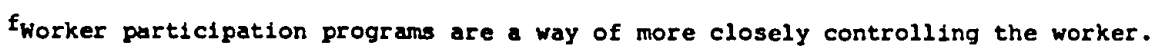


viewed cautiously, however, since it was based upon 24 cases in this attitude category.

Attitude Item Two. With almost the entire worker sample (93 cases), the tau c reveals a significant association (Sige $=.0442$ ) among the workers who generally agree with this item ("I welcome the responsibility that comes along with increased ability to participate in decision-making") . Thus, among the workers who welcome the responsibility of participating, there is a significant association such that those who most desire participation are less satisfied with their jobs. The confidence in this finding is bolstered by the number of cases in the analysis. The finding here is similar to that for item one in that workers may be frustrated in the attempt to realize the responsibility accompaning decision-making ability, with an attendant low level of job satisfaction.

Attitude Item Three. Although based upon a small sample size among low desirers, the tau c results demonstrated a significant association (Sig. = .0234) among workers who generally disagreed ("Positive") with this item ("Worker participation programs are just more work for the worker"). Thus, among these workers, those with greater desire for participation had lower job satisfaction. Again, high desire, with the attitude that participation programs are not burdensome, was not associated with greater satisfaction. The suggestion here is that 
perhaps the extant program, or other factors, were not permitting workers to actualize the participation they want.

Attitude Item Four. The tau c revealed a significant difference (sig. $=.0335$ ) among workers who generally agree that "manadement is really in charge of decisionmaking." of those workers there is a general association between greater desire and low job satisfaction. This finding may provide insight into the earlier suggestions, in that workers with a stronger desire may perceive management to, at least partially, prevent workers from having greater decision-making ability.

Attitude Item Five. The results for this item reveal a tau $c$ that approaches a significant level (sig. = .0528) among workers who generally disagree that increased decision-making ability can lead to co-worker conflict. The trend, while based on only 29 cases, reveals that, of these workers, those with stronger desire for participation have less job satisfaction. These results tend to give general support to the findings for item four, although the nature of the statistical results create less confidence for this particular item.

Attitude Item Seven. Both the chi-square (Sig. = $.0549)$ and tau c (Sig. $=.0091)$ results indicate a significant association between desire and job satisfaction among workers who generally disaqree that participation 
programs are methods for controlling workers. Of these workers, those with greater desire for participation also evince less job satisfaction. This appears to be a strong positive statement in favor of participation programs in general. Whether the QC program in place was perceived as being efficacious is another issue to be addressed.

\section{DISCUSSION OF FINDINGS FOR HYPOTHESES TWO THROUGH SIX}

Prior to a discussion of the qualitative data (Chapter VI) which may provide additional insight into the findings already discussed, it is necessary to briefly review the statistical results and sugaestions arising from hypotheses two through six.

Several stable findings emerged from the analyses of the hypotheses. These findings were based upon the fact that, generally, there was no relationshio between participation in the QC program and job satisfaction. In analyzing the data for a potential explanation of this finding which is consistent with a number of studies discussed in Chapter II, the following conclusions were reached. First, workers do differ in the degree to which they desire participation. Second, the QC program in operation does not sufficiently represent or enlist workers with a high desire for participation. Third, workers display different attitudes toward participation in decision-making. By analyzing those workers with high 
desire for participation (and holding QC participation constant), it was found that they welcomed the responsibility of decision-making, and did not perceive participation programs as burdensome. Among these same workers, general trends emerged suggesting that management was perceived as being unsupportive, and that participation programs are being used as a mechanism to control workers.

Fourth, it was found that, in general, workers with increased desire for participation also evinced less job satisfaction. This was found to be especially true among non-QC participants when QC participation was controlled.

Fifth, it was found that desire for participation is related to job satisfaction, especially when attitudes toward participation were controlled. The resultant findings were that the inverse relationship between desire and job satisfaction was true among workers who (a) disagree that decision-making is management's domain, (b) welcome the responsibility of decision-making, (c) disagree that worker participation programs are burdensome, (d) agree that management may actually be in charge of decision-making, (e) disagree that increased decisionmaking ability can lead to co-worker conflict, and (f) disagree that worker participation programs are methods for controlling workers. 
Analyzing these findings leads to the emergence of several suggestions regarding the overall relationship between worker participation and job satisfaction. First, desire for participation is a better variable to analyze than participation in the QC program due to the ineffectiveness of the extant QC program in representing high desire. Second, there appears to be positive regard for worker participation programs in general. Third, the QC program is unable to promote general job satisfaction. Fourth, the reason may at least partially be attributable to the management structure which obstructs the QC program from reaching its full potential.

The qualitative data in Chapter VI is intended to clarify these issues by gaining further insight into workers' reasons for their responses to the survey, and into their general attitudes toward participation. The data emerging from observations of the ongoing functioning of the QC program may additionally be useful in this process. 
CHAPTER VI

THE WORKER'S VIEW

INTRODUCTION

Although primarily quantitative in nature, this study also includes data which are qualitative. In an attempt to provide information regarding the efficacy of worker participation, the study includes an analysis of individual interviews conducted with workers, and information obtained through observations of QC meetings throughout the four month data collection phase. An attempt was made to gather information from a number of sources which, according to Jick (1979) and others, enables the researcher to capture a more "holistic" and contextual portrayal of the focus of study.

The call for a more comprehensive methodology in organizational research has come from many quarters, all of which agree that over reliance on quantitative measures may result in undiscerning conclusions. Most strident in the criticism of quantitative methods, Van Maanen (1979) notes that:

There seems to be a rather widespread skepticism surrounding the ability of conventional data collection techniques to produce data that do not distort, do violence to, or otherwise falsely 
portray the phenomena such methods seek to reveal. (p. 522).

A bit less caustically, Hackman (1982) observes that traditional methods of studying organizations are grounded in narrow disciplinary perspectives, and may blind researchers to new findings and insights.

Although not totally in the mold of qualitative researchers of organizations (e.g., Downey and Ireland, 1979; Salanick, 1979; Webb and Weick, 1979), this study provides observational and interview information which is interpretive in nature. The nature of this attempt was different than most studies of worker participation which, as noted in the literature review, are primarily mechanical in positing a direct link between worker participation and its supposed effects (i.e., worker satisfaction). Like phenomenological sociologists who study organizations and related processes (Manning, 1979; Jehenson, 1973; Fish and Dorris, 1975), the attempt here was to explore more comprehensively the meaning of worker participation for individual workers' experiences, and how this affected job satisfaction.

As noted in Chapter III, the interviews addressed three main areas: the follow-up questions on the "desire for participation" items used in the survey; a section designed to assess workers' attitudes toward QCs and worker participation generally; and an open ended section designed to provide further insight into workers' 
attitudes and experiences at the specific plant studied. Following a discussion of these interviews, data are presented on attendance at $\mathrm{QC}$ meetings visited during the study •

\section{DESIRE FOR PARTICIPATION : WHY}

The interview format allowed workers to reveal their perceptions of worker participation through a question designed as a follow-up to the "desire for participation" question on the survey. Workers were shown the survey questions (administered some two weeks before) and asked, "In general, why do you feel workers should be allowed to participate?," especially in the areas where the workers had earlier indicated a desire for participation. This "clarification of responses" method is patterned after Witte's (1980) analysis of "belief in participation" study, with changes in the overall survey as noted in Chapter V. Table XXX lists some of the major themes which emerged from workers' responses to the question.

Workers Perform the Work

The largest category of responses contains the theme that, since workers perform the work, more participation in decision-making is called for, and would affect them in various ways. Among these responses, several subthemes emerged.

First, workers stated that they were "there" (at 
work) every day, knew the job, and thus developed specific knowledge about the work which no one else possessed. One assembler stated, "They (workers) are doing the job and they know what helps, what makes it easier." A technician added that, "day to day contact with their work is where problems arise and can be eliminated." Some workers communicated this theme by placing their own work habits in contradistinction to management. One inspector noted that, "Managers don't always know what goes on . . they aren't on the floor. . the: aren't involved in everyday stuff." An assembler echoed this theme in the assessment that, "(workers) are there every day and know what goes on. Managers aren't there, they are in meetings, etc. Workers themselves know the work habits and can make these decisions."

TABLE XXX

WORKERS' RATIONALE FOR DESIRE FOR PARTICIPATION

\begin{tabular}{ll}
\hline \multicolumn{1}{c}{ Response Categorya } & Percent of Interviewees \\
\hline Workers perform the work & 56.0 \\
Impacts on how the worker feels & 33.0 \\
Management medium & 23.0 \\
Affects quality/productivity & 18.0 \\
\hline
\end{tabular}

Note. Percentages do not total 100.0 due to multiple responses from some individual cases.

a"In general, why do you feel workers should be allowed to participate?" 
A second subtheme is that workers perform the work and this gives them a different perspective from that of management. As one assembler stated, "Workers are the backbone of the business. Sometimes we see problems from our standpoint where managers can't see them." A technician similarly noted that, "A lot of things management doesn't see that people who are working can see."

The notion that, since workers perform the work they deserve to have decision-making power, comprised a third subtheme among the interviews. As one assembler stated, "It's our job, we work there. - . You should have some say on what's going on . . the more input you can give the more it will help you on the job."

A last subtheme is that, since workers actually perform the job, decision-making about the work is going to affect them directly. This subtheme is intimated by almost all of the responses in this category, but one inspector summed it up succinctly in the statement that, "a lot of decisions in our work areas directly affect us . - it's nice to be able to have a say."

\section{Affects the worker}

A second major theme reported by workers as a rationale for desiring participation in decision-making is that having this potential affects the worker in a number of ways. Most of the responses in this category centered upon the subjective impact of decision-making on the 
worker. That is, having a voice in decision-making will prevent the worker from feeling unimportant or insignificant. Greater decision-making was perceived by these workers as a way of bolstering their self perception. The following responses reflect the overall comments comprising this theme:

An inspector: "It's nice to be able to have a say. - . Thus we don't feel like robots or drones every ãay." A stockhandler: "It gives you a feeling that you have an input-make a difference-not just putting in eight hours and that's it." A technician: "(Participation is needed) to be part of what they (workers) are doing-not as a tool."

Management Vehicle

The third major theme revealed by the first question related to the effect of participation upon the relationship between worker and manager. The responses reflected a range of attitudes. Primarily, workers noted that participation in decision-making serves as a potential vehicle for managers to better understand and communicate with workers. A number of workers, however, perceived that greater participation would prevent the worker from being taken advantage of by management. The following comments are a sample of this range of attitudes: 


\begin{abstract}
A technician: "(Workers are) a big storehouse for management. They know what's going on for managers. - . From management's point of view, you can get down to finding out what the problems are. The old motivation stuff doesn't work nowadays."
\end{abstract}

An assembler: "(By using participation) managers can see how her group can feel. . even if they don't use it, it is a good informationgetting device."

An inspector: "(If you didn't have a say), upper management would walk on you, take advantage of you."

A technician: "Managers should be there to work for the group. . . . Some managers have the attitude that managers are the master, the workers are the slaves . . . it doesr't work that way nowthings are changing day to day."

\title{
Affects Quality
}

The final theme resulting from the initial question of the interview related to the workers' perceptions that increasing worker participation would result in changes in quality and productivity:

An assembler: "If (workers) have a voice they will do a better job. You care more if your opinion is valued.. . you do a better job."

A technician: "It is better for the company, they benefit-it lowers the cost of productionif managers would listen."

A technician: "Workers need to feel like they are worth a damn or they won't perform well." 
DESIRE FOR PARTICIPATION: WHY NOT

The interview format included a second question designed to elicit responses from workers which clarified their views on what areas, and why, workers should not be allowed to participate. As with the first question, workers were shown a copy of the desire for participation questions as a reminder, and then asked the question, "In some areas you don't think workers should have much say. In general, in those areas, why don't you feel workers should be allowed to participate?" Workers were not asked to specify the areas in which they had previously indicated no desire to participate (in the survey), but rather to respond in a general fashion as to why less participation was desired in certain areas. Table XXXI lists the main themes which emerged from workers' responses.

\section{Management's Responsibility}

The most prominent theme among workers' responses centered upon the extent to which there are certain responsibilities which belong to management, and some responsibilities which belong to workers. These workers clearly accepted participation in decision-making (according to the interview question) as falling within the management domain. Several of the responses indicated this succinctly, such as the following statement from an inspector: "Some things we (workers) shouldn't be 
involved in. - . Some things are management responsibility, some are workers." Other workers elaborated on the rationale for this difference in responsibility, as illustrated by the responses of the following workers:

A technician: "There are some things that managers should do-they are responsible for workers and their performance. That's why we have managers-to be responsible for certain things . . . they are responsible to their managers for what workers do. (Otherwise) you will have too many chiefs and not enough workers."

A technician: "Upper management has a lot of time and money invested in a decision-they can't waste this on what happens down the line. only so much time exists and you can't waste it - . Iike planning a new plant. . . We have upper management to make these decisions. However, every six months or so, upper management should tell the worker what is going on. But workers shouldn't be involved in the detailed workings."

TABLE XXXI

WORKERS' RATIONALE FOR NOT DESIRING PARTICIPATION

Response Category Percent

Decision-making is management's $\quad 31.0$ responsibility

Workers lack the understanding/ 28.0 expertise/qualifications

It may affect other workers/ 18.0 whole group

$\begin{array}{ll}\text { Managers have a different view } & 10.0\end{array}$

Just about any area is o.k. 10.0

Note. Percentages do not total 100.0 due to multiple responses from some individual cases. 
An assembler summarized the decision-making structure between management and workers this way: "A good manager will take in the feelings of the workers but make the final decisions. Kind of like at home-mommy and daddy."

A related (minority) theme which emerged among the interviews $(10 \%)$ was that workers should not be allowed to participate due to managers having a more advantaged viewpoint from which to make decisions. The advantage was perceived to have rested with managers having greater access to information, and also as having a privileged position which is more holistic ("seeing how things come together").

\section{Lack of Worker Expertise}

Several workers responded that, generally, workers should not be allowed to participate since they don't have the qualifications to make the necessary decisions. The statement made by the following assembler best reflects this theme: "(Workers) aren't qualified to make those decisions. - . There are some people who should not - . haven't had education in those areas." A technician stated simply that workers should not participate, "because they don't know anything about it-don't understand what has to go into the decision. There are some things we don't know." 
Affecting other workers

Some workers responded $t$ : he question by stating that some decisions should not be made by workers since the decisions might affect other workers or the whole group. These interviewees noted that decisions which affected only the worker were acceptable, however, decisions impacting others were management's job. One assembler made the statement:

(Workers shouldn't be allowed to participate in) making decisions on other people. . . . It is not the place of an assembler to tell managers how other people should do. Managers should be out there watching.

This was stated more concisely by a technician who noted that, "Some areas should be left to the manager. Major decisions for the group that would affect the whole group should be left to the manager."

No Area Prohibited

While representing only a small portion of the responses, this theme reflected the strong desire for participation among some workers. One technician commented that, "The workers are the backbone of the company . . just about everything is O.K." Another technician suggested that, "Workers should be at least asked for any decisions."

DISCUSSION: DESIRE FOR PARTICIPATION

one finding which clearly emerged from these two 
interview questions is the extent to which workers view themselves in contradistinction to managers with respect to participation in decision-making activity. Although workers desire participation due to their direct contact with the work and because it has an impact on their subjective definitions of importance, they nevertheless accept the legitimacy of a decision-making structure, in theory. This is evident in the 23 percent of workers (interview question number one) who saw participation as a management vehicle, and in the large number of workers (from the second question) who assigned decisionmaking responsibility and capability to managers. This finding is consonant with witte (1980) who noted the "workers' natural acceptance of hierarchical authority and their perception that obedience to authority is an integral part of one's job (p. 38)." Leitko, et al. (1981) also spoke to this point in their conclusion that workers learn situational adjustment attitudes at work, one of which is the notion that it is the manager's job to manage, and that workers have limited job information from which to make decisions.

The apparent paradox in workers' attitudes-on the one hand desiring participation and on the other hand accepting the legitimacy of a decision-making structure which may not deliver--may be partially explained by the domination by (or unresponsiveness of) managers over 
decision-making at this location. That is, the workers apparently accepted the theory of a structure which includes management control, along with workers having access to decision-making. However, there were also hints of a concurrent dissatisfaction with the way the management structure works in practice. This was suggested by the workers who noted that participation in decisionmaking is necessary to prevent managerial manipulation of the worker. In a sense, managers may be partially perceived by workers in this study as an active hindrance to decision-making ability.

The remaining sections touch on this suggestion by examining workers' attitudes toward QCs (as well as their unsolicited comments) ard observations of $Q C$ meetings.

\section{QC: MEMBERSHIP}

The third question asked in the interviews dealt with whether QC members' attitudes toward Quality Circles had changed since joining. The attempt was to gain greater insight into workers' overall attitudes toward worker participation, as well as to ascertain their attitudes toward the specific QC program at their plant. The responses of QC members (72 percent of all interviewees) can generally be classified into three groups: those who are positive toward QC (39 percent); those who are 
ambivalent, expressing contradictory opinions (25 percent); and those who are negative toward QC (36 percent). An analysis of the change in workers' attitudes is also addressed in the discussion of these three groups.

\section{QC Positive}

Several workers commented very generally that QC was positive in terms of helping the individual learn, save time, and to improve quality. Of those who commented on changes since joining, all reported changes for the better.

Another segment of the "positive" workers were more specific in articulating why the QC program was good. Some of these workers reported changes (all for the better) since joining. One worker (technician) commented that he initially thought the QC program was a "grievance session," however, it has turned out to be a good method for problem solving. Others noted the capacity for QC as a problem solving device, especially in terms of being able to draw upon the ideas of the members ("two heads are better than one"). A few workers noted that the QC was an appropriate vehicle for providing input on problems to management, and also to allow management to "know how workers feel." Another worker explained that the QC program is a good "venting area," which was free from penalty. This worker (assembler) went on to comment that managers should be on the same level as everyone 
else in QC meetings, and not to hold what a worker says against them.

QC Ambivalent

Within this group of interviewees, the responses were fairly clearly divided into those commenting on positive and negative aspects of the group process and upon conflicting aspects of worker-manager interface. Among the first group, workers noted that the $Q C$ system of using groups was generally positive, but there were problems with red tape ("it takes forever to get through the system") and the group problem solving process. One worker summed it up as follows:

(The QC program) is mostly positive if the group knows what they want to do . . ( (have) a specific role and some goal in mind. You can get carried away . . they are just putting in an hour without any sound ideas.

Among the workers who commented on the manager's role vis-a-vis the group, several noted the extent to which a strong or "talkative" manager could dominate QC meetings and general process. While the workers noted overall satisfaction with the QC program, they stressed the potential for managerial interference. One technician summed it up this way:

(QC provided more understanding of) how strong of a role managers should have in operating QCs - . it works best if they are members but not leaders. Managers should be there (to suggest) what is practical and what isn't. If they are leaders, QC can become their agenda... coworkers aren't as intimidating as the boss. 
Another worker noted that group members were inhibited, and felt that they "couldn't step on anyone's toes."

Although the potential for managerial interference was clearly felt, some workers noted that it differed from department to department. One worker concluded by stating that workers would feel "less apart from managers" by interacting with them over time. Thus, the success of the QC program appeared to be tied to the nature of management and the extent to which managers facilitated or obstructed the group problem solving process.

QC Neqative

Among the workers who responded more negatively toward the QC program, several echoed the problem of managerial dominance, as with some in the ambivalent group. One vocal technician noted a difference between two QC groups to which he had belonged, by observing that, while the manager of the current group seemed interested in helping, the previous group manager completely dominated the QC process. The worker stated that:

My first impression was complete optimism, excitement about it (QC). After being involved, certain management responses completely devalued what I thought about it. . . . Management 'requested' that a QC be instituted . . . we were given token things to work on, then the manager discarded the findings.

One QC group leader (inspector) echoed these comments by stating that:

Before, I was neutral on managerial 
participation. Now, if managers participate, they shouldn't try to take over and run the group - . their opinion shouldn't be worth more than anyone else's. In our group it's like 'I'm the manager, this is what I think and this is the way it's going to be.' That's not the way QC is supposed to be.

The notion of being given token or insignificant projects was another of the themes in several of the workers' responses. One technician stated that "some of the problems chosen are not really needed-small stuff-like fixing a crack in the floor." A utility person stated that:

I'm not participating in the (QC) anymore. Projects we work on are small. We should do projects that are big and out of our hands . . . so that when you are done you can see what you have accomplished. . . Most projects are just with procedures. We need this, but we should do big things like how to lower product costs, production efficiency, how to rearrange areas.

A theme somewhat related to the limitation of issues was the notion that the group process was slow or inefficient. As with the ambivalent workers, some in this group expressed dissatisfaction with not accomplishing objectives, or especially, group motivation. This notion is best expressed by one assembler who lamented that:

Our group doesn'i participate as a team.. . we have four people-it's kind of discouraging. I get the feeling 'maybe I shouldn't go' . . . it bothers me what others think. The others (non QC members) don't want to attend $Q C$, but want to know what goes on. 
QC: NON MEMBERSHIP

Almost all of the workers interviewed in this category reported that they either had been members in the past and dropped out, or that they had gone to an initial meeting but decided not to join.

Some stated that QC was impractical in their work areas: their areas were perceived as either too small or that the problems in the area "don't go away." One technician noted that it "was not a matter of joining. What does that mean? $Q C$ is a labelling thing. We work on quality problems daily. . . we try to do the same things on a daily basis."

Other workers noted that QCs were just extra work, or that the initial meetings were negative. One of the more pronounced themes related to the workers' perception that the QC process is a "waste of time." Several workers commented that the same things were discussed over and over, that the "input has been more than the output," and that suggestions by the QC group were unheeded.

Some workers in this group also noted that the QCs were just "a pacifier-token efforts by managers to show their managers they are getting better quality. They (managers) didn't listen to output of QCs." One technician stated simply that, "We were just having to impress management for (the leader) . . the things we did, the projects chosen." 


\section{DISCUSSION : QC PARTICIPATION}

Although the sample size was small, the workers interviewed nevertheless made responses which provided insight into their perceptions of the extant QC program. While the comments were varied, several themes emerged which are relevant to the overall questions of the efficacy of worker participation (QC) at this plant. These themes can best be represented by summarizing the apparent perceived advantages and disadvantages of the QC program.

\section{Advantages}

The main perceived advantage centered around the potential for the QC program to provide a convenient problem solving mechanism. Among some workers, this aspect of QCs was being realized, while among other workers it remained a positive, but latent, possibility.

Another potential advantage is the extent to which the QC program could provide a common ground upon which management and workers could share information and communicate. For some workers, the suggestion was that this communication proceed from workers to management. For others, the QC was less unidirectional.

\section{Disadvantages}

One of the most dominant themes (even implied among some of the "positive" comments) was managerial domination. Either managers were perceived as intimidating or 
authoritarian influences within the group processes, or that managers used QC groups for their own purposes. The group process also received negative evaluation in that members were not motivated or task oriented. While the potential may exist for the $Q C$ to be an efficient problem solving group, several workers seem to have perceived a certain degree of lethargy resulting from inertia. This may have been, in part, a function of another disadvantage, that of circumscription of projects. That is, some workers perceived that the problems chosen for the QC to address were inconsequential.

While these analyses are important for indicating overall attitude toward QC programs, it is also necessary to discuss the relationship of these attitudes toward the earlier interview material and the survey data. First, however, the final interview question is discussed for further clarity of workers' attitudes toward other aspects of their work environment.

\section{UNSOLICITED COMMENTS}

After the structured questions in the interviews, workers were asked "anything else?", in an attempt to reveal workers' attitudes toward any aspect of their work environment. This method proved to be very useful in acquiring information pertinent to the findings obtained from survey and structured interview questions. 
of all workers interviewed, 23 percent chose not to respond to the question. Among the workers who responded, the comments fell into clearly distinguishable categories. Table XXXII lists those categories.

TABLE XXXII

RESPONSE CATEGORIES FROM WORKERS' UNSOLICITED COMMENTS

\begin{tabular}{lc}
\hline \multicolumn{1}{c}{ Response Category } & Percent \\
\hline Poor management & 70.0 \\
The company has changed & 26.7 \\
Positive toward company & 10.0 \\
Money & 10.0 \\
Morale (poor) & 6.7 \\
Miscellaneous (lack of team \\
$\begin{array}{l}\text { spirit, reviews, paper- } \\
\text { work, cafeteria food prices) }\end{array}$
\end{tabular}

Note. Percentages do not total 100.0 due to multiple responses from some individual cases.

Poor Management

The most overwhelmingly dominant response to the last question concerned workers who perceived that management was inferior. As noted in Table XXXI, 70 percent of the workers stated that management was in some way problematic. For the most part, workers articulated why they felt management was poor. There were very few general responses.

Communication. The most prominent criticism was that the communication between management and workers was 
very poor. Several workers commented that the managers do not listen to employees. Furthermore, managers are perceived as being difficult to speak with, which results in problems with production. In addition, the workers feel that managers do not provide the information needed to do a proper job. On a more personal level, managers are criticized for not giving adequate feedback regarding how workers are doing on their jobs. All these communication problems are viewed by workers as adversely affecting production and quality.

Never There. In addition to poor communication, managers were criticized by workers for "never being around." Perhaps the reason managers are not around, according to one worker, is that they are always in meetings. One utility person noted that, "managers are never there in our area. We must have management approval and they are gone. It seems like we are running the show, not the managers." Another worker commented, "managers don't work like workers. . . They are always doing something else, reading a book, etc. . . but I do my job." The consequence of managerial absence is perceived to be poor attitudes on the part of the worlier. As one technician noted, the problem was "neglect by management - . all the way up. They have jobs and if they don't do them it gives you a bad attitude."

Bias. Another perceived problem with management was 
that individual managers were biased in their treatment of employees. This was especially noted by several workers who accused managers of "playing favorites" among workers or giving some workers "special treatment." This bias was mainly identified as resulting in unfair promotion. As one assembler stated, "It's not what, but who you know to get anywhere. . . The manager plays favorites." In addition to the bias toward workers, managers are perceived as getting their management jobs through bias, and as enjoying privileges not accorded to all workers equally (e.g., taking a training class without charge). Additional Rationale for Poor Management. Additional reasons for poor management cited by workers relate to the number of managers and to the individual style of supervision. Several workers stated plainly that there were too many managers for an efficient work process. A number of other workers pointed to the managerial style as being an obstruction to their jobs. In addition to being perceived as unqualified, managers appeared to be either too authoritarian or domineering. Consequently, the relationship between management and workers suffered. Workers felt that they were not properly encouraged, that managers did not get involved with them, or that management used and overworked the workers.

The Company Has Changed

Two primary comments emerged from workers' responses 
regarding the manner in which the company had changed negatively: (1) The company formerly had a reputation for high quality and caring for workers; (2). the company is much less participative, and more hierarchical than it was when it started.

Several workers cited the founding principles of the company as focusing upon excellence of products and upon people orientation. However, the workers perceived these principles as having changed, so that the company is presently less concerned about its workers. The result is that the ideal of caring and quality is maintained in the face of company policy which mitigates against this in practice. One inspector summed it up as follows:

(The company) has lost sight of its objectives; it was a people-oriented place. I don't feel that way anymore-a lot of people don't. They (the company) ask for a little more (production) and then that becomes a standard for you to live up to. It's not enough to do 100 percent and be doing a good job anymore.

other workers noted a perceived change in company philosophy toward decision-making. These agreed that the company had begun under a participative style of management, but had become much less so over the last few years. As one technician stated, "(The company) has lost its creativity. It started as very participative . . has become very hierarchical - . used to work as a group, now decisions are handed down." These sentiments are reflected in the response of another technician, from 
a different work area, who attempted to exemplify how the company had changed by contrasting early from late decision-making styles. He noted that, "five years ago - . 'now we have a problem-what can we do to solve it.' Now . . 'we have a solution-here is how to implement it.'"

Additional Categories

The workers who comprise several of the latter categories commented mainly upon working conditions (i.e., reviews, paperwork, food prices) or work atmosphere (i.e., team spirit, morale). A few workers commented that the pay was inadequate for their particular job or their evaluation rating. Among all the workers responding, only 10 percent commented that they either liked their job, or that the company was a nice place to work. A number of others (26.7 percent) noted that the company had changed somehow, but always in a perceived negative direction.

\section{Discussion}

A Drief comparison of the findings in this section with the former sections in this chapter reflects that the earlier themes are given additional support. The theme of workers' desire for participation in a theoretical managerial context, which is compromised in practice, is confirmed by several of the categories of "unsolicited comments." Primarily, the fact that workers had perceived a 
shift from participative to hierarchical management style and that they were generally disgruntled with management both reinforce earlier findings.

overall, the results from the unsolicited comments tend to confirm Herzberg's (1975) notion of "hygiene factors." These are factors extrinsic to the job itself and include company policy, supervision, interpersonal relationships, salary, status, working conditions, and security.

One of the central questions which arises at this point concerns the extent to which the QC program functions at this company, and how it impacts upon worker attitudes. The next section provides insight into these matters through a discussion of findings emerging from observations of QC meetings, which spanned the length of the research project.

\section{OBSERVATIONS: QC MEETINGS}

One of the most important phases of this research was observation and attendance at QC meetings. These meetings typically lasted one hour (per week) and were set by the QC group in order to best accomodate production schedules. According to the QC process, meetings were attended by workers, an elected QC leader, and the firstlevel manager in charge of the production area. (There were only a few cases where QCs incorporated workers from 
adjacent work areas.) Meeting business centered upon the identification and resolution of projects relating to the work process. For the most part, these included activities central to streamlining procedures for assembly, testing, and quality assurance of the electronic instruments produced.

The observation of findings are based upon attendance at ongoing weekly meetings of several circles over a period of approximately four months. Three of the ten circles were not included due to numerous cancellations, or inaccessible meeting times. The general observations include information about these circles collected through indirect means, however. These means included ongoing exposure to the individuals involved, employee interviews, and access to extant records relating to QC activity

In addition, the findings include attendance at "general QC meetings," which involved QC leaders from all groups; and divisional quality meetings, which included all members and managers of the entire manufacturing area. Although difficult to sulunarize, these observations are best discussed by describing three categories of QCS: (1) management dominated circles; (2) stable circles; and (3) circles in crisis. In an attempt to avoid procrusteanism, it should be noted that these categories are based upon a small number of circles, and cannot 
adequately capture the dynamics of QC activity. In addition, the issues discussed cannot be considered mutually exclusive, but interactive. The objective is to provide insight into the QC process while avoiding simplicity.

\section{Management Dominated Circles}

In virtually all of the QC groups under observation, manager dominance was present in some guise. In most groups, the manager took a very high profile in terms of the extent to which he or she actually took charge of the meeting. In some QCs, the manager was less talkative, however, the degree of control over meetings was evident in the style of leadership exhibited. In one group there appeared to be no clear managerial dominance, however, comments from group members suggested that it was present.

Among the "overtly" dominated QC groups, the usual condition was that the manager completely took over the leadership of the meetings, and often did so in an intimidating fashion. The effect was that, in most cases, meetings ended in a dialogue among the manager, the QC leader, and one or two vocal QC members, with the majority of the members silent. This pattern was repeated frequently, but is best represented by one QC group, which can be referred to as Group A. Group A was an average sized group consisting of a manager, a QC leader and several members (both male and female). Over the research period, Group A was observed a number of times and, in 
addition, several of the members participated in individual interviews. Related information was gathered from several company sources, including resource.persons familiar with the circle.

In almost all of Group A's meetings, the manager assumed a strong leadership posture and addressed all group suggestions. This had the effect of diminishing the QC leader's role to that of group "recorder," or to simply a group member without a leadership function. This pattern was most visible during one meeting in which the manager arrived several minutes late. Prior to the manager's arrival, Group A was characterized by full participation among members, including one member who very rarely spoke. During this time, the QC leader exerted leadership in the sense of keeping the group on task and facilitating group interaction.

Subsequent to the manager's arrival, the entire dynamic of the group changed: group participation diminished drastically; the circle leader deferred to the manager for decisions, and became tentative in suggestions; the manager assumed the central focus of the group, and all members oriented themselves to the manager regarding the group task. Although this particular dynamic may have been atypical for Group A, or for the QC process generally, it nevertheless highlighted the extent to which managers can exert control over QC meetings. This 
suggestion is not based solely upon Group A, but also upon many others. In particular, another group (Group B) exhibited the same pattern between meetings when the manager was aiternately present, and then absent.

Managerial dominance was not always so visible, however. In other groups, managers exhibited influence through assertive leadership skills. In one case, the result was the same as with the other group examples: (1) obviation of the QC leader's role; (2) suppression of group interaction; and (3) the assumption of the central focus by the manager. In this case, however, group members maintained a certain level of interaction since the manager's leadership style was less intimidating. One of the outcomes of this group, was that the discussion became focused upon a concern of the manager, so that the group served as a "manager's agenda." Several meetings, and non-meeting discussions, were devoted to this agenda apart from the QC objective.

In one other group, the agenda was more covert in that group members declined to discuss a certain issue which was sensitive to the manager, but which would have become a legitimate QC project. Although this manager was non-intimidating, the unwillingness of the group to broach the subject bespoke the extent of managerial control.

In at least one QC group, no extensive managerial 
domination was evident. However, this group (Group C) was not observed as heavily as the others previously mentioned. On one occasion the manager exerted a suppressive effect; however, group members interacted in fairly "balanced" fashion overall. Group members interviewed, including the leader, did mention that managerial domination was a potential problem. It was one of these members who commented (as cited earlier), "If (managers) are leaders, QC can become their agenda . . they are strong willed - . co-workers aren't as intimidating as the boss."

\section{Stable Circles}

It was the latter group (Group C) which was considered the most stable of all groups observed. "Stable" was identified as a $Q C$ which meets regularly, keeps on task, maintains good attendance, has fairly "open and balanced communication," and in which managerial domination did not preclude the occurrence of these events. It was this group which most closely approximated these qualities, apart from the tendency toward manager domination previously discussed. Among a few other groups, manager domination was distinctly more pronounced, however, the other circumstances of the QC process seem to have been intact. Although the QC members may have had negative attitudes (which emerged from interviews and 
ongoing interaction), the groups maintained somewhat steady progress.

one factor which may partially explain the stability of these $Q C$ groups is that they all had leaders who exhibited good group interaction skills. They maintained a pleasant atmosphere, encouraged open participation, kept the group on task, and, in differing degrees, maintained control in the presence of dominant managers.

\section{Circles in Crisis}

Several of the QC groups were largely ineffective in terms of their activity, and appeared to be inert. That is, these QCs continued to meet with varying degrees of regularity, however, the overall group process deviated from the initial intent of Quality Circles (see the definition of $Q C$ in Chapter I). This was evidenced by the following factors: group meetings were irregular or frequently cancelled; attendance was erratic; membership was shrinking or very low; the group had difficulty attracting new members; there was considerable difficulty choosing new projects, or finishing current ones; participation in ongoing projects waned; leadership appeared uncommitted; and the membership was generally lethargic in terms of their overail motivation (as noted earlier in a discussion of worker comments).

It would be very difficult to ascertain all of the exact reasons for these conditions, and is clearly beyond 
the scope of this study to do so. However, one salient factor related to managerial interference may have been partially responsible. In one group, for example, the manager in charge of the work area made an independent decision regarding the production process which was the focus of the QC project. This had the effect of negating the entire QC project, and was done without consultation of the circle. This action further resulted in irregular meetings, threats by $\mathrm{QC}$ members to disband, and a general lack of direction among the group. As one member noted in a later meeting, "We are supporting the system but the system isn't supporting us . . management isn't supporting us." At the same meeting, another group member noted that, "It's like 'keeping little people happy-give them what they want." This group subsequently met with the manager to discuss the status of the group and to discuss potential future projects. Since this occurred near the end of the research activity, the outcome of the group was uncertain. However, the group was continuing to meet on an irregular basis.

Aside from managerial interferences, the only other factor which may have led to problematic circles was leadership among QC members. Just as the stable circles may have survived because of efficient leadership, the crisis circles may have faltered due to lack of 
leadership. It is difficult to suggest how these two variables interacted, however.

In Chapter VII, overall conclusions are drawn in terms of how the information considered thus far supports, or fails to support, the overall research hypothesis. Information and analyses are then drawn from extant $Q C$ literature in order to shed light on the findings of this study. 


\section{CHAPTER VII}

\section{CONCLUSIONS}

\section{INTRODUCTION}

This study has addressed the assumptions underlying the participation-satisfaction thesis through an analysis of an ongoing quality circle program in an electronics manufacturing firm. This was accomplished through the use of both quantitative and qualitative procedures which were used for testing the validity of the thesis, as well as for providing insight into the dynamics of a QC participation program.

The research attempted to resolve the disparity between, on the one hand, studies which have unquestioningly accepted the automatic linkage between participation and satisfaction and, on the other hand, studies which have intimated that workers may not desire participation, thus affecting (potential) program outcomes (i.e., job satisfaction). Specific hypotheses were tested in an attempt to assess whether participation in decision-making resulted in job satisfaction and to examine what role desire for participation, and attitudes toward participation, played in the participation-satisfaction relationship. 
This chapter briefly sumarizes the conclusions of the research study. Then, the most recent literature on QC is examined in an attempt to shed additional light on the findings. Finally, areas for potential future study are considered.

\section{SUMMARY OF CONCLUSIONS}

One of the main findings of this study is that, in and of itself, membership in a QC participation program cannot be considered to lead directly and simply to job satisfaction. There are other factors which may intervene and affect this supposed automatic relationship. The study has demonstrated that desire for participation, rather than membership in a QC program, is related to job satisfaction, and that this is especially evident when QC participation is held constant. Additionally, it was found that workers' attitudes toward participation were related to desire for participation, which is further evidence of the complex relationship between participation and job satisfaction.

The qualitative analyses suggest that, at least partially, workers' attitudes toward participation are related to their experiences in QC meetings and in everyday work life. Whereas workers had generally positive attitudes toward ideal participation, actual practice of QC may not be able to deliver all the factors necessary to 
produce worker satisfaction. One of the most prevalent criticisms among workers related to management's role. Managers were chiefly viewed as dominating or authoritarian influences in QC meetings and, for a number of reascns, they were less than effective in their jobs as managers.

The recent literature on quality circles provides further insight into the findings of this study, and for suggesting potential remedies.

\section{THE PRACTICE OF QUALITY CIRCLES}

One of the most obvious discoveries which emerges from a review of the extant literature on quality circles is the paucity of empirical analyses. Although there are many papers written on the subject, few have approached the subject using systematic social science methodology. Most are simply anecdotal in nature.

What empirical research exists largely points to the failure of QC to affect outcomes such as job satisfaction and other worker atititudes. In this sense, the majority of these research studies tend to support the findings of this study. In a recent work, R. J. Vaughn (1983) concluded that QC participation had no significant effect upon four behavior outcomes (i.e., job satisfaction, work group performance, job effort, and intent to quit/remein) in two separate United States Air Force installations. 
Benjamin (1982) likewise found no significant difference between $Q C$ members' and non members' expressed commitment to the organization at the Honeywell corporation. Srinivasen's (1982) results indicated no significant difference between $Q C$ and non $Q C$ groups on measures of interpersonal behavior, group behavior, and productivity at a large computer peripherals manufacturer. Other controlled studies are more descriptive in nature, and tend to focus upon the QC process per se (Shlemmer, 1983; Dean, 1983).

The paucity of carefully researched studies must be viewed against the extent to which QC programs are practiced. It has been estimated that over 500 American companies employ QC (Widtfeldt, 1981), with over 3,000 operative circles (Metz, 1981), in contexts including manufacturing, banking, health care, branches of the Armed Forces and educational institutions. However, Amsden and Amsden (1979) concluded that:

Research on the QC circle is virtually nonexistent . . partly because the concept developed outside of the behavioral science field . . and the proponents of the concept have been, by and large, people who are unable to perform such research work. (p. 488)

This widespread use of QC without a solid empirical foundation has led to the call for increased research activity (Gibson, 1981b).

The disparity between the limited research activity and widespread use of $Q C$ is most noticeable in the many 
anecdotal accounts of the effects of QC programs. Most of these accounts are reports by practitioners discussing the benefits of $\mathrm{QC}$, or at least the elements of the program which can lead to success (e.g., Hutchkins, 1981; Ouchi, 1981; Keefe and Kraus, 1982). Although most of these authors extol the virtues of $Q C$, many conclude that $Q C$ programs can, and do, fail to achieve positive outcomes. This caution is best expressed by Metz (1982), who noted that the United States is still in the "honeymoon" phase with QC :

I have spoken with a number of managers and facilitators who have privately admitted that their quality circle programs are in trouble. Behind the 'published success' which upper management wants to hear, facilitators are struggling in many cases to keep the circles operating and to help circle leaders and members cope with a host of problems that reduce the potential for success. Too many companies appear to have been over-sold on the idea that quality circles are a panacea for most types of organizational and managerial ills. (p. 108)

In another article, Metz (1981) comments upon the "illusory simplicity" of $Q C$, which bas resulted in a number of difficulties with QC programs. The author goes on to challenge this simplicity by noting that:

There is a 'myth' developing that a firm only needs to install Quality Circles, turn them loose, and soon all the firm's problems will be solved. . . Actual experiences point out that Quality Circles have more potential for failure than for success. (p. 72)

Thus, the assumption of a simple, mechanistic participation-satisfaction relationship is addressed by 
practitioners of Quality Circles who have begun to publish accounts of failures. Although anecdotal in nature, these comments nevertheless support the findings of this study, which indicate a more complex participation-satisfaction relationship.

Although accounts of $\mathrm{QC}$ problems in the United States are growing (e.g., Ingle, 1982), reports of SC failures are not confined to this country. In Japan, the conceptual and practical birthplace of QC, failures are often experienced in industrial practice. According to Cole (1981), only about one-third of the circles established in Japan are doing well. A similar report of QC failure in Japan led one author (Thackray, 1982) to suggest that the same phenomenon may be true for the United states, beneath the "public relations veneer." These and similar accounts have sparked a great deal of debate concerning the feasibility of the United states adopting a Japanese management style (e.g., Ingle, 1982; Mazique, 1981; Yankelovich and Immerwahr, 1984; Jones, 1983; Ouchi, 1981).

Most all of the recent literature on QC attempts to identify the potential reasons for failure and also to prescribe procedures for success. In most cases, the success factors are simply a positive transposition of the factors responsible for QC failure. Among the key elements of success are: gaining management support; 
provision of adequate training for managers, leaders and facilitators; development of adequate communication; and creation of the proper "atmosphere" for the programs (Ingle, 1982; Metz, 1982; and Widtfeldt, 1981).

The most dominant factor which is implicated in both success and failure lists is management. Almost all the recent reviews on $\mathrm{QC}$ note that management is a crucial link in the ability for QC to produce significant results. Yankelovich and Immerwahr (1984), in a generic sense, point out that it is management which has failed (but which is needed for success) in implementing programs which can garner worker commitment. The authors suggest that managerial resistance is linked to matters of authority, status and fairness. That management fears loss of authority and power is similarly noted by Ingle (1982), and Jones (1983).

The IAQC report by Gibson (1983) is more specific in identifying potential reasons for managerial difficulties in QC programs. In this report, the author lists the following problem areas: lack of support by middle management; slow management response to circle recommendations; apprehension or suspicion about management motives; problems chosen by management. Other accounts point out that managers may be using QC for their own purposes (Thackray, 1982). 
Although the current study was focused primarily upon worker attitudes toward participation, the data and information which emerged clearly pointed to management as being an obstacle to the functioning of the QC program. Management dominance of meetings was demonstrable, as were workers' perceptions that managers were doing less than adequate jobs as managers. There was also the suggestion that, while workers may accept the theory of a decisionmaking structure involving management, the result of this structure, in practice, may have affected workers' view of $Q C$, and of participation generally.

In a collective sense, conclusions from this study include at least the following points. First, further careful social scientific research is needed regarding QC specifically and worker participation generally. Second, the relationship between participation and job satisfaction is much more complex than it is made out to be by writers from all perspectives. A comprehensive model relating to the participation-satisfaction thesis should include at least some attention to workers' desire for participation, as well as other variables.

Third, management interface with worker participation programs can spell success or failure, but most often spells failure when managers obstruct the participation process and affect workers' attitudes toward the participation program. This is evident not only from the 
qualitative analyses, which suggested managerial interference and dominance of the QC process, but from the quantitative analyses as well. specifically, as noted in Chapter $V$, there was an inverse relationship between desire for participation and job satisfaction among workers who welcomed participation, but who agreed that management may actually have been in control of decisionmaking. The implication is that management may have prevented general job satisfaction among some workers, in addition to introducing problems into the QC process.

\section{QC INTERVENTION}

Although the intent of this study is not to prescribe measures for improving the extant QC program, it is nevertheless important to mention general avenues for intervention. To the extent that the QC program under study is similar to other QC operations, these intervention ideas can serve as tools for understanding, as well as areas for future research.

Perhaps the most crucial area for potential intervention is in management-worker interaction. Not only the analyses from this study, but the recent QC Iiterature also points to the general inability of managers to effect a smoothly running program. At this particular study site, many of the problems in the QC program appear to stem from the disparity between workers and managers 
(especially first and second level managers). The workers desire participation, and do not perceive the program as burdensome. However they may be prevented from realizing actual decision-making ability due to managers who maintain distance between their own roles, and those of the workers'. According to the QC literature, and the results of this study, the problems of managerial style, use of authority, and dominance are all implicated in the failure of the QC program to fully reach its objectives. Although there are no "quick fixes" for this problem, managerial training and education are needed; training which would include a reinterpretation of the managerial role towards advocacy and support, rather than dominance and authoritarianism.

A related problem which may require intervention in this, and similar, programs is program inertia. From the worker comments examined earlier, it is apparent that the QC process, apart from managerial interference, is less than optimal. Problematic QC elements include trivial projects, weak leadership, erratic attendance, and lethargic members; all of which may be at least partially attributable to inertia (and/or management). That is, the QC program may have reached a point of stagnation without the external intervention required to reestablish its momentum. Successful intervention for this set of 
circumstances may also require training, but on the level of QC leaders, members, and facilitators.

The overall question to be answered prior to any intervention, however, is the extent to which the QC program has been established to increase true decisionmaking ability for workers, or for some other purpose. The success of any intervention effort ultimately rests upon this issue.

\section{AREAS FOR FUTURE STUDY}

Since the participation-satisfaction thesis is more complex than has been presented, further research is needed on the specific variables which may illuminate the relationship. From the current study, desire for participation and specific attitudes toward participation have been identified as potential variables in a more comprehensive effort. Additional influences need to be explored.

The overall question of the extent to which the QC process is a "true" participation program is a thorny problem, but one which should be examined. This research is especially called for in light of the literature which points to QC failure. This study has touched upon the question in terms of management interface with $\mathrm{QC}$, however structural analyses are needed, in addition to worker attitude studies. This, of necessity, calls for a broad 
examination of whether quality circles have approximated the ideals of industrial denocracy as it has been described by Pateman (1970) and others.

Last, the question of the relationship of $\mathrm{QC}$ and productivity needs to be explored. The current study has pointed to the difficulties with assuming a simplistic relationship between $\mathrm{QC}$ and job satisfaction. Perhaps the same simplicity has affected performance outcomes, aside from the unquestioned acceptance of the benefits of QC. A comprehensive test of job satisfaction and productivity outcomes of QC could prove useful both to industry and the academic community. 
Almond, G. A., and Verba. The Civic Culture. Boston: Little Brown \& Co., 1965.

Amsden, Davida M., and Robert T. Amsden. "The Research Aspects of QC Circles." IAQC 1979 Annual Conference Transaction, 31-36.

Argyris, C. Integrating the Individual and the orqanization. New York: Wiley, 1964.

Argyris Chris. Intervention Theory and Method: A Behavioral Science View. Reading, Mass.: AddisonWesley, 1970 .

Argyris, Chris. Management and Organizational Development. New York: McGraw Hill, 1971.

Argyris, Chris. "Is Capitalism the Culprit?" Organizational Dynamics, Spring 1978, 21-37.

Bellas, Carl J. Industrial Democracy and the Worker Owned Firm: A Study of Twenty-one plywood Companies in the Pacific Northwest. New York: Praeger, 1972.

Benjamin, Ellen R. Participation and the Attitude of Organizational Commitment: A Study of Quality Circles. Diss. University of Minnesota 1982.

Berenbach, Shari. "Peru's Social Property: Limits to Participation." Industrial Relations, Vol. 18, No. 3, Fall 1979, 370-375.

Blauner, Robert. Alienation and Freedom. Chicago: University of Chicago Press, 1964.

Blumberg, Paul. Industrial Democracy. New York: Shocken, 1968.

Cammann, Cortlandt, and David A. Nadler. "Making Effective Use cf Control Systems." In Perspectives on Behavior in Orqanizations. Ed. Richard J. Hackman, et al. New York: McGraw-Hill, 1977. 
Clarke, R. O., D. J. Fatchett, and B. C. Roberts. Workers' Participation in Management in Britain. London: Heineman, 1972 .

Cole, Robert E. Work, Mobility and Participation. Berkeley, Ca: U. of California Press, 1979.

Cole, Robert, E. In "Caution: Quality Circles Ahead." Edmund $J$. Metz. Training and Development Journal, August, 1981,72 .

Dachler, Peter H. and Bernhard Wilpert. "Conceptual Dimensions and Boundries of Participation in Organizations: A Critical Evaluation." Administrative Science Quarterly, March 1978, Vol. 23, pp. 1-39.

Davis, Louis E. and Eric L. Trist. "Improving the Quality of Work Life: Sociotechnical Case Studies." In Work and the Quality of Life. Ed. O'Toole. Cambridge, MA: MIT Press, 1974.

Dean, James Warren. An Investigation of Quality Circles. Diss. Carnegie-Mellon University 1983.

Derber, Milton. "Crosscurrents in Workers Participation." Industrial Relations, 9, 2, Feb. 1970, 123-136.

Dewitt, Sherri. Worker Participation and the Crisis of Liberal Democracy. Boulder, CO: Westview Press, 1980 .

Downey, H. Kirk, and Duane R. Ireland. "Quantitative Versus Qualitative: Environmental Assessment in Organizational Studies." Administrative Science Quarterly, Dec. 1979, Vol. 24, pp. 630-637.

Durham, T. R., et al. "Control of the Work Process: The Workers' Viewpoint." International Journal of Health Services. Vol. II, No. 2, 1981, 207-220.

Ellul, Jacques. The Technological Society. New York: Alfred A. Knope, Inc., 1964.

Ferratt, Thomas W., et al. "Self-Report Measures of Job Characteristics and Affective Responses: An Examination of Discriminant Validity." Academy of Management Journal, 1981, Vol. 24, No. 4, 780-794.

Fish, Sandra L., and James M. Dorris. "Phenomenology and Communication Research." Journal of Applied Communications Research, April, 1975, pp. 9-26. 
French, John R. P., Jr., Joachim Israel, and Dagfinn As. "An Experiment of Participation in a Norwegian Factory." Human Relations, 1960, 13, 3-20.

Gibson, Price. "Quality Circles Facilitator Research and Educational Development Needs . . A Report on Research Conducted in Northeastern Ohio Organizations." IAQC Report, Narch $198 \mathrm{ia.}$

Gibson, Price. "Short Term Fad or Long Term Fundamental? The Need for Research Into the Quality Circle Process." Quality Circles Journal, May 1981b.

Gibson, Price. "Highlights From 1981 and 1982 Quality Circles Research." 1983 IAQC Conference Trarsactions. 486-502.

Goldstein, S. G. "Employee Share Ownership and Motivation." Journal of Industrial Eelations, Sept. 1978, $\mathrm{XX}, 311-330$.

Greenburg, Edward S. "The Consequences of Worker Participation: A Clarification of the Theoretical Literature." Social Science Quarterly, 1975, 56, 191-209.

Greenburg, Edward S. "Participation in Industrial Decision Making and Work Satisfaction." Social Science Quarterly, Dec. 1980, LX, 551-569.

Gyllenhammer, Pehr G. "How Volvo Adapts Work to People." Harvard Business Review, July-August, 1977.

Hackman, Richard J. and Greg R. Oldham. Work Redesign. Reading, Mass: Addison-Wesley, 1980.

Hackman, Richard J. In Varieties of Qualitative Research. Ed. John Van Maanen, et al. Beverly Hills, CA: Sage, 1982 .

Halal, William E., and Bob S. Brown. "Participative Management: Myth and Reality." California Management Review, Sunmer, 1981, Vol. XXIII, No. 4, 20-30.

Herzberg, Frederick. "One More Time: How Do You Motivate Employees?" In Harvard Business Review-On Management, N. Y.: Harper and Row, $197 \overline{5}$.

Holter, H. "Attitudes Towards Employee Particination in Company Decision-Making Process." Human Relations, $1965,18,297-321$. 
Hull, C. Hadlai, and Norman H. Nie. SPSS Update 7-9. N. Y.: McGraw-Hill, 1981.

Hutchkins, D. "How Quality Goes Round in Circles." Manaqement Today, January, 1981, 27-28.

Ingle, sud. "How to Avoid Quality Circle Failure in Your Company." Training and Development Journal, V. 36 , N. 6, June, $1982,54-59$.

Jacob, Philip E. and Chungsi Ahn. "Impetus for Worker Participation." Paper presented at the IX World Congress of Sociology, Uppsala, Sweden, Aug. 1978.

Jain, Hern C., and Genevieve Louloux Jain. N. Y.: Praeger, 1980.

Jehenson, Roger. "A Phenomenological Approach to the Study of the Formal Organization." In Phenomenological Sociology. Ed. George Psathas. N. Y.: John Wiley \& Sons, 1973.

Jick, Todd D. "Mixing Qualitative and Quantitative Methods: Triangulation in Action." Administrative Science Quarterly, Dec. 1979, Vol. 24, pp. 602-611.

Johannessen, Janette E. "VAG: A Need for Education." Industrial Relations, 1979, XVIII. 364-369.

Jones, W. G. "Quality's Vicious Circles." Management Today, March, 1983, 97-102.

Keefe, John and William A. Kraus. Building Effective Quality Circles: A Research Report. General Electric Company, Quality Projects, 1982, 1-24.

King, Charles D., and Mark van de Vall. Models of Industrial Democracy. N. Y.: Mouton, 1978 .

Labovitz, Sanford. "The Assignment of Numbers to Rank order Categories." American Sociological Review, 35 : $515-524,1970$.

Labovitz, Sanford. "Statistical Usage in Sociology: Sacred Cows and Ritual." Sociological Methods and Research, 1: 13-38, 1972 . 
Leitko, Thomas A., and Steven A. Peterson. "Worker Participation as the Nexus of Control." Paper presented at the society for the study of social Problems, August, 1980 .

Leitko, Thomas A., Arthur L. Greil, and Steven A. Peterson. "Lessons at the Bottom: Worker Participation as Situational Adjustment." Paper presented at the Society for the study of Social problems, August, 1981.

Lewin, K. "The Conceptual Representation and the Measurement of Psychological Forces." Contemporary Psycholoqical Theory, 1938, 1, No. 4 .

Likert, R. New Patterns of Management. New York: McGraw-Hill, 1961.

Lindenfeld, Frank, and Joyce Rothschild-Whitt, Eds. Workplace Democracy and Social Change. Boston, MA: Porter Sargent Publishers, Inc., 1982.

Lipset, S. M., M. A. Trow, and J. S. Coleman. Union Democracy. New York: Free Press, 1956.

Locke, Edwin A., and David M. Schweiger. "Participation in Decision-making: One Mcre Look." In Research in organizational Behavior. Ed. Barry M. Staw. JAI Press, 1979, Vol. 1, 265-339.

Long, R. "Job Attitudes and Organizational Performance Under Employee Ownership." Academy of Management

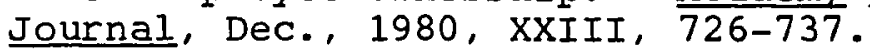

Long, Richard J. "Worker Ownership and Job Attitudes: A Field Study." Industrial Relations, Vol 21, No. 2, $1982,196-215$.

Manning, Peter K. "Metaphors of the Field: Varieties of Organizational Discourse." Administrative Science Quarterly, Dec. 1979, Vol. 24, pp. 660-671.

Mansbridge, Jars J. Beyond Adversary Democracy. New York: Basic: Books, 1980.

Maslow, Abraham. Motivation and Personality. New York: Harper and Brothers, 1954. 
Mayo, Elton. The Human Problems of an Industrial Civilization. Second Ed. N. Y.: Macmillan, 1933.

Mazique, Mignon. In "But Will Quality Circles Work Here?" Data Management, October, 1981, 33 .

McGregor, D. M. The Human Side of Enterprise. N. Y.: McGraw-Hill, 1960 .

Metz, Edmund J. "Caution, Quality Circles Ahead." Training and Development Journal, August, 1981, $71-76$.

Metz, Edmund J. "Do Your Quality Circle Leaders Need More Training?" Training and Development Journal, December, 1982, 108-112.

Mills, C. Wright. "The Contribution of Sociology to Studies of Industrial Relations." from Proceedings of the First Annual Meeting of Industrial Relations Research Association, 1948. 199-222.

Mills, C. Wright. The Sociological Imagination. N. Y.: oxford, 1959.

Nie, Norman H., et al. Statistical Package for the Social Sciences. N. Y.: McGraw-Hill, 1975.

Nord, Walter R. "Job Satisfaction Reconsidered." American Psychologist, Dec. 1977, Vol. 32, 10261035.

Ouchi, William. Theory $\mathrm{Z}$ : How American Business Can Meet the Japanese Challenqe. Menlo Park, CA: Addison Wesley, 1981 .

Pasmore, William A. "Overcoming the Roadblocks in Work Restructuring Efforts." Organizational Dynamics, Spring, 1982. 54-67.

Pateman, Carole. Participation and Democratic Theory. N. Y.: Cambridge U. Press, 1970.

Powell, Reed M., and John L. Schlacter. "Participative Management a Panacea?" Academy of Management Journal, June, 1971. 165-173.

Poza, Ernesto J., and Lynne M. Markus. "Success Story: The Team Approach to Work Restructuring." Organizational Dynamics, Winter, 1980. 3-25. 
Ramsay, Harvie. "Cycles of Control: Workers Participation in Sociological and Historical Perspective." sociology, 1977, 11, 3, 481-506.

Roethlisberger, F. J., and W. J. Dickson. Management and the Worker. Cambridge: Harvard University Press, 1939.

Rowat, Christine I. Worker Participation: A Bibliographic Survey. Emerson, Rowat Information Services, 44 Broadwheel Rd., Helpston, Peterborough, England, 1976.

Rus, Veljko. "Influence Structure in Yugoslav Enterprise." Industrial Relations, 9, 2, 1970, 148-160.

Salancik, Gerald R. "Field Stimulations for Organizational Behavior Research." Administrative Science Quarterly, Dec. 1979, Vol. 24, pp. 638-649.

Seelye, H. Ned., Edward C. P. Stewart, and Joyce A. Sween. Evaluating Quality Circles in U.S. Industry: $A$ Feasibility Study, Research Report prepared by International Research Development for the Organizational Effectiveness Research Programs, Psychological Sciences Division, Office of Naval Research, Department of the Navy, July, 1982.

Shimada, Justin Y. "Effects of Quality Control Circles on Worker Performance: A Field Experiment." A paper presented at the Academy of Management Conference. summer, 1983.

Shlemmer, Richard Louis. An Analysis of the Implementation of a Quality Circle Program. Diss. United States International University, 1983.

Siegel, Sidney. Nonparametric Statistics for the Behavioral Sciences. N. Y.: McGraw-Hill, 1956 .

Sprow, Eugene E. "The Quality Commitment." Tooling and Production, March, 1982a. 73-80.

Sprow, Eugene E. "Made in USA." Tooling and Production, Feb., 1982b. 73-80.

Srinivasan, Chandramowli. Influence of Quality Circles on Productivity, Group Behavior, and Interpersonal Behavior: An Exploratory Micro-organizational Development Perspective. Diss. University of Northern Colorado, 1982. 
Staines, Graham L., and Robert P. Quinn. "American Workers Evaluate the Quality of Their Jobs." Monthly Labor Review, Jan., 1979, 3-12.

"Stonewalling Plant Democracy." Business Week, Vol. 24, 28 Mar. 1977.

Strauss, George. "Workers Participation in Management: An International Perspective." In Research in Organizational Behavior. Ed. Barry M. Staw and L. L. Cummings. Greenwhich, CT: JAI Press, 1982, $197-214$.

Strauss, G. and E. Rosenstein. "Worker Participation: A Critical View." Industrial Relations, 9, 1970.

Suda, Zdenek. "In What Do Workers Really Want To Participate?" A paper presented to the Xth World Congress of Sociology, Mexico City, 1982.

Sutermeister, Robert A. People and Productivity. N.Y.: McGraw-Hill, 1969.

Taylor, Frederick Winslow. "The Principles of Scientific Management." 1916. In Classics of Industrial and Organizational Psychology. Ed. Mankin, et al. Oak Park, ILL: Moore, 1980.

Thackray, John. "U.S. Labor: The Quest for Quality work." Management Today, March, 1982, 66-69.

Thompson, Philip C. Quality Circles: How to Make Them Work in America. AMACOM, American Management Associations, 135 West 50 th Street, New York, N.Y., 1982 .

Turner, Barry A. Exploring the Industrial subculture. London: Macmillan, 1971.

Vanek, Jaroslav. The General Theory of Labor Managed Market Economies. London: Cornell University Press, 1970.

Vanek, Jaroslav. The Participatory Economy. London: Cornell University Press, 1971.

Van Maanen, John. "Reclaiming Qualitative Methods for Organizational Research: A Preface." Administrative Science Quarterly, Dec. 1979, Vol. 24, pp. 520526 . 
Vaughn, R. J. Effects of a Quality Circle Intervention on Four Behavioral outcomes. M.A. Thesis. Air Force Institute of Technology, 1983.

Verba, S. Small Groups and Political Behavior. Princeton University Press, 1961.

Vroom, Victor H. Work and Motivation. N.Y.: Wiley and Sons, 1964.

Wall, Toby D., and Joseph A. Lischeron. Worker Participation: A Critique of the Literature and Some Fresh Evidence. N.Y.: McGraw-Hill, 1977.

Wanous, John P. "Individual Differences and Reactions to Job Characteristics." Journal of Applied Psychology, 1974, Vol. 59, No. 5, 616-622.

Wanous, John. "Who Wants Job Enrichment?" 1976. In Perspectives on Behavior in Organizations. Ed. Richard J. Hackman, et al. N.Y.: McGraw-Hill, 1977.

Warwick, Donald P., and Charles A. Lininger. The Sample Survey: Theory and Practice. N.Y.: McGraw-Hill, 1975.

Webb, Eugene, and Karl E. Weick. "Unobtrusive Measures in Organizational Theory: A Reminder." Administrative Science Quarterly, Dec. 1979, Vol. 24, pp. 650-659.

Westenholz, Ann. "Workers' Participation in Denmark." Industrial Relations, Vol. 19, No. 3, Fall, 1979. 376-380.

Widtfeldt, James R. "Jumping on the Quality Circles Bandwagon." Data Management, October, 1981, 32-35.

Witte, John F. Democracy, Authority, and Alienation in Work. Chicago: U. of Chicago Press, 1980 .

Woodworth, Warner P. "Tearing Down the Pyramids." Contemporary Sociology, March 1982, 11, 2, 173-175.

Work in America. Report of a Special Task Force to the Secretary of H.E.W. Cambridge: MIT Press, 1973.

"Workers' Participation." Final Summary, Organization for Economic Cooperation and Development, Paris, March, 1975 . 
Yankelovich, Daniel, and John Immerwahr. "Putting the Work Ethic to Work." Society, January-February, $1984,58-76$.

Zwerdling, Daniel. Workplace Democracy. N:Y.: Harper Row, 1980. 
APPENDIX A

SURVEY INSTRUMENT 
BIOGRAPHICAL BACKGROUND

1. Sex: Male Female

2. Age (check one):

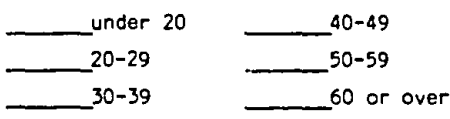

3. Education (check one):

Grade School

Some High School

High School Degree

Some Business College or Technical School Experience

Some College Experience (other than business or technical school)

Business College or Technical School Degree

College Degree

Master's or Higher Degree

4. What is your brief job title?

5. I am a member of an active Cuality Circle:

Yes Is the leader of your circle a manager or coworker?

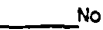

6. I am a manager:

Yes

No 
Directions: The first part of this questionnaire is designed to obtain information on worker's attitudes toward participation in decision-making.

Please answer each item.

Please place a check mark under the response that best describes your desire for participation in each area.

Question: TO WHAT EXTENT DO YOU DESIRE PARTICIPATION IN THESE AREAS?

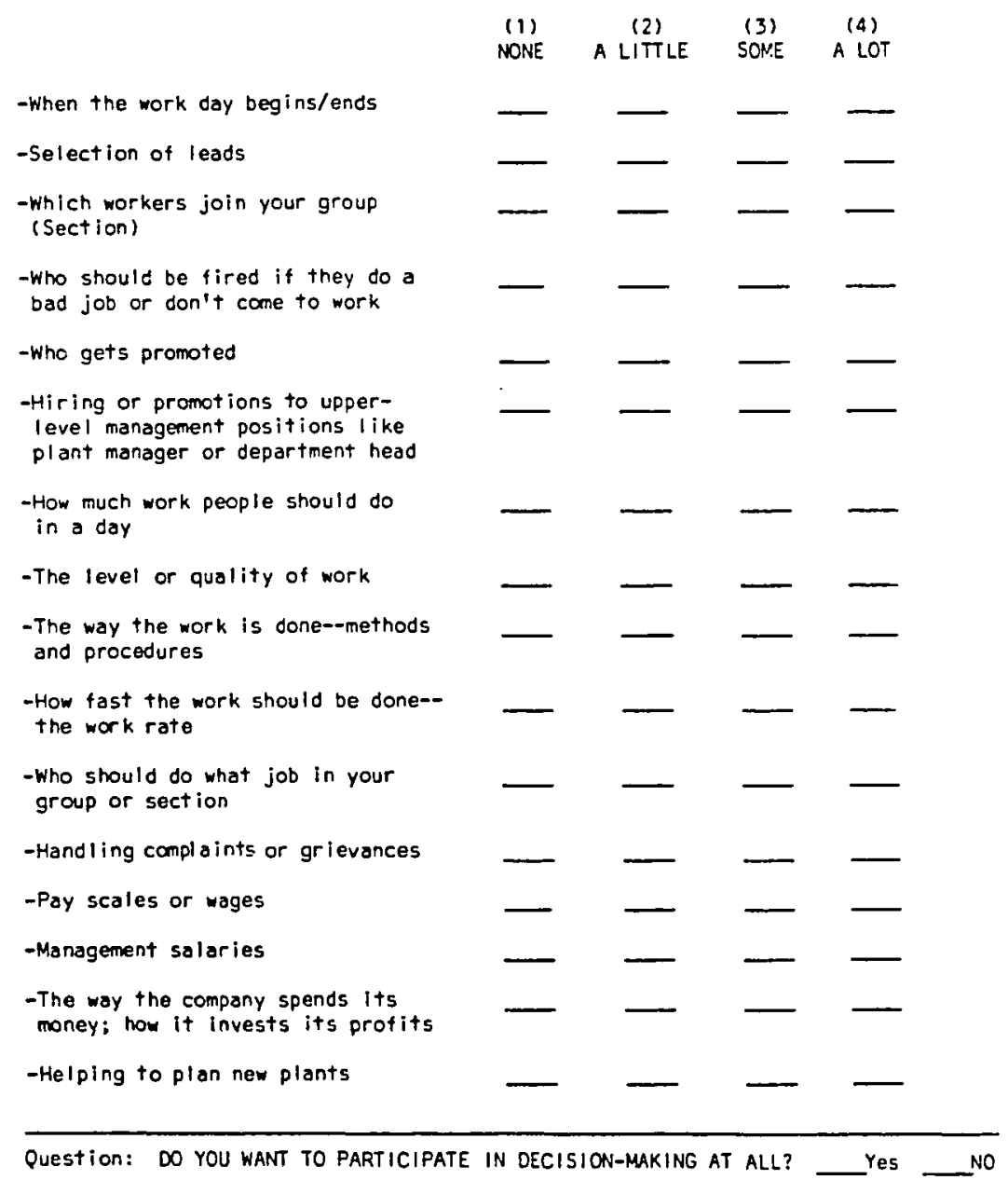


Please write a number in the blank beside each statement, based on the following scale: HOW ACCURATE IS THE STATEMENT IN OESCPIBING YOUR ATTITUDES TOWARD PARTICIPATION IN DECISION-MAKING?

$\begin{array}{cccccc}(1) & (2) & (3) & (4) & (5) & (6) \\ \text { Strongly } & \text { Agree } & \text { Agree } & \text { Disagree } & \text { Disagree } & \text { Strongly } \\ \text { Agree } & & \text { Slightly } & \text { Slightly } & & \text { Disagree }\end{array}$

1. It is management's job to make decisions concerning job activity.

2. I welcome the responslbility that comes along with increased ability to participate in decision-making.

3. Worker participation programs are just more work for the worker.

4. Workers know that management is really in charge of decision-making.

5. Added responsibility that comes with increased ability to participate in decision-making can create conflict with co-workers.

6. Management can be trusted to support the worker participation program which gives the worker increased decision-making ability.

7. Worker particlpation programs are a way of more closely controlling the worker. 
IOB DIAGNOSTIC SURVEY

This questionnaire was developed a pan of a Yale Universiry study of jobs and how people reset to then. The This questionnaire was developed as part an ae betler designed, by oblaining information about how people react to questionnaire helps 10 det
different tisds ol jobse

On the following papes you will find veveral differens kinds of questions about your job. Specific instructions are given al the stan of each rection. Please read them carefully. It should take no more than 25 minules to complete the entire questionnaire. Please move throweh it quickly.

The quertions are derigned to oberin your pereeptions of your job and your reactions to it.

There are no trick quesions. Yoor individual answers will be kept completely confidential. Plesse answer each item a tonestly and lrantly as possible.

Thank you for your cooperntion.

\section{SECTION ONE}

This part of the qoetioanaire asks you wo dexcribe your job, as objectively as you can.

Please do not us this part of the questionnaire to show how much you like or dislike your job. Questions about that will come laiet. Instead. in wo make your descriptions as accurate and as objective as you possibly can.

A semple quedion is given below.

A. To what extent does your job requirt you to work with mechanical equipment?

Very little: the job requires
almost no contact with
mechanical equipment of
any kind.

You are to circle the number which is the mos accurate description of your job.

II. for esample, your job requires you to work with mechanical equipment a good deal al the time-but aleo requires sme paperwork - you might circle the number six, as was done in the example sbove.

If you do not understand these instructions, plese atk for axsistance. If you do understand them. you mav begin.

1. To what eztent does your job require you to wark elavely with other people (eithee "elients," or people in related jobs in your own organizicioal?

\begin{tabular}{|c|c|c|}
\hline \multicolumn{3}{|c|}{ 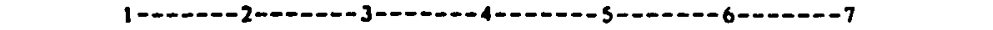 } \\
\hline $\begin{array}{l}\text { Very little: dealing with } \\
\text { other people is nor at an } \\
\text { neceswry in doing the job. }\end{array}$ & $\begin{array}{l}\text { Moderaicly: some dealing } \\
\text { witb oubers is necesury. }\end{array}$ & $\begin{array}{l}\text { Very much: dealing with } \\
\text { orher people is an absolutely } \\
\text { essenti=t and erucial part of } \\
\text { doing the job. }\end{array}$ \\
\hline
\end{tabular}

2. How much aufonomy is there in your job! That it w what extent does yout job permit you to decide on your own how lo go about doing the work!

\begin{tabular}{|c|c|c|}
\hline \multicolumn{3}{|c|}{ 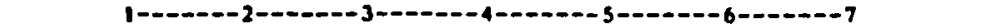 } \\
\hline $\begin{array}{l}\text { Very little: the job gives ane } \\
\text { almost no personal any } \\
\text { aboul how and when the } \\
\text { work is done. }\end{array}$ & $\begin{array}{l}\text { Moderate aulonomy: many } \\
\text { ithings are standardized and } \\
\text { not under my control. but I } \\
\text { can make some decisions } \\
\text { aboul the work. }\end{array}$ & $\begin{array}{l}\text { Very much: the job gives } \\
\text { me almost complete respon- } \\
\text { sibility lor deciding how } \\
\text { and when the wort is done. }\end{array}$ \\
\hline
\end{tabular}


3. To what extent does your job involve doing a "whole"ond identifiable picce of work? That is, is the job a complete piece of work that has an obvious beginning and end? Or is it only a small port of the overall piece of work, which is finished ty other people or by automatic machines?

\begin{tabular}{|c|c|c|}
\hline $\begin{array}{l}\text { My job is only a tiny pan of } \\
\text { the overall piece of work: } \\
\text { the resulis of my activitie: } \\
\text { cannot be seen in the final } \\
\text { product or service. }\end{array}$ & $\begin{array}{l}\text { My job is a modernte-sized } \\
\text { "chunk" of the overall piece } \\
\text { of work: my own contribu. } \\
\text { tion can be seen is the final } \\
\text { outcome. }\end{array}$ & $\begin{array}{l}\text { My job involves doing the } \\
\text { whole piece of work. Irom } \\
\text { stan to finish; the results of } \\
\text { my activities are easily seen } \\
\text { in the final product of } \\
\text { service. }\end{array}$ \\
\hline
\end{tabular}

4. How much reriety is there in your job? That is, 10 what extent does the job require you to do many different things at work. using a variety of your skills and ulenis?

\begin{tabular}{|c|c|c|}
\hline $\begin{array}{l}\text { Very litite: the job requires } \\
\text { me to do the same routine } \\
\text { things over and over again. }\end{array}$ & Moderate variety. & $\begin{array}{l}\text { Very much: the job requires } \\
\text { me io do many dilferent } \\
\text { things. using a number of } \\
\text { different shilis and talents. }\end{array}$ \\
\hline
\end{tabular}

5. In general. how significant or important is yout job? That is. are the resulis of yout work likely to significantly alfect the lives or well-being of other people?

$\begin{array}{ll}\text { Not very significant: the } & \text { Highly significant: the } \\ \text { Outcomes of my work are } & \text { Outcomes of my work can } \\ \text { not likely lo have imporant } & \text { affect other people in very } \\ \text { eflects on other people. } & \text { igmportant ways }\end{array}$

6. To what extent do monagers or coworkers let you know how well you are doing on your job?

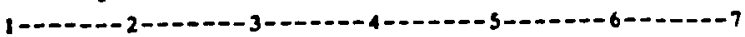

Very little: people almost Moderately: sometimes Very much: manapers or

never let me know how well people may give me "leed. co-workers provide me with

$\begin{array}{ll}\text { I am doing. } & \text { almost constant teedback } \\ & \text { brout how well l am doing. }\end{array}$

7. To what extent does doing the job iuself provide you with information sbout your work performance? That is. does the ectual work isself provide clues about how well you are doing - eside from any teedback" coworiters or supervison may provide?

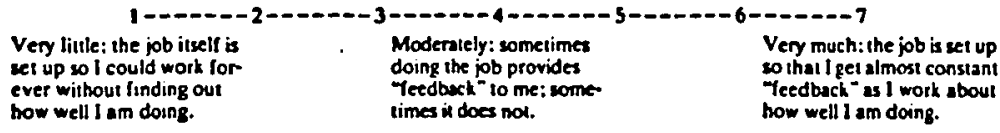

SECTION TWO

Listed below are a number of statements which could be uned to describe a job.

Yov are to indicate whether each sutement is as accurate or an inaceurase deacription of your job.

Once again. piease try to be as objeclive as you can in deciding bow wocurateby each wetement describes your jobrequedless of whether you like or dislike your job. 
Write a number in the blank beside each sutenent, based on the following scale:

\begin{tabular}{|c|c|c|c|c|c|c|}
\hline \multicolumn{7}{|c|}{ How accurole is the statement in describing your job? } \\
\hline $\begin{array}{c}\text { Very } \\
\text { Ineceurate }\end{array}$ & $\underset{\substack{\text { Mosity } \\
\text { Insecurate }}}{2}$ & $\begin{array}{c}3 \\
\text { Slightly } \\
\text { Inaccurate }\end{array}$ & Unceruin & $\begin{array}{c}\text { Slightly } \\
\text { Accurate }\end{array}$ & $\underset{\substack{\text { Mostly } \\
\text { Accurate }}}{6}$ & $\underset{\text { Accurate }}{V_{\text {ery }}^{7}}$ \\
\hline
\end{tabular}

1. The job requires the to use a number of complex or hightevel atille.

2. The job requires a bo of cooperative work with other people.

3. The job is amanged so that I do not have the chance to do an eatire piece of work from beginning to end.

4. Jusa doing the work required by the job provides many chances for me 10 figure out how well I am doing.

5. The job is quile simple and repetitive.

6. The job can be done adequately by a person working alone - without talking or checking with other people.

7. The supervisors and coworkers on this job almost never give we any Teedback" about how well I am doing in my work.

8. This job is one where a lot of other people can be affected by bow well the work gets done.

9. The job denies me any chance to use my personal initiative or judgment in carrying out the wotk.

10. Supervisors often ket me know how well they think I am performing the job.

11. The job provides me the chance to completely finish the pieces of work I begin.

12. The job itself provides very lew clues about whether or not 1 am performing well.

13. The job gives me considerable opportunity for independence and Ireedom in how I do the work.

14. The job itself is not very signilicant or important in the broader scheme of things.

SECTION THREE

Now please indicate bow raw personally feel about your job.

Each of the satements below is something that a person might ay atout his or her job. You are to indicate your own personal /ealings ahout jour job by marking how much you agree with each of the sistements.

Wrile a number in the blank for each uatement, based on this seak:

How much do you agres with ihe seacment?

\begin{tabular}{|c|c|c|c|c|c|}
\hline $\begin{array}{c}1 \\
\text { Disagnee } \\
\text { Sirongly }\end{array}$ & $\frac{2}{\text { Disagree }}$ & $\begin{array}{c}3 \\
\text { Disegree } \\
\text { Slighlty }\end{array}$ & Neutral & $\begin{array}{c}\text { S } \\
\text { Agree } \\
\text { Sughtity }\end{array}$ & $\begin{array}{c}6 \\
\text { Agrec }\end{array}$ \\
\hline
\end{tabular}

1. lis burd. on this job, for me to care very much about whether or not the work gets done right.

2 My opinion of angsell goes up when I do this job well.

3. Generally speaking. 1 an very atidfied with this job.

4. Most of the thinga I have to do on this job seem ualeas or trivial.

5. I wualty know whether of not my work is atisfactory on this job.

6. I feel a greal vense of pernomal suliafsction wiven I do this job well. 
7. The work I do on this job is very mesninglul to me.

8. I feel a very high degree of personal responsiblity for the watt I do on this job.

9. If frequently think of quitting this job.

10. I feel bad and unhappy when I discover that I have perforued poorty on this job.

11. I olten have croubie figuring out whether l'm doing well or poorty on this job.

12. I feel I should personally take the credit of blame for the resuls of my work on this job.

13. I am zeneralty satisfied with the kind of work I do in this job.

14. My own feelings generally are not allected much one way or the other by how well I do on this job.

15. Whether or wot this job ges done right is clearly my responsibility.

\section{SECTION FOUR}

Now please indicate how satisfied you are with esch aspect of your job lised below. Once again, write the appropriate number in the blank beside each stalement.

How satisfied are you with this espect of your job?

\begin{tabular}{|c|c|c|c|c|c|c|}
\hline $\begin{array}{l}1 \\
\text { Exiremely } \\
\text { Discatisfied }\end{array}$ & $\stackrel{2}{\text { Diveatisfied }}$ & $\begin{array}{c}3 \\
\text { Slightly } \\
\text { Dissatisfied }\end{array}$ & Neutral & $\begin{array}{c}\text { S } \\
\text { Slightity } \\
\text { Sutinficed }\end{array}$ & $\begin{array}{c}6 \\
\text { Satiaflied }\end{array}$ & $\begin{array}{c}7 \\
\text { Entremely } \\
\text { Satislied }\end{array}$ \\
\hline
\end{tabular}

1. The atrount ol job security I have.

2. The amount of pay and Iringe benefis I receive.

1. The amount of personal growh end development I get in doing wy job.

4. The people I calk to and work with on my job.

5. The degree of respect and fair trea!ment I receive froen noy boes.

6. The feeling of worthwbile eccomplishment I get Irom doing ay job.

7. The chance to get to know other people while on the job.

8. The amount of suppon and guidance 1 receive from my supervisor.

9. The detree to which I am fairly paid for what I contribute to this organization.

10. The anount of independent thought and action I can exercise in my job.

11. How recure things look for me in the future in this organization.

12. The chance to help other people while at wort.

13. The amount of challenge in my job.

14. The overall quality of the wpervision l receive in my wat. 


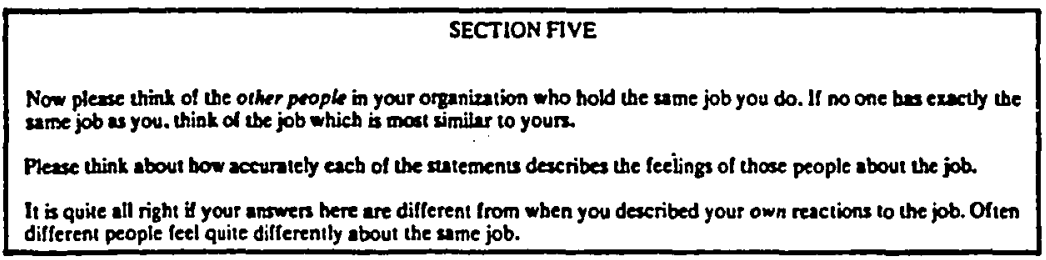

Once apaip. write a sumber in the blank for esech gentement, based on this seale:

How much do you agree with she stotement?

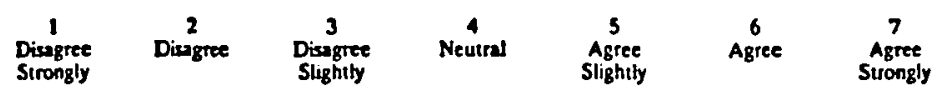

1. Mos peopte on this job feel a greal sense of personal satisfaction when they do the job well.

2. Mose people on this job are very satisfied with the job.

1. Moar people on this job feel that the work is usetess or trivial.

4. Moss peopte on this job feel a great deal of personal responsibility for the work they do.

5. Most people on this job have a pretty good idea of how well they are performing their work.

6. Most people on this job lind the work very meaningful.

7. Most people on this job feel that whether of not the job gets done right is clearty their own responsibility.

8. Prople os this job oflen think of quitting.

9. Moat people on this job leel bad or unhappy when they find that they have performed the work poorty.

10. Mosa people on this job have trouble figuring out whether they are doing a grod or a bad job.

SECTION SIX

Lised betor are a number of characteristics which could be present on any job. People differ about how much they would like to huve each one present in their own jobs. We are interested in leaming how much you personally would like to have each one present in your job. 
Using the scale below, please indicate the degres to which you would ühe 10 tave each chanateristic present in your job.

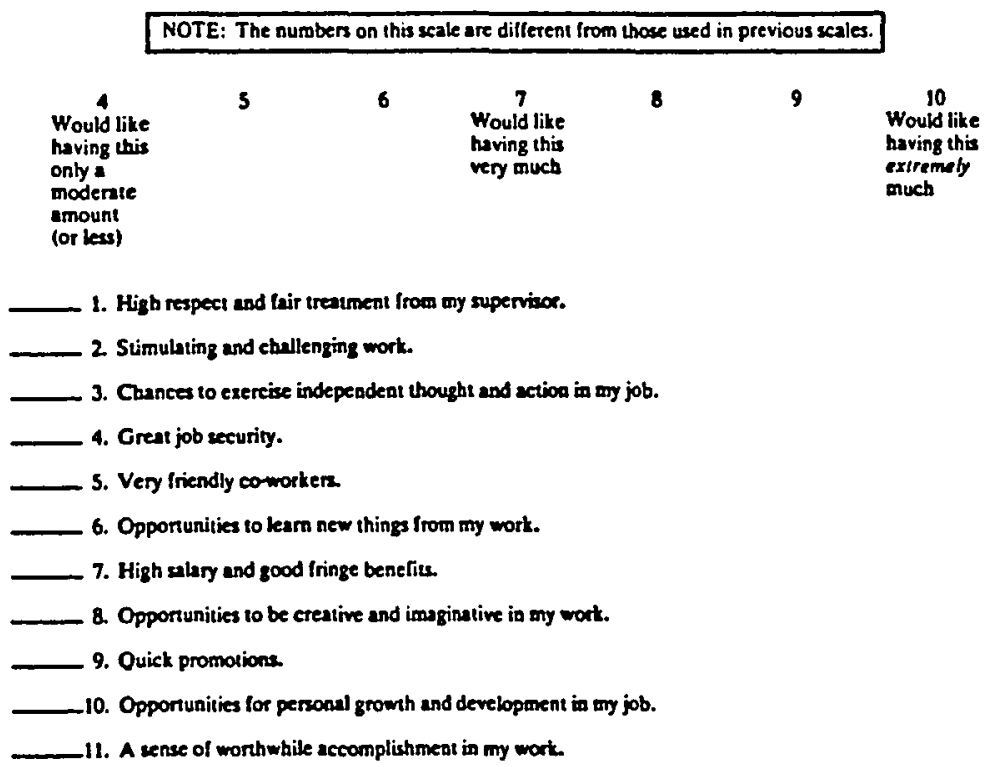

SECTION SEVEN

People dilfer in the kinds of jobs they would most like to bold. The quescions in this section give you a chance to ay just whal is is about a job that is most important to you.

For each question, imo different kinds of jobs are briefly deseribed. You are to indicale which of the jobs voy personelly would prefer-il you had to make a choice between them

In answering each question. assume that everything ebe sbout the jobs is the seme. Pay attention only to the chureterisica sctually lised.

Two examples are given below.

\begin{tabular}{|c|c|c|c|}
\hline \multicolumn{2}{|c|}{$\begin{array}{l}J O B A \\
\text { A job requining work with mechani- } \\
\text { cal equipanent moas of the day }\end{array}$} & \multicolumn{2}{|c|}{$\begin{array}{l}\text { JOB B } \\
\text { A job requiring work with atber } \\
\text { people most of the day }\end{array}$} \\
\hline \multicolumn{4}{|c|}{ 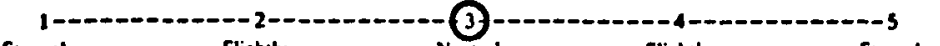 } \\
\hline $\begin{array}{l}\text { Strongly } \\
\text { Preler A }\end{array}$ & $\begin{array}{l}\text { Slightly } \\
\text { Preter A }\end{array}$ & $\begin{array}{l}\text { Slightly } \\
\text { Prefer B }\end{array}$ & $\begin{array}{l}\text { Strongly } \\
\text { Prefer B }\end{array}$ \\
\hline
\end{tabular}

If you like working with people and working with equipnent equally well, you would circle the number 3, as thas been done in the eximple. 
Here b another example. This one asks for a barder choice-between two jobs which both have some undesinble teatures.

\begin{tabular}{|c|c|}
\hline $\begin{array}{c}\text { JOB A } \\
\text { A job requiring you to expose your. } \\
\text { self to considetabte physical danger. }\end{array}$ & $\begin{array}{l}10 B \text { B } \\
\text { A job localed } 200 \text { miles from yous } \\
\text { bome and family. }\end{array}$ \\
\hline $\begin{array}{ll}\text { Strongly } & \text { Slightiy } \\
\text { Prelet A } & \text { Prefer A }\end{array}$ & $\begin{array}{ll}\text { Slighily } & \text { Strongly } \\
\text { Prefer B } & \text { Prefer B }\end{array}$ \\
\hline
\end{tabular}

If you would alightly prefer risking physical danger to working far from your bome, you would circle number 2. as has been done in the example.

Plouse ask for ausistance if you do not undersiand eract by how to do ihese questions.

$\operatorname{IOBA}$

1. A job where the pay is very good.

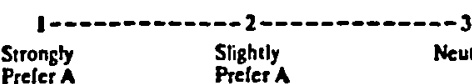

2. A job where you are often required to make in portant decisions.

$$
1-0-0-0-0-2-
$$

Strongly Slighily

Preler A Prefer A

3. A job in which greater responsibility is givea to those who do the best work.

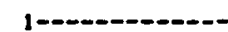

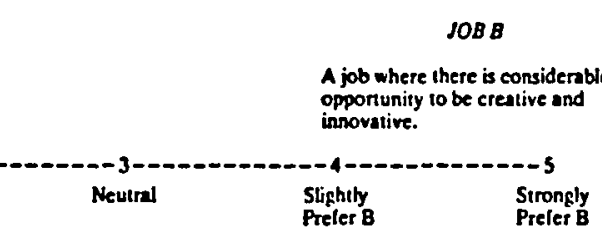

A job with many pleasant people to work wib.

\begin{tabular}{|c|c|c|c|}
\hline $\begin{array}{l}\text { Strongly } \\
\text { Preter A }\end{array}$ & $\begin{array}{l}\text { Slighily } \\
\text { Prefer A }\end{array}$ & Neutral & $\begin{array}{l}\text { Stightly } \\
\text { Prefer B }\end{array}$ \\
\hline
\end{tabular}

4. A job in un organization which is in financial trouble - and might have to close down withis the year.

$A$ job in which you are not allowed to have any lay whatever in how procedures to be used in carrying it

oute

$\begin{array}{lllll}\text { Strongby } & \text { Slightly } & \text { Neutral } & \text { Slightly } & \text { Sirongiy } \\ \text { Prefer A } & \text { Prefer A } & & \text { Preler B } & \text { Preler B }\end{array}$

3. A very routine job.

A job where your coworters are not very friendly.

$\begin{array}{lllll} & \text { Slightly } & \text { Neutral } & \text { Slightly } & \text { Strongly } \\ \text { Strongly } & \text { Prefer A } & & \text { Preler B } & \text { Preler B } \\ \text { Prefer A } & & & \end{array}$




\begin{tabular}{|c|c|c|c|c|}
\hline & $\begin{array}{l}\text { A job with a supervisor who is often } \\
\text { very critieal of you and your wark in } \\
\text { front of other people. }\end{array}$ & & $\begin{array}{l}\text { A job: } \\
\text { in numt } \\
\text { burd io }\end{array}$ & $\begin{array}{l}\text { you from using } \\
\text { al you worked }\end{array}$ \\
\hline & 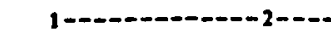 & $--3--$ & $---4-\infty$ & ---5 \\
\hline & $\begin{array}{ll}\text { Sirongly } & \text { Slightly } \\
\text { Prefet A } & \text { Preler A }\end{array}$ & Neutral & $\begin{array}{l}\text { Slightly } \\
\text { Preler B }\end{array}$ & $\begin{array}{l}\text { Strongly } \\
\text { Prefer B }\end{array}$ \\
\hline & $\begin{array}{l}\text { A job with a supervisor who respects } \\
\text { you and ireats you laitly. }\end{array}$ & & $\begin{array}{l}\text { A job } \\
\text { opport } \\
\text { and int }\end{array}$ & $\begin{array}{l}\text { consunt } \\
\text { to leam new } \\
\text { s. }\end{array}$ \\
\hline & $1---n-\infty-2-\infty-2-\infty-1$ & $---3--$ & $---4--$ & ---5 \\
\hline & $\begin{array}{ll}\text { Sirongly } & \text { Slightly } \\
\text { Preler A } & \text { Preler A }\end{array}$ & Neutral & $\begin{array}{l}\text { Slightly } \\
\text { Preler B }\end{array}$ & $\begin{array}{l}\text { Strongly } \\
\text { Prefer B }\end{array}$ \\
\hline 8. & $\begin{array}{l}\text { A job where there is a real chance } \\
\text { you could be laid off. }\end{array}$ & & $\begin{array}{l}\text { A job } \\
\text { challen }\end{array}$ & chance to do \\
\hline & $1---n-0-0-0-2-0$ & $--3-$ & $--4-n$ & ---5 \\
\hline & $\begin{array}{l}\text { Strorighty } \\
\text { Preler A }\end{array}$ & Neutral & $\begin{array}{l}\text { Slightly } \\
\text { Prefer B }\end{array}$ & $\begin{array}{l}\text { Strongly } \\
\text { Prefer B }\end{array}$ \\
\hline 9. & $\begin{array}{l}\text { A job in which there is a real chance } \\
\text { for you to develop new skills and } \\
\text { advance in the organiantioa. }\end{array}$ & & $\begin{array}{l}\text { A job: } \\
\text { tion tir } \\
\text { benefit }\end{array}$ & $\begin{array}{l}\text { lots of vaca. } \\
\text { ellent linge }\end{array}$ \\
\hline & $1--\infty-\infty-\infty-\infty-\infty 2-\infty$ & 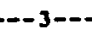 & $---4---$ & --5 \\
\hline & $\begin{array}{l}\text { Sirongly } \\
\text { Prefer A }\end{array}$ & Neutn & $\begin{array}{l}\text { Slighthy } \\
\text { Preter B }\end{array}$ & $\begin{array}{l}\text { Sirongly } \\
\text { Preler B }\end{array}$ \\
\hline
\end{tabular}

10. A job with binke freedom and independence io do your wort in she way you thiak best.

$A$ job where the working conditions

$\begin{array}{lllll}\text { Strongly } & \text { Stightly } & \text { Neutus } & \text { Stighity } & \text { Strongly } \\ \text { Prefer A } & \text { PrelerA } & & \text { Prefet B } & \text { PreJer B }\end{array}$

11. A job with very antiafying veam- A job which allows you to use your work.

dills and abilisies to the fullest exient.

\begin{tabular}{|c|c|c|c|}
\hline $\begin{array}{l}\text { Sirongly } \\
\text { Preler A }\end{array}$ & $\begin{array}{l}\text { Slightly } \\
\text { Prefer A }\end{array}$ & Neutral & $\begin{array}{l}\text { Slightly } \\
\text { Prefer B }\end{array}$ \\
\hline
\end{tabular}

12 A job which oflers titue or 10 challenge.

A job which requires you to be

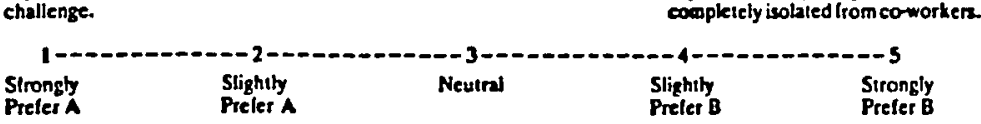


APPENDIX B

INDIVIDUAL INTERVIEW FORM 
NAME

Q.C. Y_Yes No

JOB TITLE

$\begin{array}{ll}\text { Male } & \text { Female } \\ \text { PP } & \text { SP }\end{array}$

1. In general, why do you feel workers should be allowed to participate? 
2. In some areas, you don't think workers should have much to say. In general, in those areas, why don't you feel workers should be allowed to participate? 


\section{$-3-$}

(QC) TENURE:

3. How have your attitudes/feelings about Quality Circles changed since you have become a member?

\section{(NON QC)}

4. Why haven't you chosen to join a Quality Circle?

5. Anything else? (Over) 